Maristela Prado e Silva

\title{
Efeitos da imunossupressão sobre a depuração mucociliar de ratos: comparação entre dois esquemas de terapia tríplice
}

Tese Apresentada à Faculdade de Medicina da Universidade de São Paulo para obtenção do título de Doutor em Ciências.

Programa de Cirurgia Torácica e Cardiovascular

Orientador: Dr. Rogerio Pazetti

São Paulo 
Dados Internacionais de Catalogação na Publicação (CIP)

Preparada pela Biblioteca da

Faculdade de Medicina da Universidade de São Paulo

Creprodução autorizada pelo autor

Silva, Maristela Prado e

Efeitos da imunossupressão sobre a depuração mucociliar de ratos : comparação entre dois esquemas de terapia tríplice / Maristela Prado e Silva. -- São Paulo, 2016.

Tese(doutorado)--Faculdade de Medicina da Universidade de São Paulo.

Programa de Cirurgia Torácica e Cardiovascular.

Orientador: Rogerio Pazetti.

Descritores: 1.Efeitos fisiológicos de drogas 2.Depuração mucociliar 3.Combinação de medicamentos 4.Transplante de pulmão 5.Imunossupressores 6.Mucosa respiratória 7.Ratos Wistar

USP/FM/DBD-013/16 


\section{DEDICATÓRIA}

Dedico este trabalho,

Aos meus pais, Mariéti e José Augusto, pelo exemplo de vida, seu amor constante mesmo nas horas difíceis. Muitas vezes se doaram e renunciaram aos seus sonhos, para que eu pudesse realizar os meus. Essa conquista não é só minha, mas nossa. Tudo que consegui só foi possível graças ao amor, apoio e dedicação que vocês sempre tiveram por mim. Sempre me ensinaram a agir com respeito, simplicidade, dignidade, honestidade e amor ao próximo. Graças à união da família, os obstáculos foram ultrapassados, vitórias foram conquistadas e alegrias divididas.

Ao meu esposo Lauro Cecílio, pelo apoio e incentivo incondicional. Obrigada.

Ao meu filho Francisco Augusto, que com o seu sorriso e sua pureza me inspiram e me dão forças para vencer qualquer obstáculo. 


\section{AGRADECIMENTOS}

Esta tese de doutorado é o resultado de um trabalho que exigiu constantes abdicações, dedicação e esforço, e algumas pessoas foram de extrema importância para que pudesse alcançar meu objetivo maior que sempre foi fazer parte desta Instituição INCOR/FMUSP.

Agradeço ao professor orientador Dr. Rogerio Pazetti pelo estímulo e constante disponibilidade em contribuir para o meu crescimento profissional, a quem, em poucas palavras, seria impossível traduzir a minha gratidão. Mil vezes muito obrigada, nunca o esquecerei!

Aos colegas Edwin Roger Parra, Francine Maria de Almeida, Sônia de Fátima Soto e Aristides Tadeu Correia pelo apoio na pesquisa em laboratório e análise estatística, pois sem a participação de vocês o meu trabalho ficaria incompleto. A vocês o meu muito obrigada e a minha amizade constante.

Às funcionárias do Programa de Cirurgia Torácica e Cardiovascular por estarem sempre dispostas a ajudar.

À Fundação de Amparo à Pesquisa do Estado de São Paulo - FAPESP, pelo apoio financeiro para a realização deste projeto (2010/16101-2). 
É preciso saber dizer muito obrigado.

Nossos dias são ricos dos presentes que o Senhor nos oferece.

Tudo é dom de DEUS,

E é o conjunto desses presentes que fazem a vida mais bela.

Obrigada, Senhor Deus, muito Obrigada.

Agradeço a Deus, pelo dom da vida e, por dar-me forças nos momentos de fraqueza, guiando-me por esta longa caminhada. 


\section{Normalização adotada}

Esta tese está de acordo com as seguintes normas em vigor no momento desta publicação:

1. Referências: adaptado de International Committee of Medical Journals Editors (Vancouver).

2. Universidade de São Paulo. Faculdade de Medicina. Divisão de Biblioteca e Documentação. Guia de apresentação de dissertações, teses e monografias. Elaborado por Anneliese Carneiro da Cunha, Maria Julia de A. L. Freddi, Maria F. Crestana, Marinalva de Souza Aragão, Suely Campos Cardoso, Valéria Vilhena. 3a ed. São Paulo: Divisão de Biblioteca e Documentação; 2011.

3. Abreviaturas dos títulos dos periódicos de acordo com List of Journals Indexed in Index Medicus. 


\section{Sumário}

Lista de Figuras

Lista de Gráficos

Lista de Tabelas

Resumo

Abstract

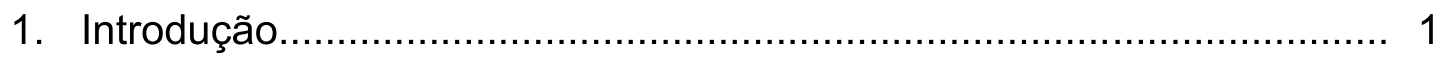

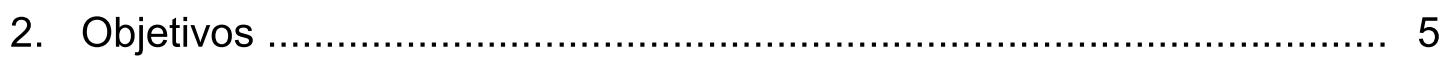

3. Revisão da literatura......................................................................... 7

3.1 Transplante pulmonar................................................................ 7

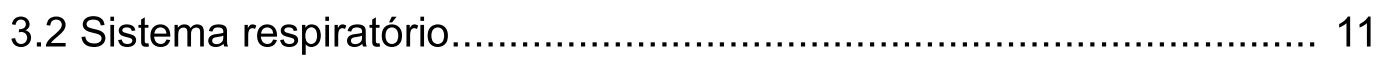

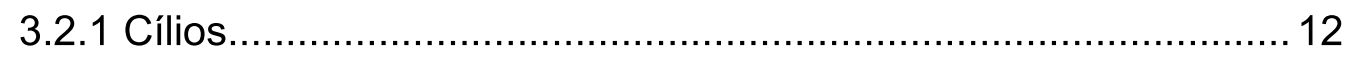

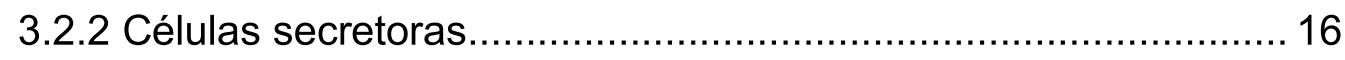

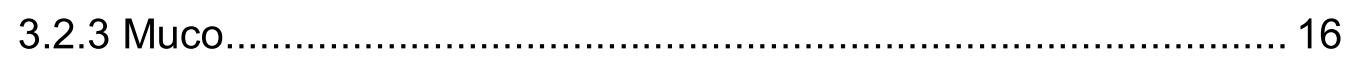

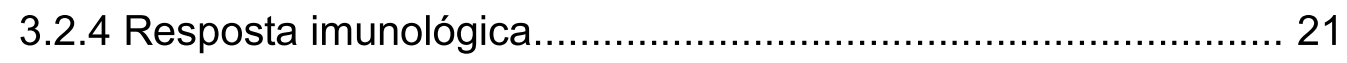

3.2.5 Células inflamatórias do sistema BALT..................................... 23

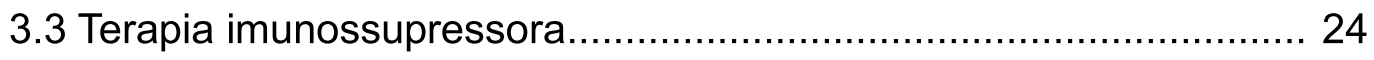

3.3.1 Prednisona

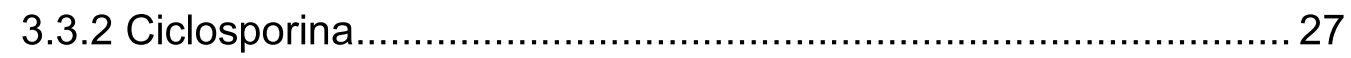

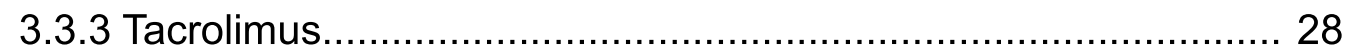

3.3.4 Azatioprina

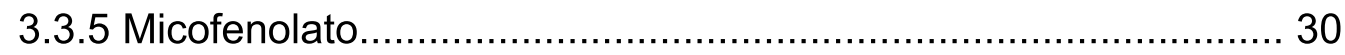

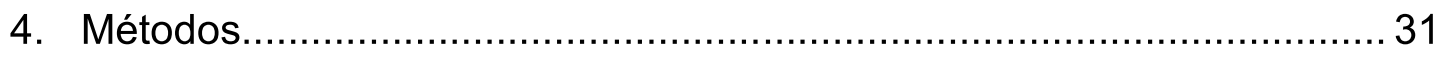

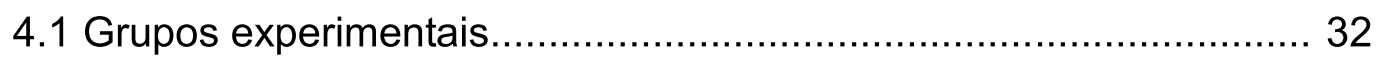

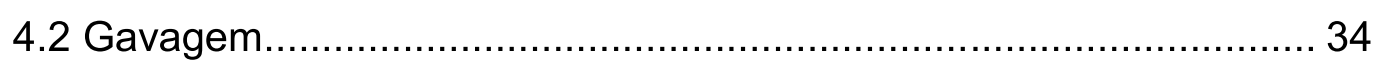

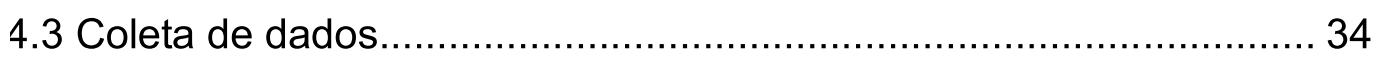

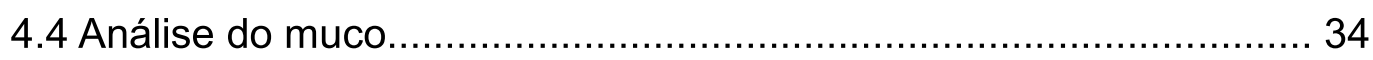


4.4.1 Coleta 34

4.4.2 Transportabilidade do muco (TM) ................................. 35

4.5 Frequência de batimento ciliar in situ (FBC) ........................... 38

4.6 Velocidade de transporte mucociliar in situ (VTMC) .................... 40

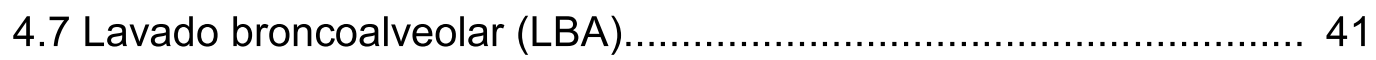

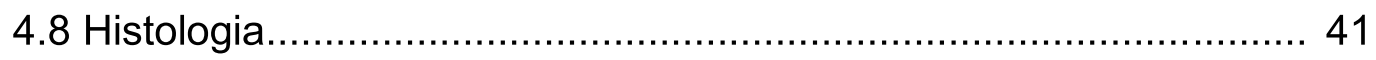

4.9 Análise da proliferação de linfócitos e macrófagos........................ 45

4.10 Análise da apoptose de linfócitos e macrófagos....................... 45

4.11 Análise estatística...................................................... 46

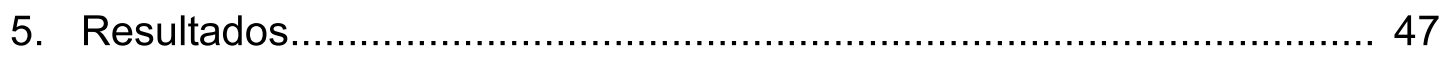

5.1 Transportabilidade do muco.................................................... 48

5.2 Frequência de batimento ciliar in situ......................................... 49

5.3 Velocidade do transporte mucociliar in situ................................ 50

5.4 Produção de muco neutro e ácido................................................52

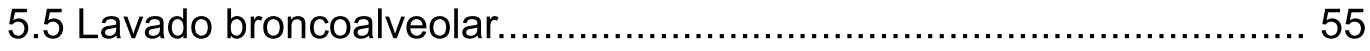

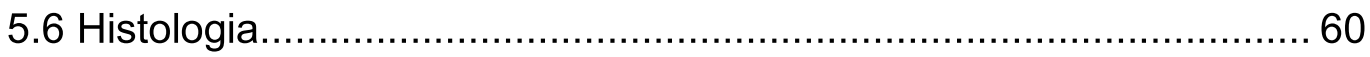

5.7 Proliferação de linfócitos e macrófagos......................................63

5.8 Apoptose de linfócitos e macrófagos....................................... 66

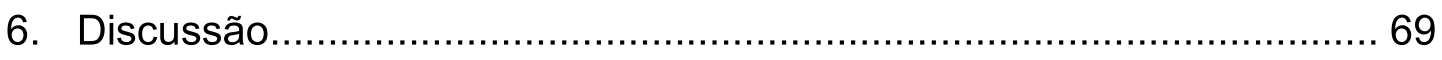

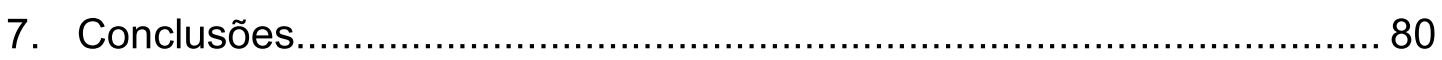

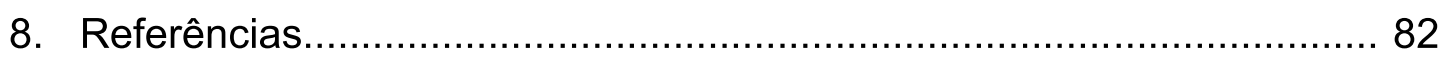
Apêndice 


\section{Lista de Figuras}

Figura 01. Fotomicrografia do epitélio respiratório destacando as células ciliadas e as células caliciformes.

Figura 02. Diagrama da secção transversal de um cílio do epitélio respiratório, mostrando os nove pares de microtúbulos e os braços de dineína e nexina.

Figura 03. Microscopia eletrônica de células epiteliais e cílios em movimento.

Figura 04. Desenho esquemático do transporte mucociliar com apresentação das camadas de muco (gel e sol), cílios, zona de penetração dos cílios na camada gel do muco, e direção do movimento ciliar para região de orofaringe.

Figura 05. Microscopia óptica do epitélio pseudoestratificado traqueal marcada uma célula secretora.

Figura 06. Desenho esquemático do muco em vias aéreas superiores na sua fase sol e gel.

Figura 07. Microscopia óptica mostrando a distribuição do sistema BALT no epitélio e submucosa traqueal

Figura 08. Fluxograma mostrando a composição dos grupos de acordo com o tratamento terapêutico a que foram submetidos

Figura 09. Coleta de amostra de muco do brônquio

Figura 10. Equipamentos utilizados para medida da transportabilidade das amostras de muco em palato de rã

Figura 11. Representação do palato de rã sendo visualizada através de ocular reticulada.

Figura 12. Equipamentos utilizados para medida da velocidade de transporte mucociliar in situ e da frequência de batimento ciliar.

Figura 13. Equipamentos utilizados para quantificar o muco.

Figura 14. Captação da imagem a partir de lâmina corada com PAS pela câmara fotográfica digital. Imagem inserida no programa de computador analisador de imagem para quantificação do percentual de área corada.

Figura 15. Delimitação da coloração alvo pelo pesquisador, com uso do 
programa de computador, para quantificação do percentual de área corada.

Figura 16. Determinação da quantidade de muco na área determinada pelo pesquisador, com uso do programa de computador...

Figura 17. Delimitação da área do brônquio respiratório pelo pesquisador, com uso do programa de computador, para quantificação do percentual de área corada. 


\section{Lista de Gráficos}

Gráfico 1. Distribuição da transportabilidade do muco........................... 48

Gráfico 2. Distribuição da frequência do batimento ciliar......................... 49

Gráfico 3. Distribuição da velocidade do transporte mucociliar................ 51

Gráfico 4. Distribuição da quantidade de muco neutro.......................... 52

Gráfico 5. Distribuição da quantidade de muco ácido............................ 54

Gráfico 6. Número de linfócitos no lavado broncoalveolar....................... 56

Gráfico 7. Número de macrófagos no lavado broncoalveolar................. 57

Gráfico 8. Número de neutrófilos no lavado broncoalveolar.................... 58

Gráfico 9. Número de células totais no lavado broncoalveolar............... 59

Gráfico 10. Número de células mononucleares no parênquima pulmonar 61

Gráfico 11. Número de células polimorfonucleares no parênquima

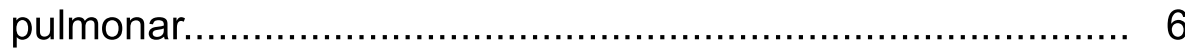

Gráfico 12. Número de linfócitos marcados com Ki67 no parênquima pulmonar.................................................................... 64

Gráfico 13. Número de macrófagos marcados com Ki67 no parênquima

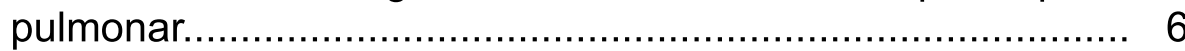

Gráfico 14. Número de linfócitos marcados com caspase no parênquima

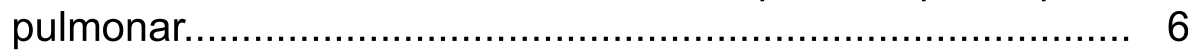

Gráfico 15. Número de macrófagos marcados com caspase no parênquima pulmonar.......................................................... 68 


\section{Lista de tabelas}

Tabela 1. Teste de Bonferroni para comparações entre os grupos Controle, TI e TII em 7, 15 e 30 dias em relação aos valores médios de Transportabilidade do Muco................................

Tabela 2. Teste de Bonferroni para comparações entre os tempos 7, 15 e 30 dias para os grupos Controle, TI e TII em relação aos valores médios de Transportabilidade do Muco.

Tabela 3. Teste de Bonferroni para comparações entre os grupos Controle, TI e TII em 7, 15 e 30 dias em relação aos valores médios de Frequência de Batimento Ciliar..

Tabela 4. Teste de Bonferroni para comparações entre os tempos 7, 15 e 30 dias para os grupos Controle, TI e TII em relação aos valores médios de Frequência de Batimento Ciliar..........

Tabela 5. Teste de Bonferroni para comparações entre os grupos Controle, TI e TII em 7, 15 e 30 dias em relação aos valores médios de Velocidade de Transporte Mucociliar..

Tabela 6. Teste de Bonferroni para comparações entre os tempos 7, 15 e 30 dias para os grupos Controle, TI e TII em relação aos valores médios de Velocidade de Transporte Mucociliar.. 51

Tabela 7. Teste de Dunn para comparações entre os grupos Controle, TI e TII em 7, 15 e 30 dias em relação aos valores médios de quantidade de muco neutro.

Tabela 8. Teste de Dunn para comparações entre os tempos 7, 15 e 30 dias para os grupos Controle, TI e TII em relação aos valores médios de quantidade de muco neutro

Tabela 9. Teste de Dunn para comparações entre os grupos Controle, TI e TII em 7, 15 e 30 dias em relação aos valores médios de quantidade de muco ácido.

Tabela 10. Teste de Dunn para comparações entre os tempos 7, 15 e 30 dias para os grupos Controle, TI e TII em relação aos valores médios de quantidade de muco ácido.

Tabela 11. Teste de Bonferroni para comparações entre os grupos Controle, TI e TII em 7, 15 e 30 dias em relação aos valores médios de número de linfócitos no lavado broncoalveolar......

Tabela 12. Teste de Bonferroni para comparações entre os tempos 7, 15 e 30 dias para os grupos Controle, TI e TII em relação aos valores médios de número de linfócitos no lavado 
Tabela 13. Teste de Bonferroni para comparações entre os grupos Controle, TI e TII em 7, 15 e 30 dias em relação aos valores médios de número de macrófagos no lavado broncoalveolar. 57

Tabela 14. Teste de Bonferroni para comparações entre os tempos 7, 15 e 30 dias para os grupos Controle, TI e TII em relação aos valores médios de número de macrófagos no lavado broncoalveolar.

Tabela 15. Teste de Bonferroni para comparações entre os grupos Controle, TI e TII em 7, 15 e 30 dias em relação aos valores médios de número de neutrófilos no lavado broncoalveolar

Tabela 16. Teste de Bonferroni para comparações entre os tempos 7, 15 e 30 dias para os grupos Controle, TI e TII em relação aos valores médios de número de neutrófilos no lavado broncoalveolar.

Tabela 17. Teste de Bonferroni para comparações entre os grupos Controle, TI e TII em 7, 15 e 30 dias em relação aos valores médios de número de células totais no lavado broncoalveolar.

Tabela 18. Teste de Bonferroni para comparações entre os tempos 7 , 15 e 30 dias para os grupos Controle, TI e TII em relação aos valores médios de número de células totais no lavado broncoalveolar.

Tabela 19. Teste de Bonferroni para comparações entre os grupos Controle, TI e TII em 7, 15 e 30 dias em relação aos valores médios de número de células mononucleares no parênquima pulmonar.

Tabela 20. Teste de Bonferroni para comparações entre os tempos 7, 15 e 30 dias para os grupos Controle, TI e TII em relação aos valores médios de número de células mononucleares no parênquima pulmonar.

Tabela 21. Teste de Bonferroni para comparações entre os grupos Controle, TI e TII em 7, 15 e 30 dias em relação aos valores médios de número de células polimorfonucleares no parênquima pulmonar.

Tabela 22. Teste de Bonferroni para comparações entre os tempos 7, 15 e 30 dias para os grupos Controle, TI e TII em relação aos valores médios de número de células polimorfonucleares no parênquima pulmonar. 
Tabela 23. Teste de Bonferroni para comparações entre os grupos Controle, TI e TII em 7, 15 e 30 dias em relação aos valores médios de número de linfócitos marcados com Ki67 no parênquima pulmonar.

Tabela 24. Teste de Bonferroni para comparações entre os tempos 7, 15 e 30 dias para os grupos Controle, TI e TII em relação aos valores médios de número de linfócitos marcados com Ki67 no parênquima pulmonar..

Tabela 25. Teste de Bonferroni para comparações entre os grupos Controle, TI e TII em 7, 15 e 30 dias em relação aos valores médios de número de macrófagos marcados com Ki67 no parênquima pulmonar.

Tabela 26. Teste de Bonferroni para comparações entre os tempos 7, 15 e 30 dias para os grupos Controle, TI e TII em relação aos valores médios de número de macrófagos marcados com Ki67 no parênquima pulmonar.

Tabela 27. Teste de Bonferroni para comparações entre os grupos Controle, TI e TII em 7, 15 e 30 dias em relação aos valores médios de número de linfócitos marcados com caspase no parênquima pulmonar.

Tabela 28. Teste de Bonferroni para comparações entre os tempos 7, 15 e 30 dias para os grupos Controle, TI e TII em relação aos valores médios de número de linfócitos marcados com caspase no parênquima pulmonar.....

Tabela 29. Teste de Bonferroni para comparações entre os grupos Controle, TI e TII em 7, 15 e 30 dias em relação aos valores médios de número de macrófagos marcados com caspase no parênquima pulmonar.

Tabela 30. Teste de Bonferroni para comparações entre os tempos 7, 15 e 30 dias para os grupos Controle, TI e TII em relação aos valores médios de número de macrófagos marcados com caspase no parênquima pulmonar..... 


\section{Resumo}

Silva MP. Efeitos da imunossupressão sobre a depuração mucociliar de ratos: comparação entre dois esquemas de terapia tríplice [tese]. São Paulo: Faculdade de Medicina, Universidade de São Paulo; 2016.

INTRODUÇÃO: O transplante de pulmão é a principal modalidade terapêutica para pacientes com doença pulmonar incapacitante, progressiva e em estágio final. Apesar dos inúmeros progressos que têm sido obtidos em vários aspectos da cirurgia de transplante, a expectativa de vida dos pacientes ainda é baixa, sendo que as complicações infecciosas, principalmente as respiratórias, estão entre as causas mais comuns de morbidade e mortalidade após o transplante de pulmão. Vários estudos relatam que após o transplante pulmonar ocorre a diminuição do transporte mucociliar e da frequência do batimento ciliar, bem como o aumento da rigidez do muco, sugerindo uma associação com o uso de drogas imunossupressoras. Embora essas drogas sejam imprescindíveis para o controle da rejeição do enxerto, sérias complicações podem ocorrer como resultado do seu uso crônico. Dessa forma, a investigação dos efeitos tóxicos das drogas imunossupressoras sobre o epitélio respiratório é de suma importância. No presente estudo, visamos comparar os efeitos dos dois principais esquemas de terapia tríplice utilizados na prática clínica. Nossa hipótese é que diferentes terapias podem ter efeitos diversos sobre a depuração mucociliar das vias aéreas desempenhando um papel importante no desenvolvimento das infecções respiratórias observadas após o transplante pulmonar. MÉTODOS: Noventa ratos foram distribuídos igualmente em 3 grupos $(\mathrm{n}=30$ cada): Controle = veículo; Terapia I = tacrolimus + micofenolato + prednisona; Terapia II = ciclosporina + azatioprina + prednisona. Após 7, 15 ou 30 dias de tratamento diário por gavagem, os animais foram eutanasiados e os seguintes parâmetros estudados: transportabilidade do muco in vitro, frequência de batimento ciliar in situ, velocidade de transporte mucociliar in situ, produção de muco neutro e ácido e contagem de células inflamatórias no lavado broncoalveolar e no tecido pulmonar. RESULTADOS: Houve uma diminuição significativa da frequência de batimento ciliar, da velocidade de transporte mucociliar, e da produção de muco neutro em todos os animais imunossuprimidos; além disso, ambas as terapias, principalmente a TI, causaram um aumento na produção de muco ácido nos tempos estudados. CONCLUSÕES: As duas terapias tríplices testadas prejudicaram a depuração mucociliar das vias aéreas de ratos, sendo que a terapia I teve um efeito mais deletério.

Descritores: efeitos fisiológicos de drogas; depuração mucociliar; combinação de medicamentos; transplante de pulmão; imunossupressores; mucosa respiratória; ratos Wistar. 


\begin{abstract}
Silva MP. Effects of immunosuppression on mucociliary clearance of rats: comparison between two triple therapy regimens [Thesis]. São Paulo: "Faculdade de Medicina, Universidade de São Paulo"; 2016.
\end{abstract}

INTRODUCTION: Lung transplantation is the main therapeutic modality for patients with end stage and progressive lung disease. Despite the many advances that have been obtained in various aspects of transplant surgery, the life expectancy of patients is still low. Infectious complications, especially respiratory, are among the most common causes of morbidity and mortality after lung transplantation. Several studies have reported a decrease in mucociliary transport and ciliary beat frequency, as well as increased mucus stiffness after lung transplantation, suggesting an association between these effects with the use of immunosuppressive agents. Although these drugs are essential for the control of graft rejection, serious complications can occur as a result of their chronic use. Thus, the investigation of the toxic effects of immunosuppressive drugs on the respiratory epithelium is of greatest importance. In this study, we aim to compare the effects of two main triple therapy regimens used in clinical practice. We hypothesized that different triple therapies could have different effects on airway mucociliary clearance, playing an important role in respiratory infections observed after lung transplantation. METHODS: Ninety rats were assigned to three groups $(n=30$ each): control $=$ vehicle, therapy $I=$ tacrolimus + mycophenolate + prednisone, and therapy $\mathrm{II}=$ cyclosporine + azathioprine + prednisone. After 7, 15, or 30 days of treatment by gavage, the animals were killed and the following parameters were studied: mucus transportability in vitro, ciliary beating frequency in situ, mucociliary transport velocity in situ, neutral and acid mucus production, and inflammatory cell counts in bronchoalveolar lavage and lung tissue. RESULTS: There was a significant decrease in ciliary beating frequency, mucociliary transport velocity, and neutral mucus production in all immunosuppressed animals; indeed, both therapies, mainly therapy 1 , caused an increase in acid mucus production in all studied periods. CONCLUSIONS: Both triple therapies impaired airway mucociliary clearance of rats, but therapy 1 had a more deleterious effect.

Descriptors: physiological effects of drugs; mucociliary clearance; drug combinations; lung transplantation; immunosupressive agents; respiratory mucosa; rats, Wistar. 
1 INTRODUÇÃO 


\section{Introdução}

O transplante de pulmão é, hoje, a principal modalidade terapêutica para pacientes com doença pulmonar incapacitante, progressiva e em estágio final, dentre as quais se destacam: doença pulmonar obstrutiva crônica, hipertensão pulmonar, fibrose pulmonar e fibrose cística (Christie et al., 2010).

Apesar dos inúmeros progressos que têm sido obtidos em vários aspectos da cirurgia de transplante, como uma melhor abordagem do doador, uma preservação mais cuidadosa do enxerto, uma técnica operatória mais precisa e um manuseio da imunossupressão mais específico, a expectativa de vida dos transplantados de pulmão ainda é baixa, principalmente se comparada com a de outros transplantes, como de coração, fígado e rim. Isso se deve, em parte, à complexidade anatômica e funcional do pulmão, além de ser mais suscetível à rejeição e desenvolver, com facilidade, lesão de isquemia e reperfusão (Pierson, 2006).

O tecido pulmonar é constantemente exposto a diferentes tipos de agentes nocivos que entram em contato direto com a mucosa respiratória, como microorganismos e poluentes atmosféricos (Macchione et al., 1995). O aparelho mucociliar, presente nas vias aéreas, tem como principal função a remoção de partículas ou substâncias potencialmente agressivas ao trato respiratório, por meio do transporte do muco pelos cílios, ou, alternativamente, pela tosse e espirro (Macchione et al., 1995). Porém, deve-se ressaltar que o batimento ciliar é extremamente influenciado e dependente das propriedades viscoelásticas e de transporte do muco respiratório (Trindade et al., 2007). 
Vários estudos relatam que após o transplante ocorre a diminuição do transporte mucociliar e da frequência do batimento ciliar, bem como o aumento da rigidez do muco, associado ou não ao uso de drogas imunossupressoras (Newhouse et al., 1987; Shankar et al., 1991).

No início, os protocolos de imunossupressão após o transplante eram mais restritos e muitas vezes limitados à administração empírica e não monitorada de azatioprina e prednisona (Ellenhorn et al., 1990). A introdução recente de múltiplas drogas levou ao sucesso alcançado no transplante da maioria dos órgãos sólidos, com efeitos mais específicos e monitorados (Dong et al., 1999).

O esquema clássico de imunossupressão empregado após o transplante é constituído de três drogas: ciclosporina, azatioprina e prednisona. Atualmente, existe uma tendência ao uso de tacrolimus, micofenolato de mofetil e prednisona (Christie et al., 2010). Diversos trabalhos apontam para melhores resultados com o uso dessas drogas quando comparadas ao esquema clássico (Griffith et al., 1994; Gerbase et al., 2001; Zuckermann et al., 2003; Kobashigawa et al., 2006; Fan et al., 2009 e Halloran et al., 2011).

Estudos preliminares sugerem que a combinação entre tacrolimus e micofenolato de mofetil diminui a taxa de rejeição aguda e há melhora na função pulmonar em longo prazo (Gerbase et al., 2001; Kobashigawa et al., 2006). Halloran et al.(2011) mostraram que administração de tacrolimus e micofenolato de mofetil, ao invés de azatioprina, parece ser mais eficaz em pacientes com disfunção precoce do enxerto. Além disso, um estudo mostrou uma maior eficácia da imunossupressão com tacrolimus do que com 
ciclosporina em pacientes com bronquiolite obliterante pós transplante pulmonar (Griffith et al., 1994).

Embora essas drogas sejam imprescindíveis para o controle da rejeição do enxerto, sérias complicações podem ocorrer como resultado do seu uso crônico, como neoplasia, neuro e hepatotoxicidade, insuficiência renal, trombocitopenia, hipertensão e infecções, entre outras (Speich e van der Bij, 2001; Pazetti et al., 2013).

As complicações infecciosas estão entre as causas mais comuns de morbidade e mortalidade após o transplante de pulmão, correspondendo a $35,3 \%$ das causas de morte entre 31 dias e 1 ano no pós-operatório; e ao menos $65 \%$ das infecções envolvem o trato respiratório (Taylor e Palmer, 2006).

Dessa forma, a investigação dos efeitos tóxicos das drogas imunossupressoras sobre o epitélio respiratório das vias aéreas é de suma importância. No entanto, são escassos os estudos na literatura com esse objetivo.

Todas as drogas que compõem os dois principais esquemas de terapia tríplice já foram testadas isoladamente em nosso laboratório e mostraram possuir efeitos diversos sobre os componentes do aparelho mucociliar (Pazetti et al., 2007; Xavier et al., 2007; Pazetti et al., 2008; Pego-Fernandes et al., 2008; Paes e Silva et al., 2011; Braga et al., 2012).

No presente estudo, visamos investigar a ação dessas mesmas drogas quando administradas em conjunto, conforme os dois principais esquemas de terapia tríplice utilizados na prática clínica. 
2 OBJETIVOS 


\section{Objetivos}

\section{Principal:}

Avaliar o sistema mucociliar traqueobrônquico de ratos submetidos a dois esquemas de terapia tríplice imunossupressora quanto aos seguintes parâmetros:
a) frequência de batimento ciliar in situ;
b) velocidade de transporte mucociliar in situ;
c) transportabilidade do muco in vitro;
d) produção de muco neutro e ácido pelas células caliciformes.

\section{Secundários:}

1. Avaliar a presença de células inflamatórias no lavado broncoalveolar e no parênquima pulmonar.

2. Avaliar a proliferação e a apoptose de células inflamatórias no parênquima pulmonar. 
3 REVISÃO DA LITERATURA 


\section{Revisão da literatura}

\subsection{Transplante pulmonar}

O transplante pulmonar é indicado aos pacientes com pneumopatias que esgotam os recursos terapêuticos clínicos convencionais sem resultados satisfatórios (Studer et al., 2004; Miranda et al., 2005). As doenças pulmonares mais comuns observadas nos candidatos a transplante são: doença pulmonar obstrutiva crônica, fibrose pulmonar idiopática, fibrose cística e hipertensão pulmonar idiopática (Christie et al., 2010).

Historicamente, o fisiologista russo Vladimir Demikhov foi o primeiro a realizar, de maneira experimental, em 1947, várias modalidades de transplante intratorácico em cães: coração; coração e lobo de um pulmão; coração e pulmão; e pulmões (Mendeloff, 2002). Logo a seguir, na França, Henri Metras publicou o primeiro trabalho sobre a técnica de transplante pulmonar em cães e estabeleceu o princípio técnico da anastomose da veia pulmonar realizada com o átrio esquerdo, o que é adotado até hoje (Metras, 1950).

No ano de 1954, nos Estados Unidos, Hardy et al. (1963), utilizando modelos experimentais de transplante pulmonar em cães, relataram que a deterioração funcional do enxerto levava à morte do animal receptor em aproximadamente sete dias, atribuindo esse resultado à rejeição.

Hardy, em 1963, na Universidade do Mississipi realizou o primeiro transplante de pulmão em humanos. O paciente do sexo masculino, com 58 anos, sobreviveu por 18 dias e sua morte foi atribuída à insuficiência renal e desnutrição. 
No início da década de 1980, o Dr. Joel Cooper realizou o primeiro transplante isolado de pulmão (unilateral) da "era pós-ciclosporina", em novembro de 1983. Tratava-se de um homem de 53 anos portador de fibrose pulmonar idiopática. Recebeu alta na sexta semana e viveu por mais 6 anos após o transplante, limitado devido à insuficiência renal causada pela ciclosporina. O sucesso foi atribuído à seleção cuidadosa do paciente e ao uso de ciclosporina para proteger e melhorar a cicatrização da anastomose brônquica (Cooper et al., 1987). Com essa droga imunossupressora houve benefícios para o sucesso das cirurgias de transplantes, aumentando a taxa de sobrevida logo no primeiro ano (Dong et al., 1999; Fan et al., 2009).

No Brasil, os primeiros transplantes pulmonares foram realizados em Porto Alegre, em 1989 (Camargo et al.,1990) e em São Paulo, no ano de 1990 (Forte et al., 1991). Nos últimos anos, tem-se observado um aumento expressivo não só no número de transplantes realizados, como também na qualidade dos resultados obtidos no cenário nacional, com índices de sobrevida no $1^{\circ}$. e $5^{\circ}$. ano pós-transplante próximos aos obtidos pelos principais centros de transplante do mundo (Jatene et al., 2009).

Segundo os dados do Registro Brasileiro de Transplante (RBT), em 2014 foram catalogados 600 transplantes pulmonares, dos quais 264 foram bilaterais e 294 foram unilaterais, sendo a maior parte realizada nos estados de São Paulo, Rio Grande do Sul e Ceará, e uma menor proporção em Minas Gerais.

Já a Sociedade Internacional de Transplante de Coração e Pulmão (ISHLT, sigla do nome em inglês) publicou resultados de mais de 32.000 
transplantes de pulmão realizados em 223 centros espalhados pelo mundo, mostrando que a sobrevida tem melhorado ao longo das décadas devido aos avanços nas soluções de preservação de órgãos, nas técnicas cirúrgicas, no manejo pós-operatório intensivo, no controle e tratamento das infecções e nos esquemas de imunossupressão (Christie et al., 2010).

Apesar dos avanços, alguns fatores limitam o sucesso do transplante pulmonar como opção terapêutica, como a escassez de órgãos viáveis para o transplante, dificuldades na preservação do órgão, alta mortalidade dos pacientes na fila de espera e baixa sobrevida dos transplantados, em comparação ao transplante de outros órgãos sólidos (Jatene e PêgoFernandes, 2008; Pêgo-Fernandes et al., 2008).

A sobrevida média, para os receptores, é de aproximadamente $88 \%$ nos primeiros 3 meses, $79 \%$ em 1 ano, $63 \%$ em 3 anos, $52 \%$ em 5 anos e $29 \%$ em 10 anos (Christie et al., 2010). Em pacientes com doença supurativa, que apresentam no período pré-transplante uma colonização em vias aéreas, as pneumonias bacterianas ( $P$. aeruginosa em 33\%) são comuns no período póstransplante (Chaparro et al. 2001).

Após o primeiro ano, as principais causas de morte são devido à bronquiolite obliterante, representando a forma de rejeição crônica, e às infecções não associadas ao citomegalovírus. Entre outras mais tardias, destacam-se as causas de morte por neoplasia e por doenças cardiovasculares (Hertz et al., 2008).

A síndrome de bronquiolite obliterante continua a ser o maior obstáculo para uma melhor sobrevida em longo prazo. Com efeito, a síndrome 
desenvolvida dentro de 5 anos de transplante atinge aproximadamente $40 \%$ dos receptores, e a média de sobrevida após o início da síndrome de bronquiolite obliterante é de aproximadamente 3 anos (Christie et al., 2010).

Independentemente do centro transplantador, nacional ou internacional, em geral, a principal causa de morte no primeiro mês pós-transplante é a infecção (Christie et al., 2010). Dentre os vários fatores que podem aumentar o risco do desenvolvimento de infecções nesses pacientes, além da imunossupressão propriamente dita, estão as alterações do aparelho mucociliar provocadas pelo procedimento cirúrgico, que o impedem de proteger e depurar a via aérea de maneira eficiente (Griffith et al., 1994; Crawford, 1995; Herrera et al., 2001).

\subsection{Sistema respiratório}

O sistema respiratório está dividido em porção condutora e de troca gasosa; a primeira é responsável por receber e conduzir o ar do meio externo para o interior dos alvéolos pulmonares, a porção de troca propriamente dita. À medida que o ar avança ao longo das vias aéreas durante a inspiração, encontra um sistema ramificado de túbulos que vai desde a traqueia até os bronquíolos terminais. Essas estruturas são responsáveis por transportar, filtrar, umedecer e aquecer o ar inspirado antes que ele alcance os alvéolos pulmonares. Desta forma, a porção condutora funciona na primeira linha de defesa do sistema respiratório (Saldiva et al., 2011).

A maior parte da porção condutora é revestida por epitélio ciliado pseudo-estratificado colunar com muitas células caliciformes (Junqueira e 
Carneiro, 2008) (Figura 1). O epitélio respiratório tem várias funções, dentre elas, a manutenção da permeabilidade das vias aéreas, permitindo a condução adequada de ar entre o meio ambiente e os alvéolos (Qu et al., 2005), e a defesa do sistema respiratório, pela ação da depuração mucociliar (Houtmeyers et al., 1999).

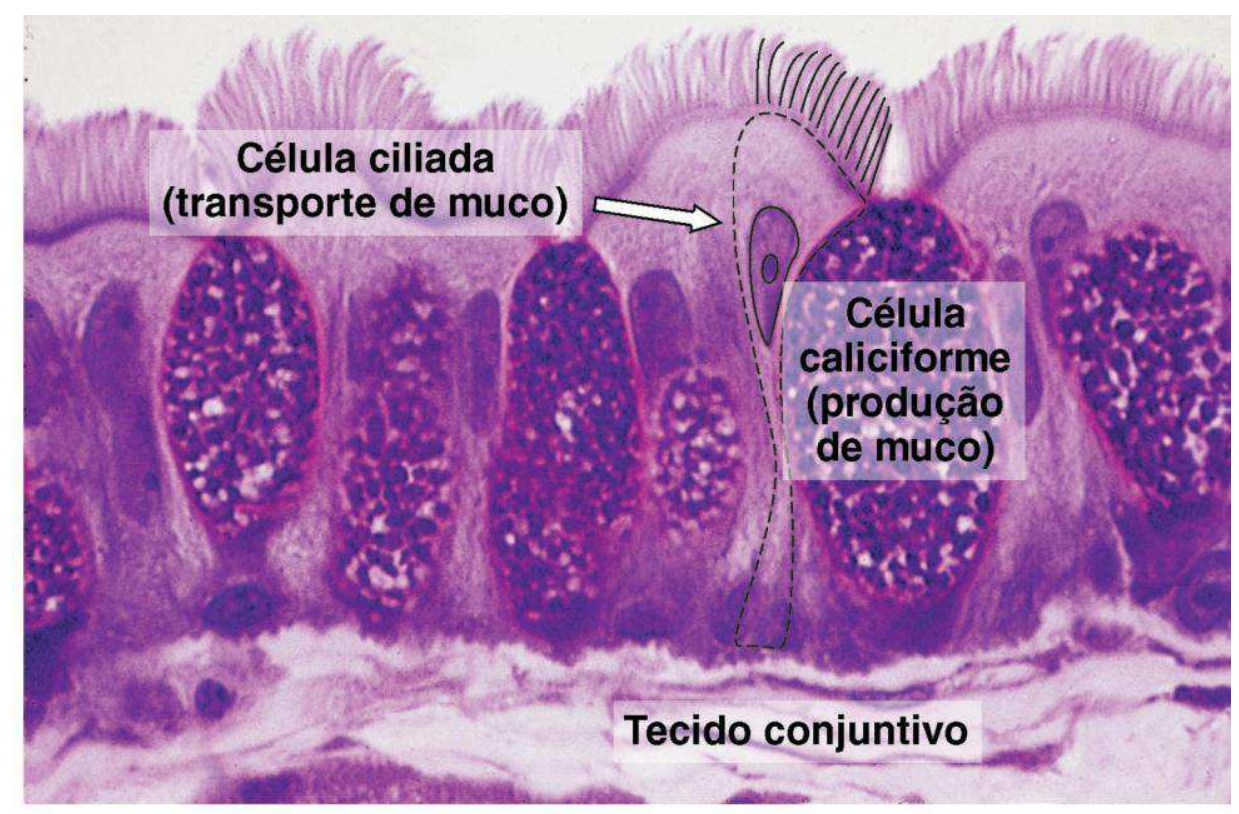

Fonte: Junqueira e Carneiro, 2008.

Figura 1 - Fotomicrografia do epitélio respiratório destacando as células ciliadas e as células caliciformes.

\subsubsection{Cílios}

Cada célula ciliada possui cerca de 200 cílios em sua superfície apical, ou seja, aproximadamente dois milhões de cílios por centímetro quadrado de superfície de mucosa, os quais podem variar com a idade e a posição no trato respiratório, com maior concentração na traqueia e em brônquios présegmentares (Moreira e Andrade, 2008). 
Os cílios são constituídos por projeções microtubulares que partem de um corpo basal, imersas em citoplasma e envolvidas por membrana celular (Satir e Christensen, 2007). Cada conjunto de nove pares periféricos e um par central de microtúbulos forma o axonema de cílios. Os pares periféricos são conectados aos pares vizinhos por dois braços de dineína, um interno e outro externo e conectado ao par central, também por meio de proteínas contráteis (Figura 2). A conexão entre os microtúbulos centrais e periféricos, através dos braços internos e externos, mediada por ATP, provoca o deslocamento dos cílios e consequentemente o batimento ciliar. Em condições normais, os cílios do epitélio respiratório movem-se a uma frequência aproximada de 10 a $20 \mathrm{~Hz}$ (Lund, 1996; Pazetti et al., 2007; Satir e Christensen, 2007; Trindade et al., 2007; Saldiva et al., 2011) (Figura 3).

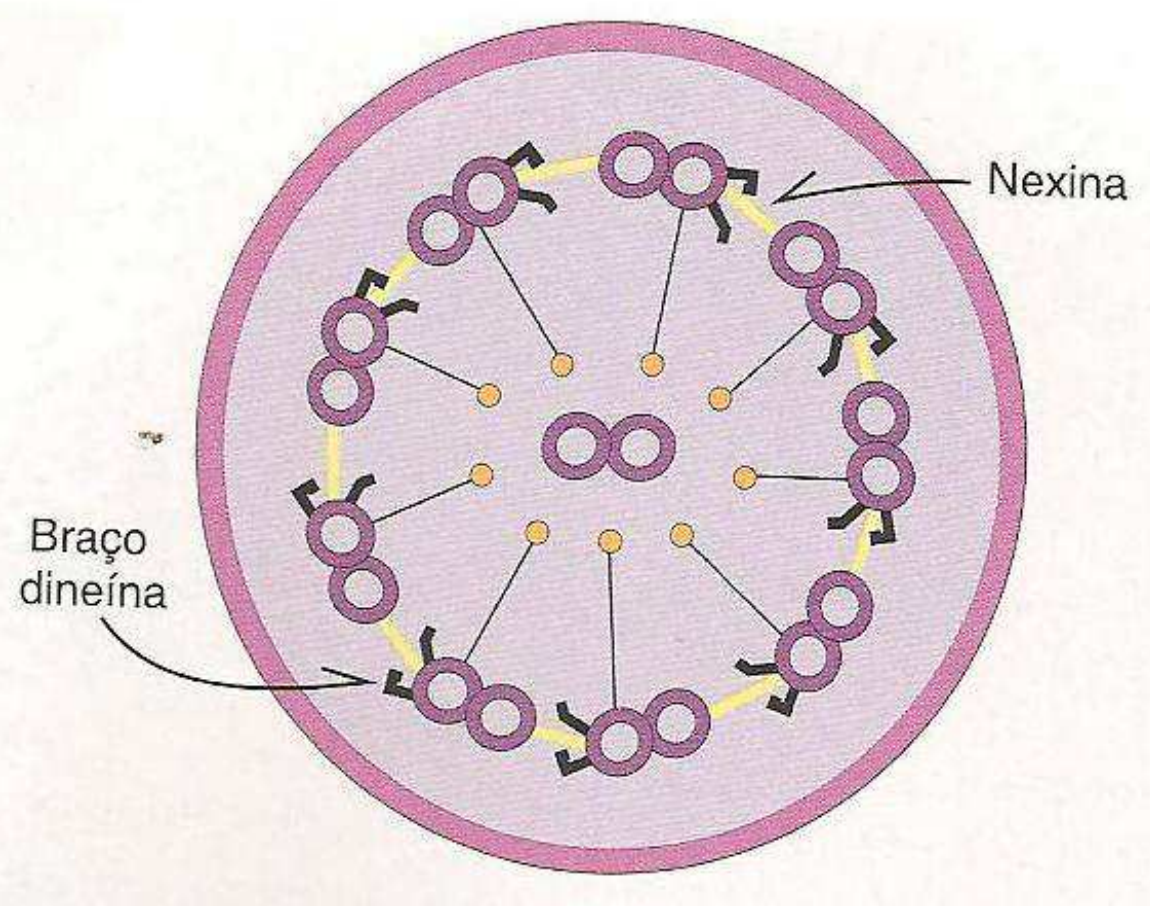

Fonte: Saldiva et al., 2011.

Figura 2 - Diagrama da secção transversal de um cílio do epitélio respiratório, mostrando os nove pares de microtúbulos e os braços de dineína e nexina. 


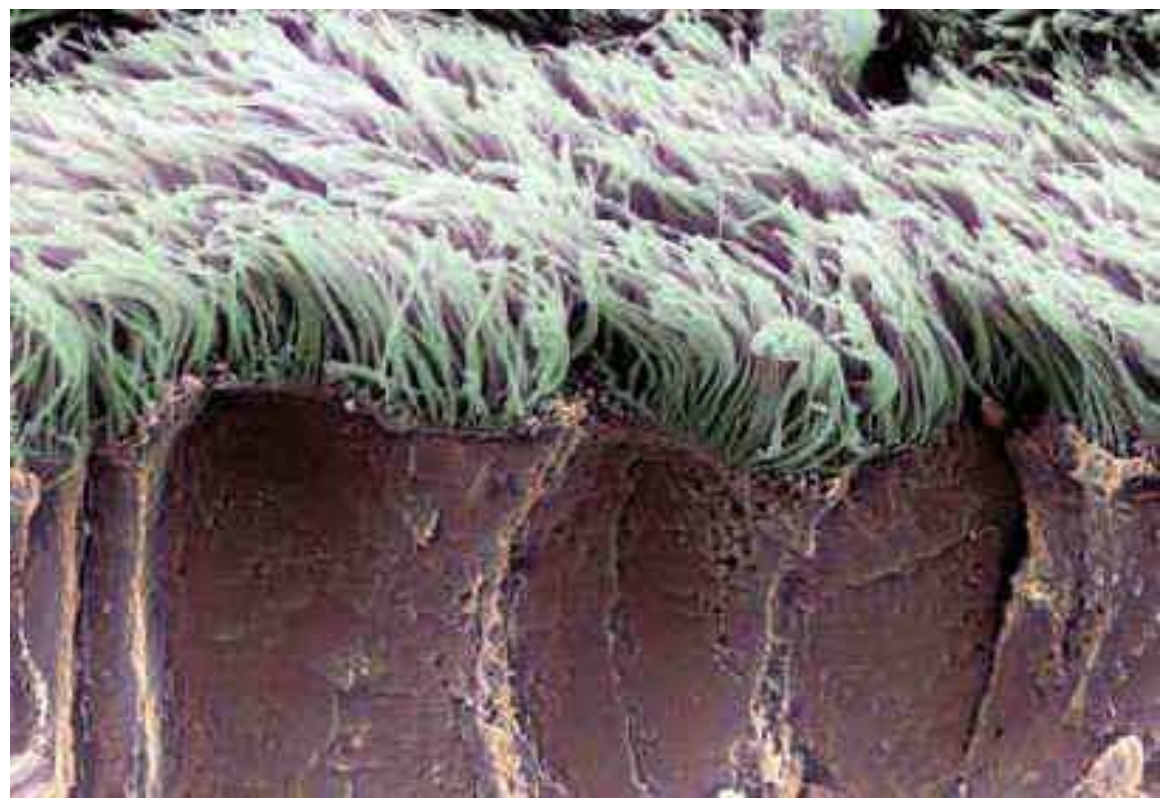

Fonte: http://cigarro.med.br

Figura 3 - Microscopia eletrônica de células epiteliais e cílios em movimento.

O ciclo de batimento ciliar é dividido em duas fases: batimento efetivo e recuperação. Durante o batimento efetivo, o cílio se estende e penetra parcialmente na epifase gel seguindo rápido e perpendicularmente para a superfície celular. Neste momento, descreve um arco que proporciona o estímulo mecânico para a movimentação da camada de muco sentido à orofaringe. Na recuperação, o cílio dobra-se lateralmente voltando à sua posição original. Na fase de recuperação, sua velocidade é duas vezes menor que a do batimento efetivo, além disso, não entra em contato com a epifase gel, diminuindo ao máximo o movimento retrógrado do muco (Satir e Sleigh, 1990; Macchione et al., 1995) (Figura 4). Existe na literatura evidência de que o batimento dos cílios possa simplesmente ser realizado no sentido ânteroposterior, ao contrário da teoria que os cílios se dobram lateralmente na fase de recuperação (Chilvers et al., 2003). 


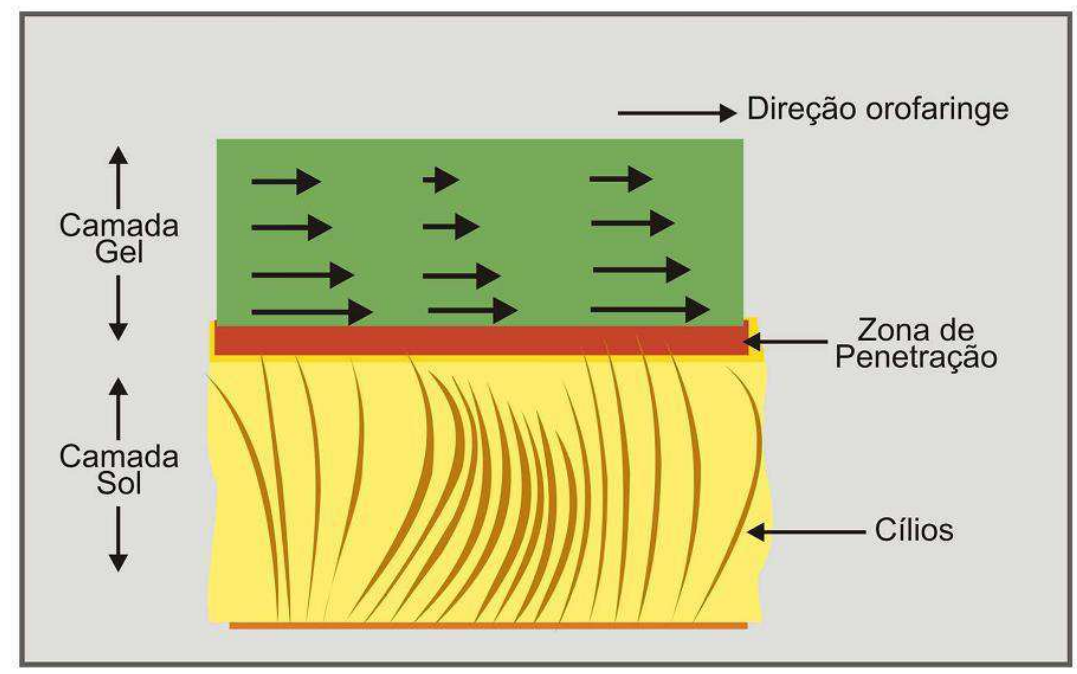

Fonte: Nakagawa et al., 2006.

Figura 4 - Desenho esquemático do transporte mucociliar com apresentação das camadas de muco (gel e sol), cílios, zona de penetração dos cílios na camada gel do muco, e direção do movimento ciliar para região de orofaringe.

Alterações ultraestruturais dos cílios, como ausência dos braços internos ou externos de dineína, deleção ou transposição de pares de microtúbulos centrais ou periféricos, produzem alterações significativas na frequência e padrão do batimento ciliar, as quais geram estase de secreções e infecções respiratórias de repetição, a exemplo das discinesias ciliares primárias (Chilvers et al., 2003).

O batimento ciliar é extremante influenciado e dependente das propriedades viscoelásticas e de transporte do muco respiratório. O tapete que reveste o epitélio ciliado é composto pelo muco respiratório e fluido periciliar (Lund, 1996). 


\subsubsection{Células secretoras}

As células secretoras são de três tipos: serosas, mucosas e de Clara (Figura 5). As células mucosas produzem diferentes tipos de glicoproteínas (ácidas e neutras) e são responsáveis pela parte viscosa do muco, enquanto as células serosas produzem uma secreção mais fluida e são responsáveis pela produção do fluido periciliar (fase sol) secretando enzimas importantes para a ação antimicrobiana, como a lisozima (Saldiva, 1990). Já as células de Clara são mais encontradas nos bronquíolos e alvéolos e produzem o líquido surfactante (Negri et al., 1987).

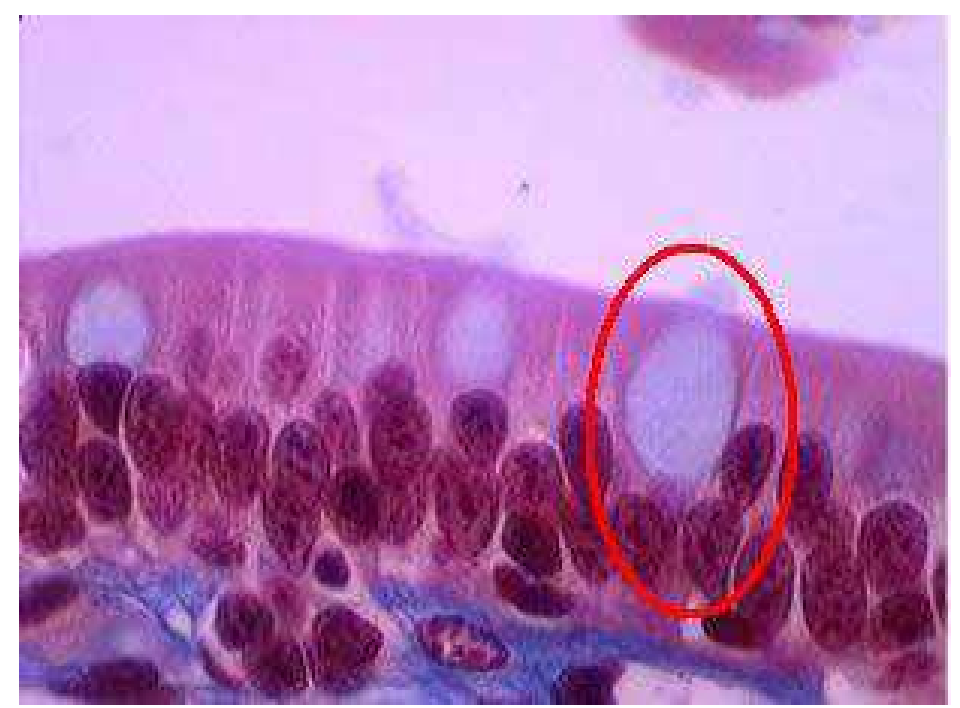

Fonte: www.mundoeducacao.com.br.

Figura 5 - Microscopia óptica do epitélio pseudoestratificado traqueal com marcação de uma célula secretora.

\subsubsection{Muco}

O muco respiratório produzido nas vias aéreas forma um filme de secreção que cobre quase a totalidade das vias aéreas de condução. Exercem funções de: lubrificar e umedecer a superfície das vias condutoras; proteger o 
epitélio contra agentes exógenos; promover um ambiente adequado para ao batimento ciliar e diminuir a tensão superficial nas pequenas vias aéreas (Saldiva, 1990).

O muco produzido pelas glândulas mistas e pelas células caliciformes prende os microrganismos e partículas inertes, ocorrendo o seu deslocamento ao longo da superfície epitelial em direção à faringe, pelo batimento ciliar (Junqueira e Carneiro, 2008).

O muco respiratório é uma mistura complexa de diferentes secreções que formam um polímero hidrofílico com propriedades viscoelásticas que recobre as vias aéreas. É constituído por aproximadamente 95\% de água e 5\% de substâncias orgânicas (aminoácidos, proteínas, glicoproteínas e lipídeos) e eletrólitos como $\mathrm{Na}+, \mathrm{K}+, \mathrm{Mg}+$ e $\mathrm{Ca}+$, sendo as principais proteínas do muco: albumina, lactoferrina, glicoproteínas, lisozimas e imunoglobulinas (Macchione et al., 1998).

O componente principal da matriz são as mucinas, macromoléculas bastante heterogêneas, compostas de açúcares e proteínas e secretadas por células mucosas do epitélio e das glândulas submucosas (Knowles e Boucher, 2002; Rogers, 2007). Além das mucinas, estão presentes proteoglicanos, lipídeos, substâncias antioxidantes, proteases, antiproteases, tampões, lisozima, peroxidase, lactoferrina, antileucoproteases, albumina, DNA, actina (Lorenzi-Filho, 1993; Wanner et al., 1996).

São as mucinas que promovem a adesão dos agentes agressores orgânicos e inorgânicos ao muco, permitindo a depuração satisfatória das vias respiratórias. Além disso, a camada de muco parece funcionar como uma 
reserva de água para o líquido periciliar durante certas condições que diminuem a hidratação dessa camada, na tentativa de preservar a função propulsora do epitélio ciliado (Randell e Boucher, 2006).

O arranjo de todas essas substâncias dá ao muco uma configuração especial própria, possuindo duas camadas: fase sol (aquosa) inferiormente, formada por células de secreção serosa glandular e de Clara, e é contínua desde a traqueia até os bronquíolos; e pela fase gel (viscosa) superiormente, formada por células de secreção mucosa glandular e caliciformes, e é fragmentada pelo movimento ciliar, responsável pelo carregamento das partículas aderidas (Saldiva et al., 2011).

A camada sol (fase sol) é a camada menos densa do líquido superficial das vias aéreas e possui as funções de umidificação do ar inalado. Ela está disposta entre o epitélio respiratório e a camada de muco. Sua composição influencia diretamente o batimento adequado dos cílios presentes no epitélio (Randell e Boucher, 2006). Quando ocorre, por quaisquer motivos, uma alteração entre as duas camadas pode haver prejuízo do movimento de propulsão e de recuperação dos cílios (Lorenzi-Filho, 1993 e Saldiva et al., 2011) (Figura 6).

A camada gel (fase gel) é a camada mais superficial das vias aéreas. As partículas aderidas na camada gel, que é mais viscosa, são movidas pelos cílios para fora das vias aéreas, um processo denominado depuração mucociliar (Rogers, 2007). 


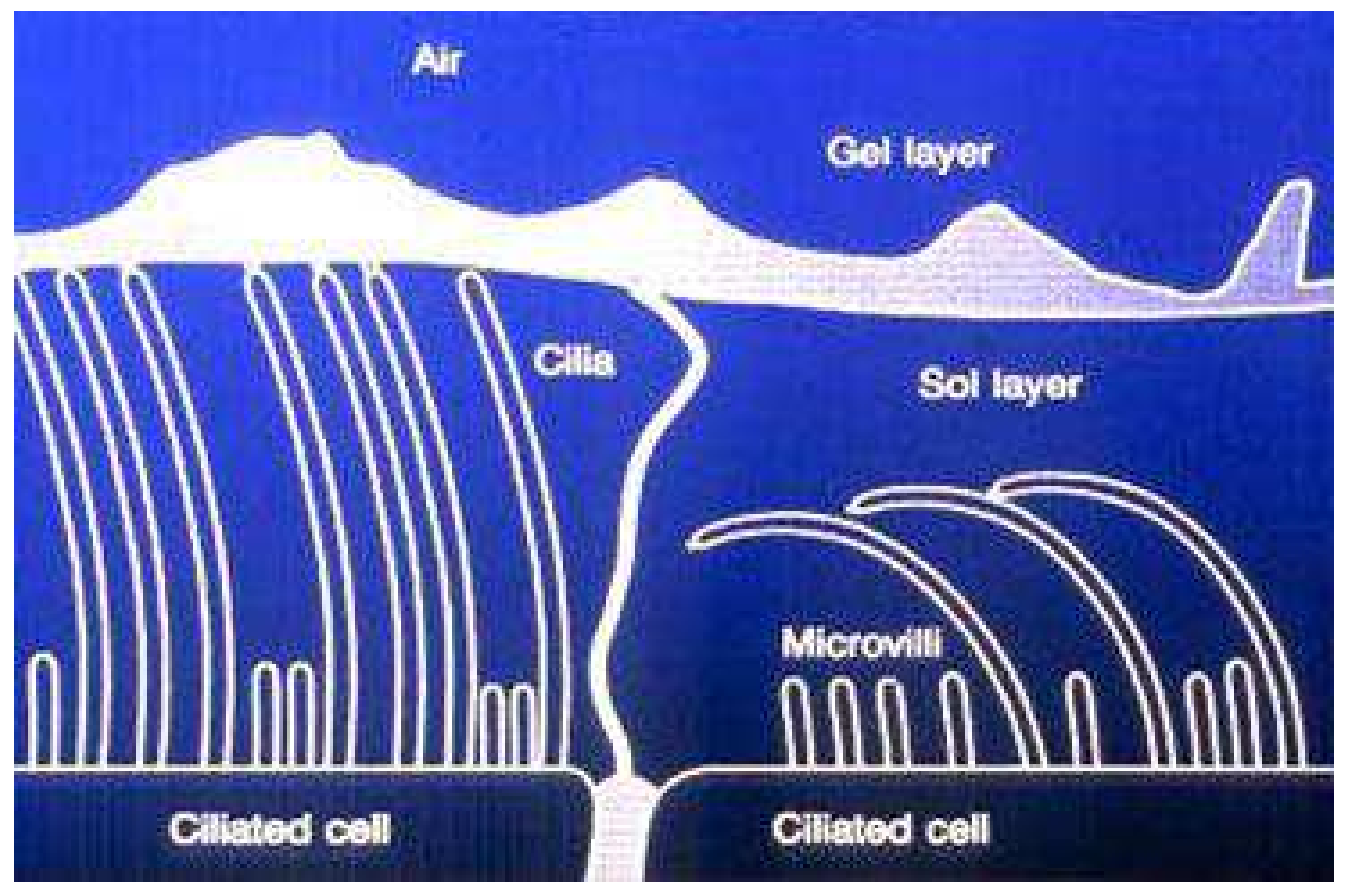

Fonte: www.sistemanervoso.com

Figura 6 - Desenho esquemático do muco em vias aéreas superiores na sua fase sol e gel. Air: vias aéreas; Gel layer: fase gel; Sol layer: fase sol; Ciliar: cílios; Microvilli: microvilosidade; Ciliated cell: células ciliadas.

A composição do muco garante a ele um componente elástico e deformável, importante para seu deslocamento em resposta à energia transmitida pelo batimento ciliar (Lund, 1996). A velocidade de eliminação do muco é influenciada por diversos fatores como, por exemplo, taxa de secreção e viscoelasticidade do muco, sincronia e frequência batimento dos cílios, alterando a sua depuração mucociliar (Foster, 2002).

Assim, a limpeza eficiente da árvore respiratória através do transporte mucociliar depende da perfeita interação entre cílios e muco, condicionada pela ação coordenada de três atividades celulares básicas: geração de força, função secretora e transporte de água e íons (Zayas et al., 2004; Pazetti et al., 2007; Trindade et al., 2007). 
Como consequência das doenças respiratórias ou outros fatores que possam agredir ou danificar o epitélio respiratório, pode ocorrer aumento no número de células de secreção mucosa (metaplasia mucosa), diminuição do número de células serosas e ciliadas, e diminuição da camada periciliar com aumento de muco. Esta secreção passa a ser de mucopolissacarídeos ácidos e sulfatados (muco ácido), alterando as características físico-químicas do muco, tornando-o mais ácido, dificultando sua remoção e, consequentemente, a eliminação de microrganismos, favorecendo processos infecciosos (Saldiva, 1990).

O mecanismo de depuração mucociliar nasal é capaz de eliminar 75 a $90 \%$ do material particulado entre 3 a $5 \mu \mathrm{m}$ de diâmetro presente no ar inalado. Sustentando-se que o transporte mucociliar ocorre graças às propriedades reológicas do muco (viscoelasticidade), ao batimento ciliar em ondas metacrônicas e ao acoplamento entre os cílios e o muco, sendo que essas características dependem da morfologia do epitélio e da lâmina própria (Proctor, 1983; Sleigh et al., 1988).

Há relatos de que o transporte mucociliar está prejudicado depois do transplante pulmonar (Herve et al., 1993; Veale et al., 1993). Tal alteração, se presente, pode colocar os pacientes imunocomprometidos em um sério risco de infecção no trato respiratório (Aeba et al., 1992).

Os mecanismos envolvidos na diminuição da função mucociliar após o transplante de pulmão não estão bem estabelecidos e podem estar relacionados com vários fatores, tais como o trauma cirúrgico de secção brônquica e sua consequente denervação e desvascularização (Shankar et al., 
1991; Tomkiewicz et al., 1995). Além disso, há estudos que mostram que as drogas imunossupressoras podem também ter um efeito adverso na função mucociliar (Pego-Fernandes et al., 2008; Pazetti et al., 2008).

A infeção respiratória é uma importante causa de morbidade e mortalidade dos pacientes receptores de enxerto pulmonar (Chaparro et al., 1994; Bando et al., 1995; Crawford, 1995). Considerando as consequências da manipulação mecânica sobre o fornecimento de sangue brônquico e da inervação autônoma quando o novo pulmão é transplantado para o destinatário, é possível especular que alterações no transporte mucociliar podem contribuir para a maior susceptibilidade à infecção respiratória apresentado pelos pacientes no pós-operatório de transplante de pulmão (Rivero et al., 2001).

O aparelho mucociliar é enervado predominantemente pelo sistema nervoso parassimpático (Jeffery et al., 1992; Bleecker, 1986) e agonistas colinérgicos e b-adrenérgicos parecem aumentar a frequência de batimento ciliar, bem como a quantidade e composição do muco traqueal e a secreção de água (Sackner et al., 1979; Peatfield e Richardson, 1983; Sanjar, 1991).

\subsubsection{Resposta imunológica}

Os pulmões são responsáveis por muitas funções, entre elas a troca gasosa, e para isso apresentam uma grande área de superfície epitelial de contato com o ambiente externo. A partir do momento em que estes agentes são depositados na superfície do trato respiratório, uma série de mecanismos 
de defesa entra em ação para manter a esterilidade pulmonar (Zhang et al., 2000).

As respostas de defesa normais do hospedeiro no pulmão incluem a resposta imunológica inata (não específica) e a adquirida (específica). A defesa imunológica inata é a principal responsável pela eliminação das partículas estranhas depositadas na superfície das vias aéreas e dos agentes patogênicos bacterianos dos alvéolos.

As células básicas responsáveis por essa eliminação são as que consistem nas defesas estruturais, as moléculas antimicrobianas geradas nas vias aéreas e as defesas fagocíticas fornecidas pelos macrófagos alveolares residentes e pelos leucócitos polimorfonucleares (PMN) que são recrutados para o pulmão em resposta à infecção pulmonar (Zhang et al., 2000 e Saldiva et al., 2011).

Os macrófagos alveolares constituem a primeira linha de defesa fagocítica contra agentes infecciosos que se furtam à defesa mecânica e têm acesso às vias aéreas de troca gasosa. Os macrófagos são morfologicamente e funcionalmente heterogêneos, e correspondem à maioria dos fagócitos encontrados em vias aéreas inferiores, são também responsáveis pela produção e eliminação de substâncias importantes na inflamação como os radicais livres e enzimas proteolíticas (Sibille e Reynolds, 1990).

Quando a resposta macrofágica não é suficiente para conter a proliferação de microrganismos no ambiente alveolar, ocorre recrutamento de neutrófilos para a região. Se a resposta inata falhar em conter o patógeno, a 
resposta imunitária adquirida torna-se criticamente importante. A resposta adquirida é tardia e inicia-se com a geração de linfócitos (Saldiva et al., 2011).

O lavado broncoalveolar (LBA) normal é formado por $85 \%$ de macrófagos, 7 a $12 \%$ de linfócitos e $3 \%$ de neutrófilos. Os agentes infecciosos podem atingir o pulmão, por meio de aspiração, inalação, ou vias hematogênicas. Uma vez encontrado no pulmão, o organismo ou antígeno sofre fagocitose pelos macrófagos alveolares, mastócitos e neutrófilos, que iniciam as respostas inflamatórias (Duncan e Wilkes, 2005).

Na presença de infecção pulmonar e inflamação, os $\mathrm{PMN}$ periféricos são recrutados em espaços alveolares para reforçar a defesa do hospedeiro nas vias aéreas. Estudos em animais mostraram que um desafio intrapulmonar com uma bactéria provoca um rápido recrutamento de PMN no pulmão: por 3 a $4 \mathrm{~h}$ após o desafio, que representam pelo menos $60 \%$ a $80 \%$ do total células recuperadas por LBA (Nelson et al., 1989, Zhang et al., 1997, Zhang et al., 1999).

\subsubsection{Células inflamatórias do sistema BALT}

As células inflamatórias do sistema BALT (do inglês Bronchial Associated Lymphoid Tissue) (linfócito B e T) são linfócitos organizados difusamente, que estão presentes no epitélio e na camada submucosa, responsável pela defesa imunológica adquirida do trato respiratório (Bjorkander et al., 1985) (Figura 7). O BALT secreta imunoglobulina IgA nos segmentos proximais dos brônquios e IgG nos distais dos brônquios. A IgA brônquica tem papel importante na proteção das superfícies mucosas contra patógenos e seus subprodutos, e é importante para a prevenção de infecções e 
reconhecimento de células tumorais, participando do sistema imunológico (Bjorkander et al., 1985; Saldiva, 1990). Pacientes com deficiência de IgA e algumas subclasses de $\lg$ mostram um aumento da susceptibilidade a infecção e prejuízo da função pulmonar (Bjorkander et al., 1985).

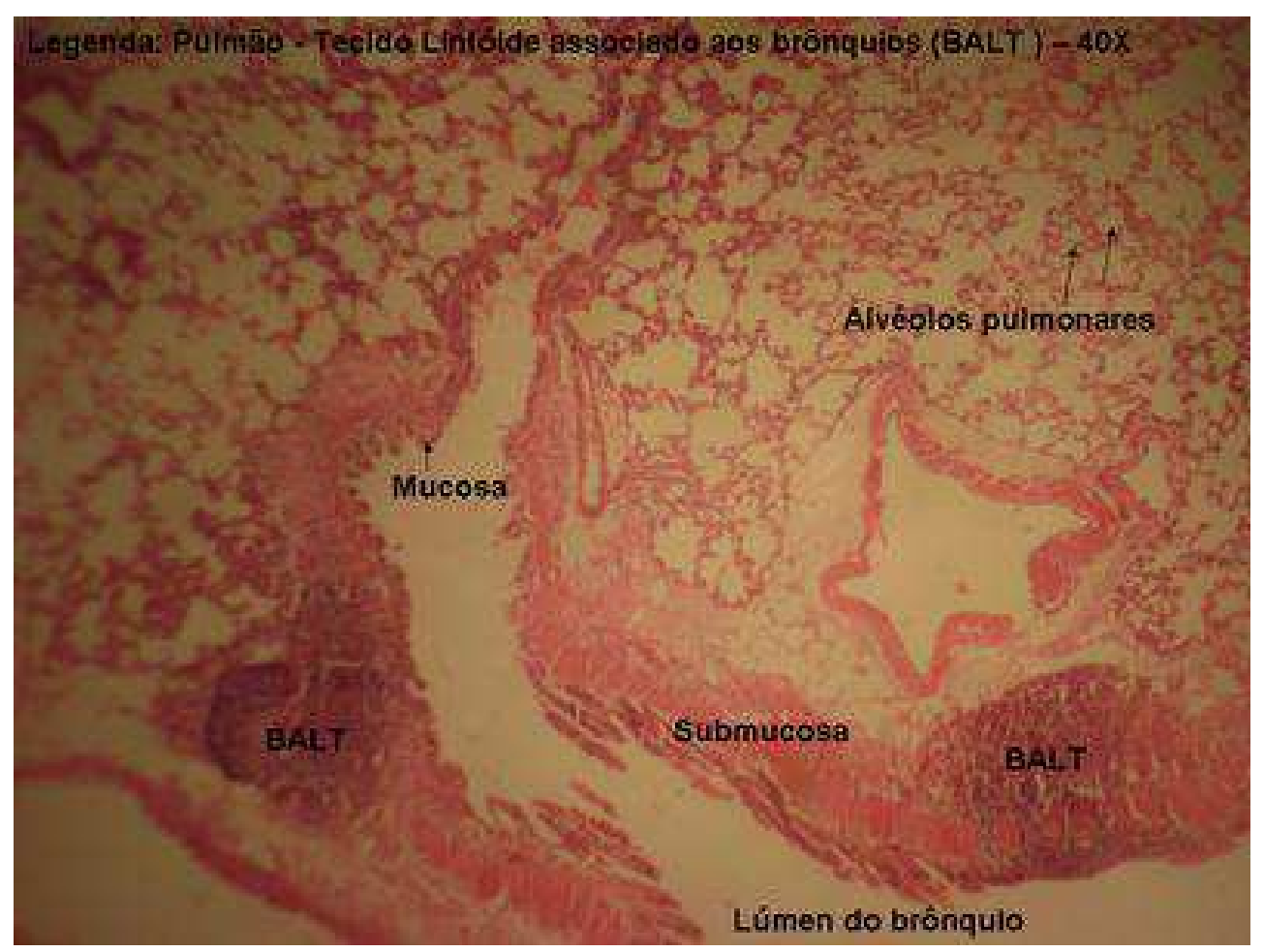

Fonte: http://histologiaufgd.blogspot.com.br

Figura 7 - Microscopia óptica mostrando a distribuição do sistema BALT no epitélio e submucosa traqueal.

\subsection{Terapia imunossupressora}

Os protocolos imunossupressores melhoraram drasticamente a sobrevida do enxerto. No entanto, a imunossupressão necessária para a sobrevivência prolongada do enxerto leva a uma suscetibilidade aumentada ao desenvolvimento de quadros infecciosos e constitui uma importante causa de 
morbimortalidade após transplantes de órgãos sólidos (Hertz et al., 2008; Christie et al., 2010).

Geralmente, a imunossupressão é baseada em um esquema tríplice que associa fármacos inibidores da produção de IL-2 (ciclosporina ou tacrolimus) a fármacos inibidores da síntese de purinas ou pirimidinas (azatioprina ou micofenolato de mofetila) e fármacos que inibem a expressão de citocinas, como a prednisona (Hertz et al., 2008 e Christie et al., 2010).

O tacrolimus ocasionalmente substituiu a ciclosporina em pacientes com rejeição persistente ou recorrente, e também eventualmente é usado em mulheres e crianças para evitar o hirsutismo associado à ciclosporina. Poucas instituições usam rotineiramente 0 tacrolimus como parte do regime imunossupressor inicial (Ausiello e Goldman, 2014).

\subsubsection{Prednisona}

A prednisona é um glicocorticoide sintético, análogo ao cortisol, com propriedades anti-inflamatórias e imunossupressoras. Consiste em uma pródroga que após a absorção é convertida em um princípio metabolicamente ativo, a prednisolona. O mecanismo clássico de ação dos corticosteroides implica na ligação do esteroide a receptores citosólicos que, dimerizados, dirigem-se ao núcleo celular e ligam-se a regiões promotoras do DNA (Castro, 2005; Clarck, 2007).

Os corticosteroides reduzem a produção de mediadores inflamatórios, incluindo as citocinas, prostaglandinas e óxido nítrico, inibem a migração de 
células inflamatórias aos locais de inflamação impedindo a expressão das moléculas de adesão, modulam direta e indiretamente a função das células $B$, reduzem a movimentação de células e fluidos a partir do compartimento intravascular, inibem a resposta proliferativa dos monócitos ao fator de estimulação de colônia e diferenciação em macrófagos e promovem a morte de células linfoides por apoptose (Castro, 2005; Clarck, 2007).

A prednisona tem sido empregada sistemicamente para o tratamento de doenças endócrinas, osteomusculares, dermatológicas alérgicas, inflamatória intestinal, respiratórias, hematológicas e outras que respondam à terapia com corticosteroides. A dosagem e o período de tratamento são controlados já que efeitos colaterais limitam seu uso (Vondracek e Hemstreet, 2006).

Os glicocorticoides são agentes seletivos e afetam linhas de multiplicação de leucócitos, incluindo células B e T, macrófagos, granulócitos e monócitos. São altamente lipofílicos e atravessam rapidamente a membrana celular onde se ligam aos receptores celulares citoplasmáticos e influenciam a transição do ativador de proteínas e do fator nuclear $\beta$, de maneira positiva ou negativa (Duncan e Wilkes, 2005).

No início da década de 50 , os primeiros estudos sobre as técnicas de transplante pulmonar já relatavam a utilização de corticoterapia. Neptune et al. (1953) documentaram uma maior sobrevivência de cães após a associação da corticoterapia ao transplante. Hardy et al. (1963) observaram o aumento da sobrevivência de cães administrando azatioprina combinada à hidrocortisona.

No entanto, atualmente, a indicação para transplante pulmonar requer a redução nas doses administradas. Isso porque um grande número de 
complicações, como baixa cicatrização e aumento na incidência de infecções, são atribuídos à utilização de esteroides durante o período pré-operatório (McAnally et al., 2006; Orens et al., 2006; Hertz et al., 2008).

O International Guidelines for the Selection of Lung Transplant Candidates contraindica doses maiores que $20 \mathrm{mg} / \mathrm{dia}$ a pacientes com prescrição de transplante (Orens et al., 2006).

\subsubsection{Ciclosporina}

Em 1972, a descoberta da ciclosporina foi crucial para o desenvolvimento do transplante. Trata-se de um polipeptídeo, derivado de duas espécies de fungos (Tolyplocadium inflatum e Cylindrocarpon lucidum), que adquire a sua forma ativa quando entra em contato com as células e forma complexos com as proteínas citoplasmáticas (Hess et al., 1988). Este complexo inibe a calcineurina do citoplasma, inibindo assim a transcrição de citocinas, nomeadamente da IL-2, IL-3, IL-4 e IL-5, interferon $\gamma$, fator de necrose tumoral a, e fator estimulador colônico de granulócitos e macrófagos (Shevach, 1985).

Além disso, a ciclosporina apresenta presumivelmente um mecanismo distinto: a expressão de fatores de crescimento fator $\beta$, que inibem o braço do estímulo da IL-2 na proliferação celular e produção de linfócito T citotóxico, e outro braço, o efeito pro-fibrinogênese do enxerto (Knoop et al., 2004; Duncan e Wilkes 2005). A ciclosporina interfere nos estágios iniciais do ciclo celular, afetando a proliferação de células linfoides no início da mitose (Hess et al., 1988), e induz também apoptose em células epiteliais brônquicas, que podem 
ser associadas a complicações das vias aéreas após o transplante pulmonar (Ha e Mun, 2012).

O efeito imunossupressor de agentes anti-rejeição, tais como a ciclosporina e prednisona, é facilmente identificado como um fator de risco para infecção pulmonar (Calhoon et al., 1992). No entanto, a imunossupressão induzida por drogas por si só não pode ser a única causa da prevalência significativa maior de infecção pulmonar em comparação com a de outros órgãos que se submetem à imunossupressão (Dummer et al., 1986).

\subsubsection{Tacrolimus}

O tacrolimus (FK-506 ou Fujimycin) é um agente imunossupressor comumente utilizado em pacientes transplantados e no tratamento de eczema. Foi descoberto em 1984 a partir do fungo Streptomyces tsukubaensis, comumente encontrado em solo japonês. O mecanismo molecular de ação do tacrolimus é desencadeado quando este se une a imunofilina FKBP12. O complexo FKBP12-tacrolimus inibe diretamente a calcineurina, impedindo a desfosforilação do fator de transcrição NFAT e, consequentemente, a liberação da interleucina-2, responsável pela ativação dos linfócitos T. Como resultado desta ação molecular, a droga inibe especialmente a resposta imune mediada por células (Yamauchi et al., 2004). O tacrolimus é o inibidor de calcineurina mais utilizada, oferecendo menor rejeição aguda nos beneficiários baseados nos acompanhamentos entre 1 de julho de 2004 a 30 de junho de 2009 (Christie et al., 2010). 
O maior efeito do tacrolimus in vivo é a inibição da imunidade celular mediada por células. As proliferações primárias e a citotoxidade ao antígeno estão reduzidas. Estudos em humanos têm demonstrado redução significativa na incidência de rejeição aguda, aguda refratária, e episódios de rejeição crônica. As principais complicações associadas ao seu uso foram: insuficiência renal, distúrbios no metabolismo da glicose e complicações neurológicas. Quando comparado à ciclosporina, os estudos não têm demonstrado diferença na sobrevida, porém o índice de rejeição aguda é menor no grupo tratado com tacrolimus, ainda que mantendo similar índice de infecção e alta incidência de diabetes (Reichenspurner et al., 1999; Webster et al., 2005; Woodroffe et al., 2005 e Fan et al., 2009).

\subsubsection{Azatioprina}

A azatioprina, sintetizada no início dos anos 50 , é utilizada extensivamente há mais de 40 anos nos transplantes de órgãos maciços. Trata-se de uma pró-droga inativa que faz parte do grupo das tiopurinas. Sua metabolização forma a 6-mercaptopurina e a 6-tioguanina, que são os compostos ativos com capacidade de incorporação no RNA e DNA celular, diminuindo progressivamente a produção de ATP até que os níveis atingidos levem à disfunção, diminuição da atividade celular e citólise, tais modificações caracterizam o mecanismo de ação desta droga imunossupressora (Aarbakke, 1995; Aarbakke et al., 1997). 


\subsubsection{Micofenolato}

O micofenolato de mofetil é um inibidor do ciclo celular, derivado do Penicillium $s p$, e tem reduzido a incidência de rejeição aguda em pacientes transplantados renais e cardíacos, quando comparado com outros imunossupressores como a azatioprina (Chen et al., 2004; Knoop et al., 2004; Studer et al., 2004).

O micofenolato de mofetil é um inibidor não competitivo e reversível da losina monofosfato desidrogenase, responsável pela depleção dos nucleotídeos de guanina. Esta droga inibe a proliferação dos linfócitos T e B, ambos responsáveis pela mitose e estimulação alogênica, além da migração de leucócitos para o local da inflamação ou rejeição. O micofenolato de mofetil reduz a produção de células que expressam o antígeno humano IL-2R, receptores de transferrina, células CD4 e CD8, além da proliferação de fibroblastos, células endoteliais e músculo liso e, menos potencialmente a proliferação linfocitária (Hausen e Morris, 1997).

O micofenolato é utilizado com muita frequência na prevenção de rejeição aguda nos transplantados renais, quando combinado com ciclosporina e esteroides. Estudos têm demonstrado se tratar de um agente efetivo no tratamento da rejeição refrataria, quando comparado a utilização de azatioprina, associado à ciclosporina e esteroides, em transplantados renais, cardíacos e hepático, e pode ser efetivo na rejeição crônica (Sievers et al., 1997; Sollinger, 2004). 
4 MÉTODOS 


\section{Métodos}

Todos os procedimentos foram realizados de acordo com os princípios éticos de experimentação animal adotados pelo Colégio Brasileiro de Experimentação Animal - COBEA (www.cobea.org.br), sendo o projeto referente a esta tese de doutorado aprovado pelo Comitê de Ética em Pesquisa da Faculdade de Medicina da Universidade de São Paulo - CEP-FMUSP, em 30 de março de 2011 (Protocolo 082/11).

Foram utilizados 90 ratos machos da linhagem Wistar, com peso médio de $300 \mathrm{~g}$, fornecidos pelo Centro de Bioterismo da FMUSP.

Os animais foram submetidos ao procedimento terapêutico no Laboratório de Pesquisa em Cirurgia Torácica - LIM61, do Hospital das Clínicas da FMUSP, e mantidos em gaiolas individuais no biotério do mesmo laboratório, onde tinham livre acesso a água e ração balanceada, sendo pesados e avaliados diariamente até a data da eutanásia. Após a eutanásia, as carcaças dos animais foram acondicionadas em sacos brancos específicos, devidamente identificados, sendo mantidos em freezer a $20^{\circ} \mathrm{C}$ negativos até a retirada para cremação.

\subsection{Grupos experimentais}

Os animais foram distribuídos em grupos, de acordo com o tratamento terapêutico a que foram submetidos:

- Grupo controle (C): os animais receberam diariamente, por gavagem, solução de $\mathrm{NaCl}$ a $0,9 \%(2,5 \mathrm{~mL} / \mathrm{kg})$. 
- Grupo terapia I (TI): os animais receberam diariamente, por gavagem, tacrolimus $(1 \mathrm{mg} / \mathrm{kg})$, micofenolato de mofetil $(30 \mathrm{mg} / \mathrm{kg})$ e prednisona $(1,25$ $\mathrm{mg} / \mathrm{kg})$.

- Grupo terapia II (TII): os animais receberam diariamente, por gavagem, ciclosporina (1 mg/kg), azatioprina $(3,0 \mathrm{mg} / \mathrm{kg})$ e prednisona $(1,25 \mathrm{mg} / \mathrm{kg})$.

Dez animais de cada grupo foram estudados após terem recebidos diariamente as terapias, e sacrificados em 7, 15 e 30 dias (Figura 8).

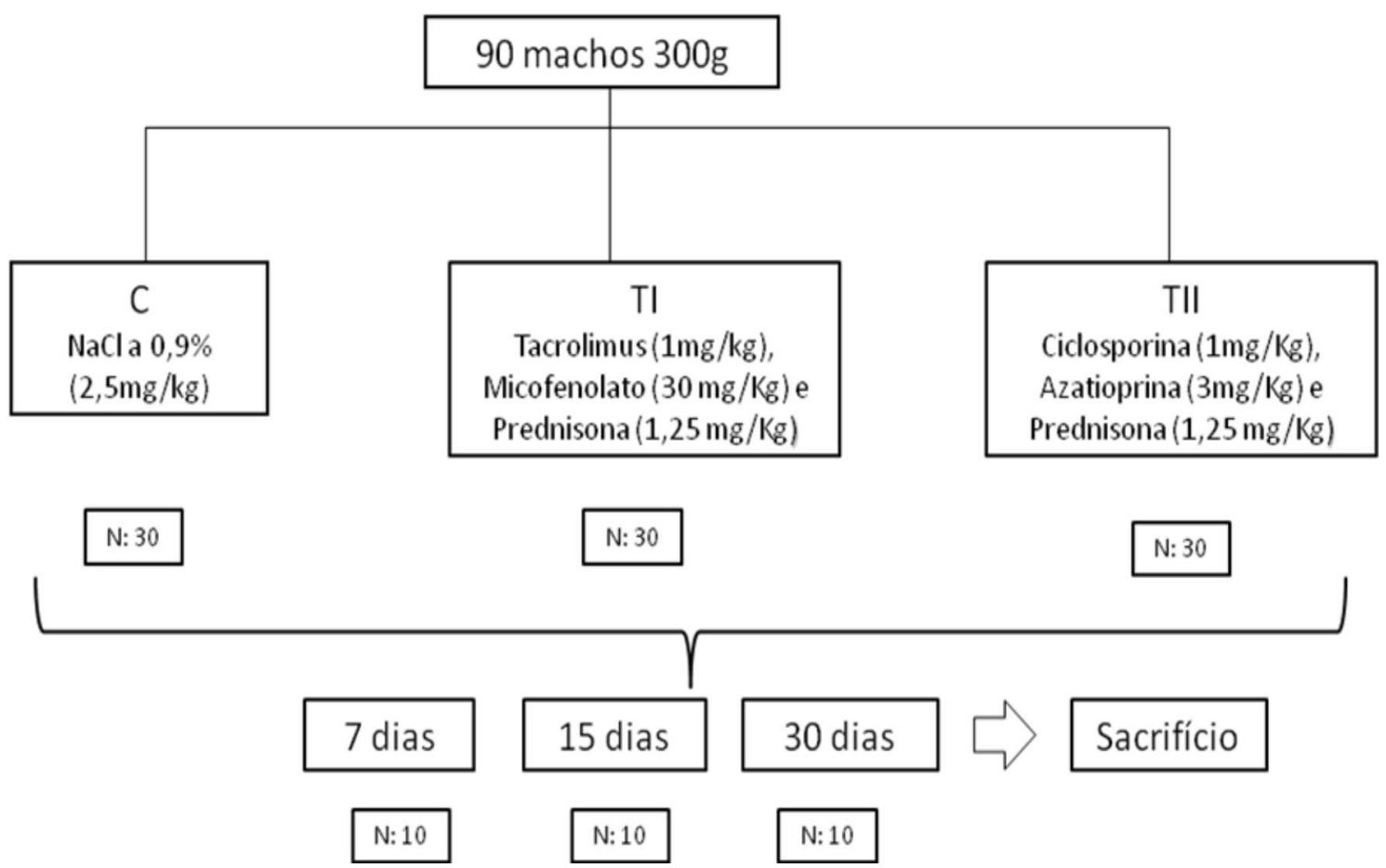

Figura 8 - Fluxograma da composição dos grupos de acordo com o tipo e tempo de tratamento terapêutico a que foram submetidos. 


\subsection{Gavagem}

Os animais foram anestesiados em câmara contendo $2 \%$ de isoflurano (Isoforine, Cristália, São Paulo, Brasil) e $98 \%$ de oxigênio e a gavagem foi realizada por via orogástrica através de cateter de polietileno, número 7 .

\subsection{Coleta de dados}

Os animais foram anestesiados com tiopental sódico (Thiopentax, 0,5g, Cristália, São Paulo, Brasil) e, após laparotomia mediana, eutanasiados por exanguinação, através da secção da artéria aorta abdominal.

\subsection{Análise do muco}

\subsubsection{Coleta}

Imediatamente após a morte do animal, foi realizada a retirada dos pulmões, com subsequente dissecação das vias aéreas superiores.

As amostras de muco foram coletadas com auxílio de um pincel de pelos macios. 


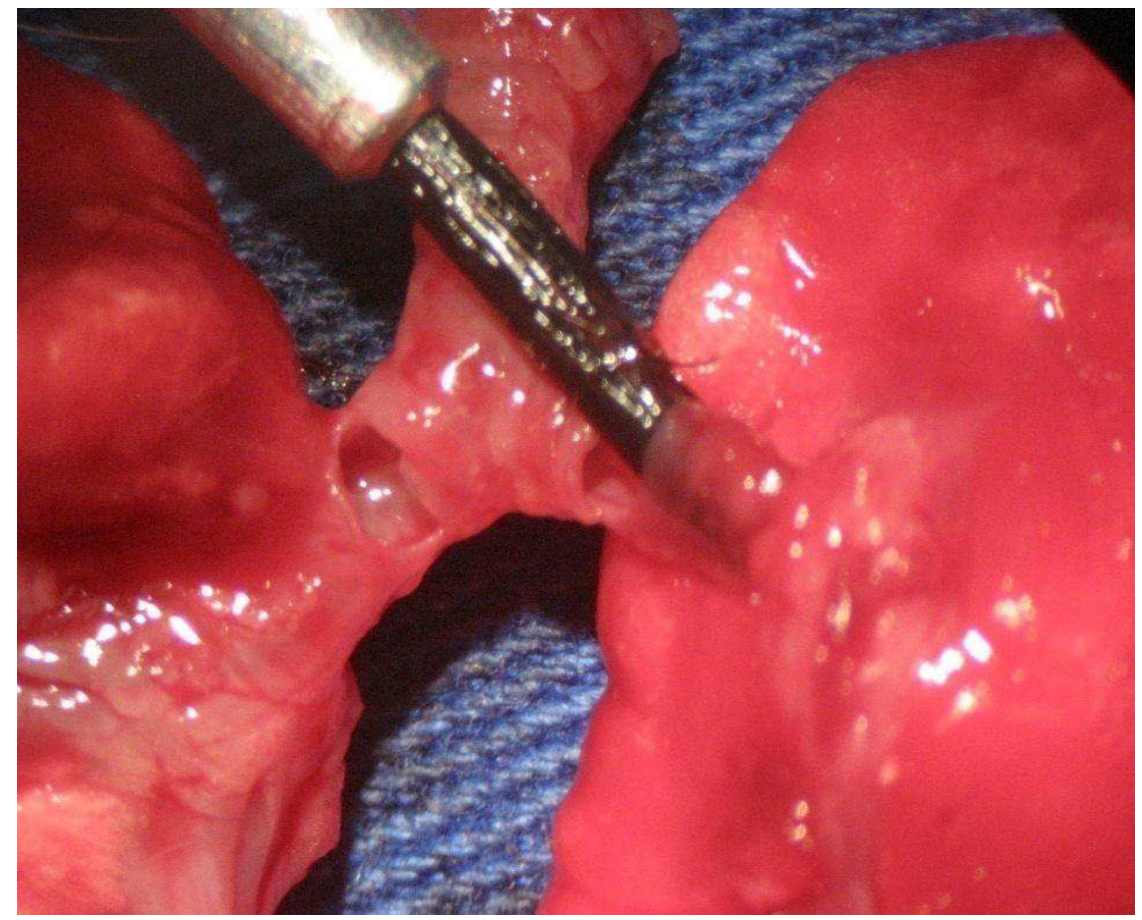

Figura 9 - Coleta de amostra de muco dos brônquios.

O pincel foi posicionado nos brônquios principais através de uma pequena abertura feita na porção cartilaginosa do mesmo (Figura 9). O muco aderido ao pincel foi colocado sobre uma lâmina histológica contendo óleo mineral, e, a seguir, colocado em tubo tipo eppendorf contendo a mesma substância. As amostras foram mantidas sob refrigeração a $70^{\circ} \mathrm{C}$ negativos até a data da análise.

\subsubsection{Transportabilidade do muco (TM)}

As amostras de muco foram submetidas a um teste classicamente aceito e relatado como sendo um método in vitro: a transportabilidade em palato de rã (Puchelle et al., 1983; Rubin et al., 1990). 
O palato de rã possui um epitélio pseudoestratificado com células secretoras e numerosas células ciliadas, cobertas por uma camada contínua de muco, com 4 a $8 \mu \mathrm{m}$ de espessura, semelhante ao epitélio das vias respiratórias dos mamíferos. Por apresentar uma superfície plana, o palato de rã permite a observação direta do deslocamento de uma amostra de muco colocada sobre seu epitélio.

O procedimento foi realizado da seguinte forma: a rã (Lithobates catesbeianus) foi anestesiada através de hipotermia induzida em câmara contendo gelo triturado, por cerca de 50 minutos. A seguir, não respondendo aos testes de verificação de reflexo, foi decapitada, com auxílio de uma guilhotina própria para sacrifício de animais de experimentação, e o seu palato retirado através de dissecação, tomando-se o devido cuidado para não danificar a superfície epitelial.

O palato foi mantido por 48 horas sob refrigeração a $4^{\circ} \mathrm{C}$ para que $\mathrm{O}$ muco da rã fosse quase totalmente esgotado pela ação de seu próprio aparelho ciliar. O muco restante foi, então, coletado para servir de controle, em relação ao muco dos ratos.

Durante os procedimentos de medida da velocidade, o palato foi mantido sob temperatura ambiente, dentro de uma câmara de acrílico com $100 \%$ de umidade relativa do ar, mantida pelo vapor de uma solução de Ringer em água destilada (1:1) $\left(73,8 \mathrm{mEq} / \mathrm{l} \mathrm{Na}{ }^{+}, 2 \mathrm{mEq} / / \mathrm{K}^{+}, 2,3 \mathrm{mEq} / \mathrm{l} \mathrm{Ca}{ }^{+2}\right.$ e $\left.78 \mathrm{mEq} / \mathrm{l} \mathrm{Cl}\right)$ produzido por um nebulizador ultrassônico (mod. US-800, ICEL) (Figura 10). 


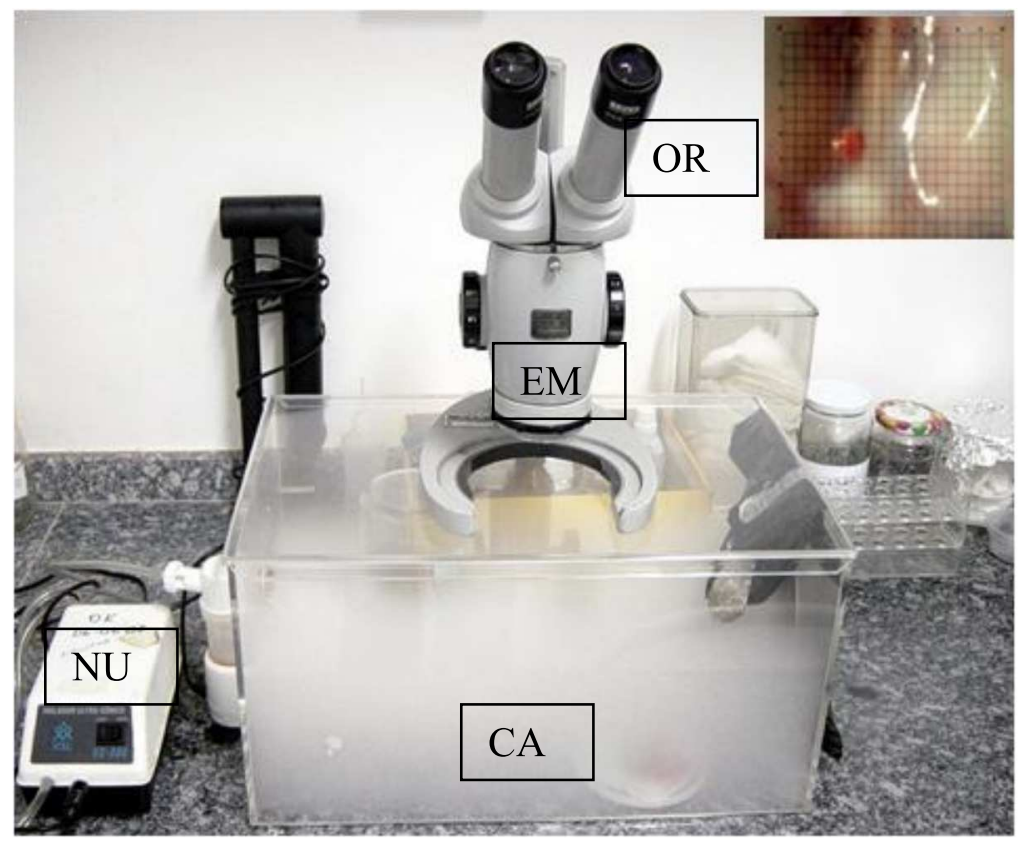

Figura 10 - Equipamentos utilizados para medida da transportabilidade das amostras de muco em palato de rã. $\mathrm{NU}=$ nebulizador ultrassônico; $\mathrm{CA}=$ câmara acrílica; EM = estereomicroscópio; OR = reticulada.

Antes de iniciar as medidas, uma pequena alíquota (cerca de $5 \mu \mathrm{l}$ ) da amostra de muco estocada em óleo mineral foi isolada e mergulhada rapidamente num recipiente contendo éter de petróleo com o objetivo de remover o óleo a ela aderido. Rubin et al. (1990) demonstraram que este procedimento não altera a transportabilidade e as características reológicas do muco.

A alíquota de muco foi colocada sobre o epitélio ciliado da região anterior do palato da rã e, durante o seu deslocamento em direção à região posterior, foi cronometrado o tempo gasto para que fosse percorrida uma distância pré-estabelecida de $6 \mathrm{~mm}$. A medida foi feita através da observação do conjunto por meio de um estereomicroscópio (Zeiss), posicionado sobre a 
tampa da câmara de acrílico, composto por uma ocular reticulada, com aumento de 8x (Figura 11).

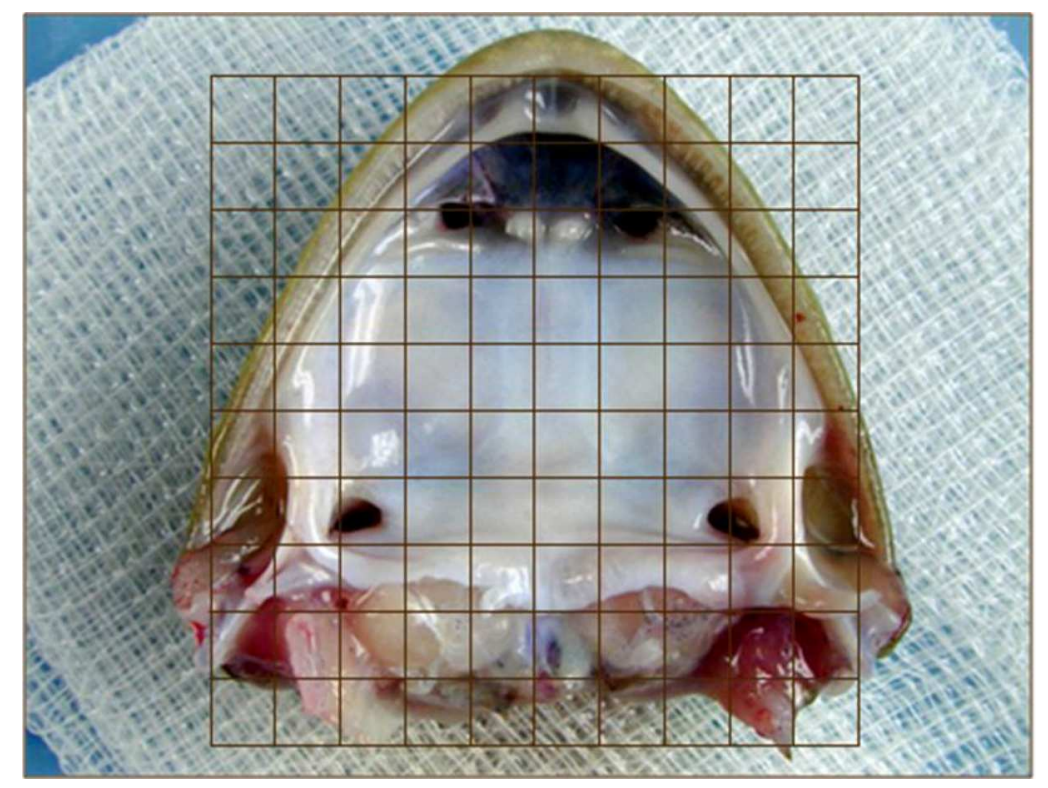

Figura 11 - Representação do palato de rã sendo visualizado através de ocular reticulada.

Foi realizada uma tomada de tempo da amostra do muco da rã e logo em seguida quatro medidas da amostra do muco do rato e por último mais uma tomada da amostra da rã; para fins estatísticos, foi realizada a média aritmética dos valores observados. A velocidade da transportabilidade do muco é expressa em velocidade relativa. Assim temos TM = velocidade média do muco de rato/velocidade média do muco da rã.

\subsection{Frequência de batimento ciliar in situ (FBC)}

Após a coleta das amostras de muco, foi realizada a abertura total das vias aéreas superiores, através de um corte longitudinal no ângulo de contato 
entre as porções cartilaginosa e membranosa, para exposição do epitélio ciliado.

A imagem do epitélio ciliado brônquico foi captada por uma câmera filmadora (Sony, mod. 3CCD Iris) acoplada a um microscópio óptico (Olympus, BX50), com aumento de 100x, e enviada para um monitor de vídeo (Sony Trinitron). Um estroboscópio (Machine Vision Strobe, mod.5000, U.S.A.), adaptado com fibra óptica, foi posicionado em frente ao epitélio ciliado, passando a emitir "flashes" a uma frequência conhecida (Figura 12).

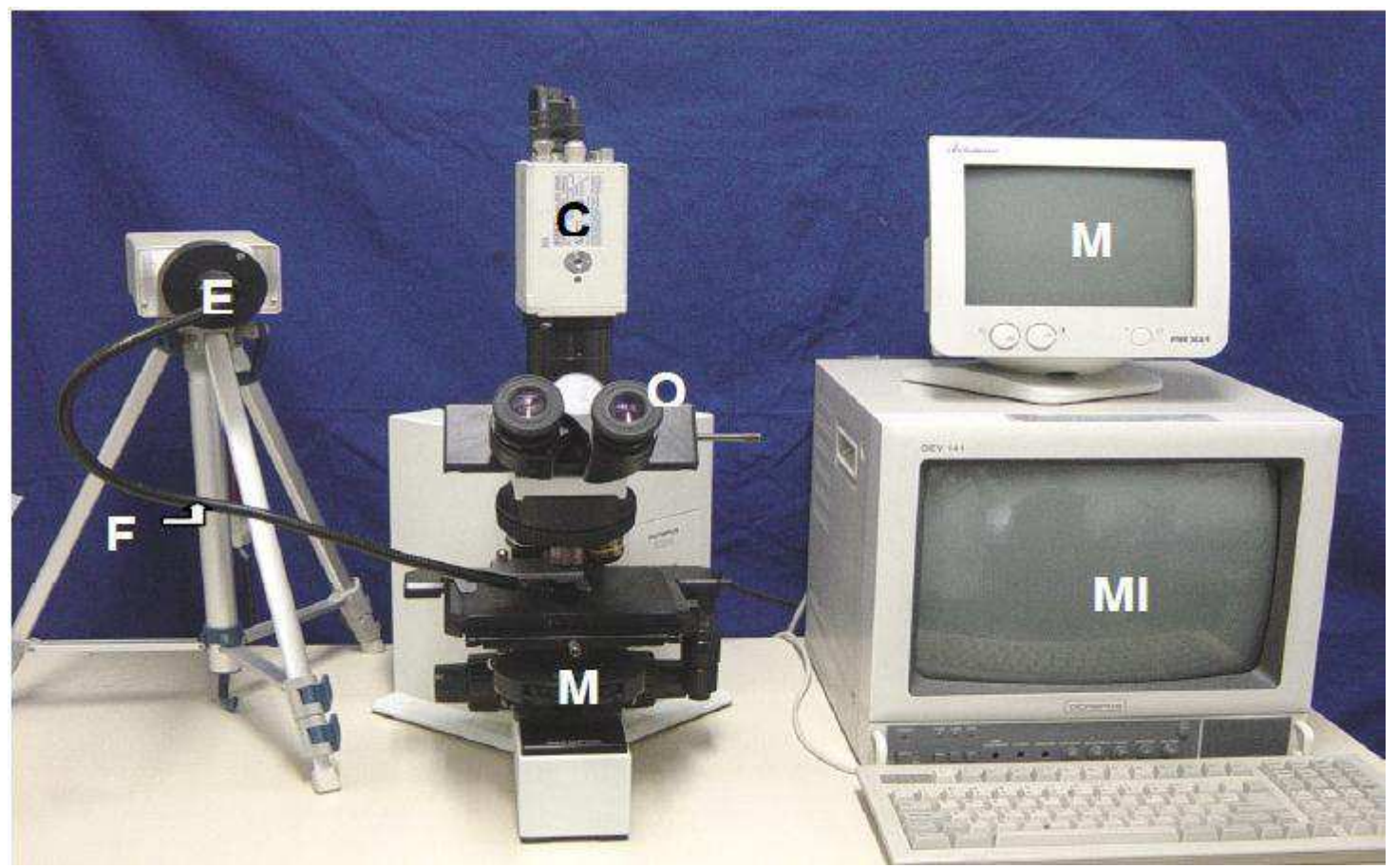

Figura 12 - Equipamentos utilizados para medida da velocidade de transporte mucociliar in situ e da frequência de batimento ciliar. $C$ = câmera filmadora; $E=$ estroboscópio; $F$ = fibra óptica; $M=$ monitor de frequência; $M I=$ monitor de imagem; $\mathrm{MO}=$ microscópio óptico; $\mathrm{O}=$ ocular reticulada. 
Ao mesmo tempo em que se observava a imagem do epitélio ciliado gerada no monitor, diminuía-se a frequência da luz emitida pelo estroboscópio, até o momento em que não era mais possível a percepção dos movimentos ciliares. Neste ponto, o mesmo valor da frequência do estroboscópio, registrado no monitor, era atribuído ao batimento ciliar.

Foram realizadas três medidas e a média destas três medidas foi tomada como valor principal para a análise estatística (Pazetti et al., 2007).

\subsection{Velocidade de transporte mucociliar in situ (VTMC)}

A VTMC foi medida através da observação direta de partículas aderidas ao muco do epitélio ciliado traqueobrônquico. A observação foi feita com o auxílio de um microscópio óptico (Olympus BX50), equipado com ocular reticulada, sob aumento de 100x (Figura 12).

A velocidade de deslocamento das partículas aderidas ao muco, ao longo do epitélio, foi cronometrada e registrada como a distância que a partícula percorreu num determinado intervalo de tempo $(\mathrm{mm} / \mathrm{min})$. Foram obtidas três medidas e transformadas em número absoluto de unidades de minuto. A média destas três medidas foi tomada como valor principal para a análise estatística (Pazetti et al., 2007). 


\subsection{Lavado broncoalveolar (LBA)}

O LBA foi realizado com instilação de $10 \mathrm{~mL}$ de solução salina pela traqueia e, a seguir, centrifugado a $1.000 \mathrm{rpm}$ por 10 minutos a $5^{\circ} \mathrm{C}$. Depois da centrifugação e retirada do sobrenadante, o botão celular foi ressuspendido com $5 \mathrm{~mL}$ de solução tampão fosfato (PBS) para a contagem do número total de células por $\mathrm{mL}$, realizada em câmara de Neubauer. Foram confeccionadas lâminas de cytospin (Cytospin-2, Shandon Instruments Sewickley, EUA), que foram posteriormente coradas com Diff-Quik para a contagem diferencial celular (300 células/lâmina) (Almeida, 2012).

\subsection{Histologia}

Após as medidas de FBC e VTMC, os pulmões e vias aéreas foram fixados em formaldeído $10 \%$ e submetidos à preparação rotineira para confecção de lâminas histológicas. Os cortes foram tratados com os corantes azul alciano e ácido periódico de Schiff para evidenciar a produção de muco ácido e neutro pelas células caliciformes do epitélio traqueobrônquico (Mowry, 1987 e Pazetti 2007), e com hematoxilina-eosina para a contagem de células inflamatórias e avaliação do índice de edema no parênquima pulmonar.

Para a quantificação do muco, inicialmente, cada lâmina foi disposta no microscópio de luz com aumento final de 400 vezes, sendo identificada a região mais preservada do epitélio (Figura 13). Em seguida a imagem foi captada pela câmara fotográfica digital (JVC Câmera de vídeo colorida TKC1380; Victor Company of Japan, Yokohama, Japão) (Figura 14). Após a captação da imagem, a coloração alvo era determinada pelo pesquisador 
(Figura 15). Em seguida, o programa Imagem Pro-Plus quantificava o percentual de muco na área do epitélio que era delimitada pelo pesquisador (Figura 16). Posteriormente, o programa de computador determinava a área total delimitada (Figura 17). No final, realizamos o cálculo de muco da área do epitélio/área total x100, para termos a quantidade de muco ácido, neutro e total nessa lâmina (Pazetti et al., 2007).

A contagem de células inflamatórias e índice de edema foi feita sob visão microscópica, com aumento de 400 vezes, utilizando-se uma ocular reticulada de 50 retas e 100 pontos (Pazetti et al., 2007).

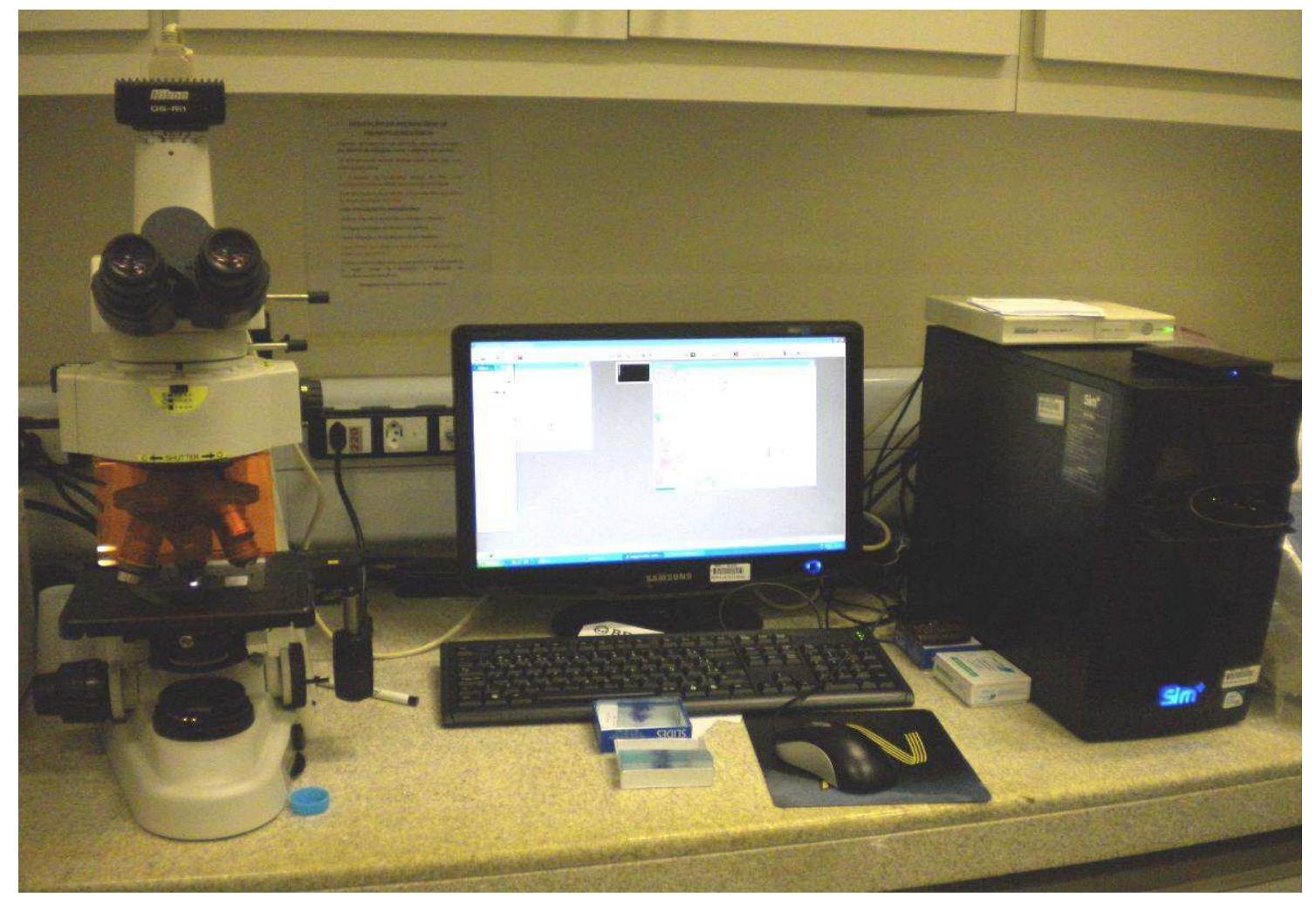

Figura 13 - Equipamentos utilizados para quantificar o muco. $\mathrm{C}=$ câmera fotográfica; $\mathrm{M}=$ monitor; $\mathrm{PC}=$ computador; $\mathrm{MO}=$ microscópio óptico. 


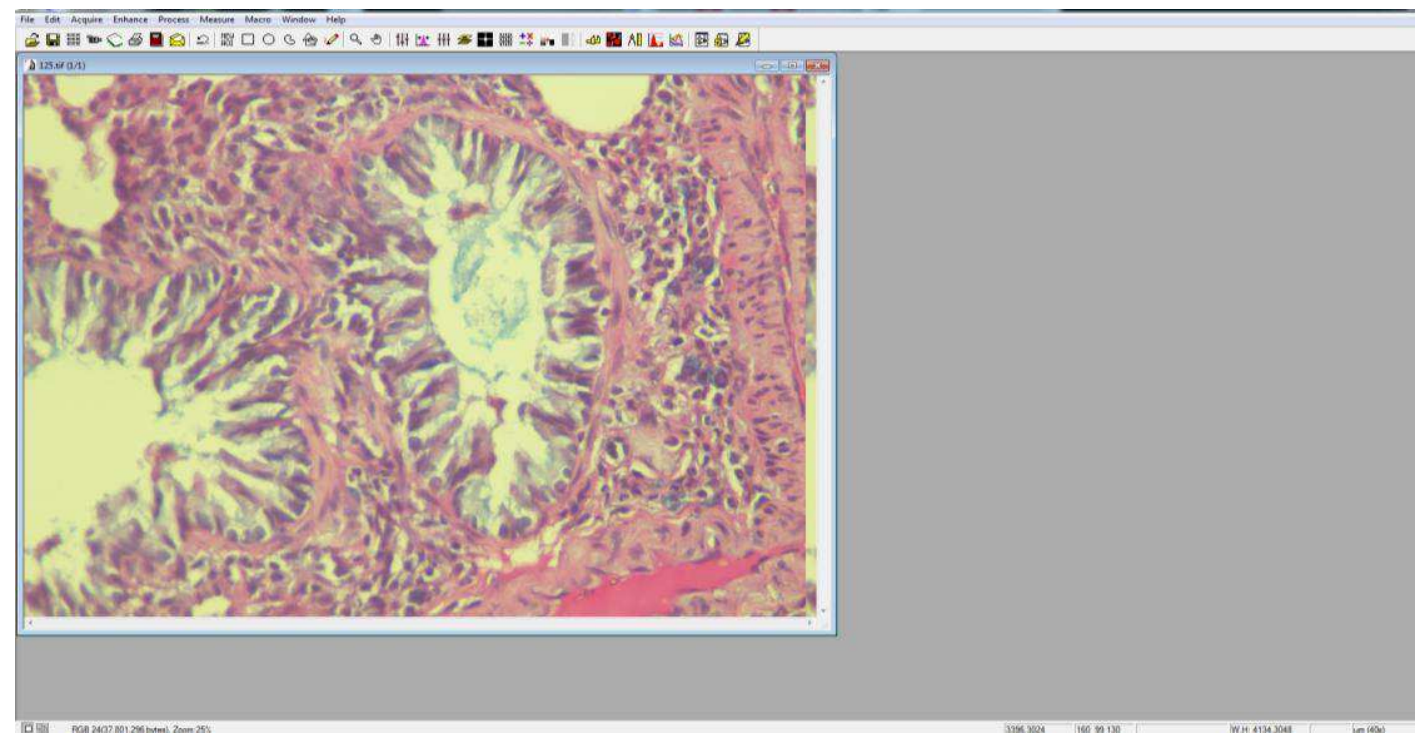

Figura 14 - Captação da imagem a partir de lâmina corada com PAS pela câmara fotográfica digital. Imagem inserida no programa de computador analisador de imagem para quantificação do percentual de área corada.

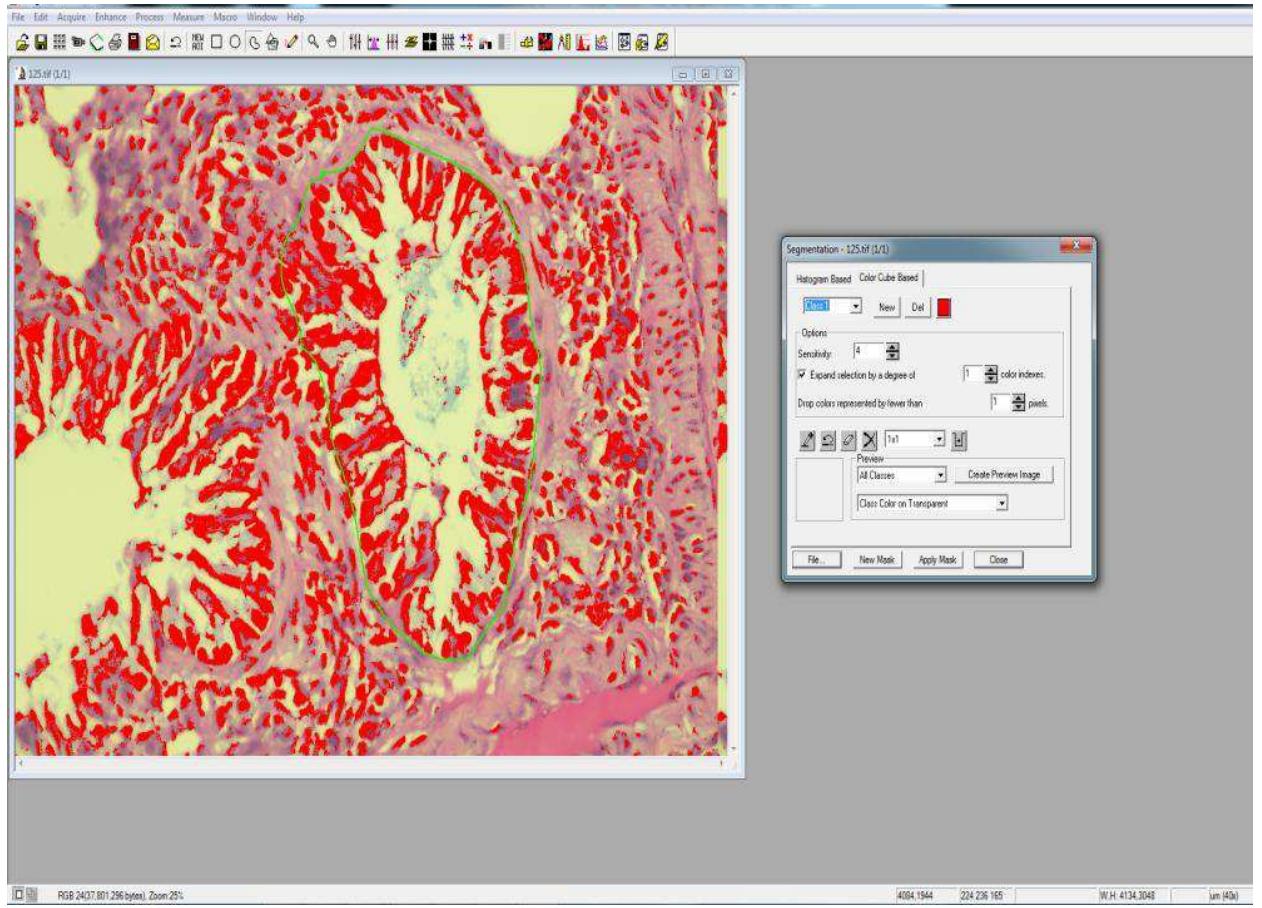

Figura 15 - Delimitação da coloração alvo pelo pesquisador, com uso do programa de computador, para quantificação do percentual de área corada. 


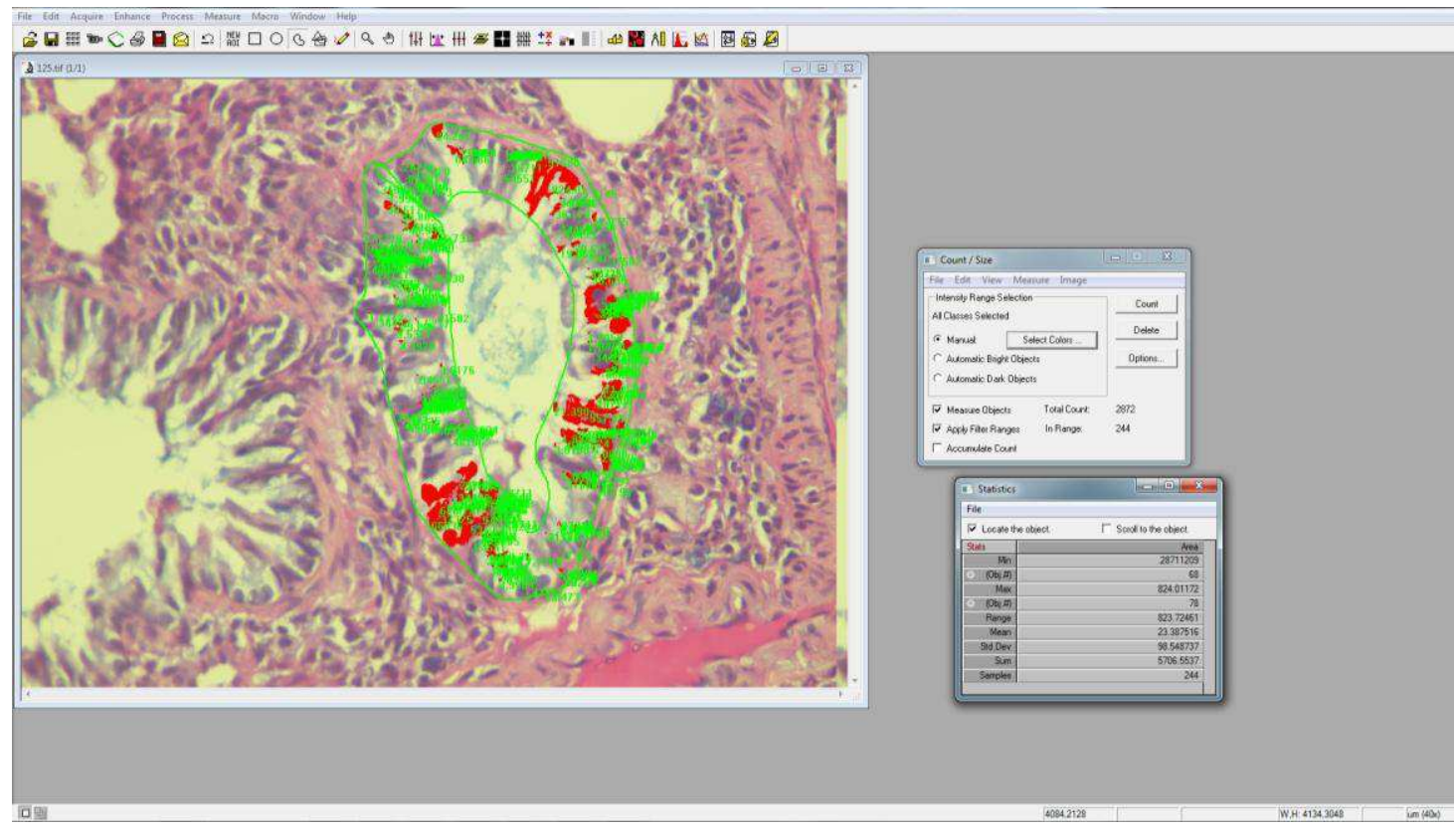

Figura 16 - Determinação da quantidade de muco na área determinada pelo pesquisador, com uso do programa de computador.

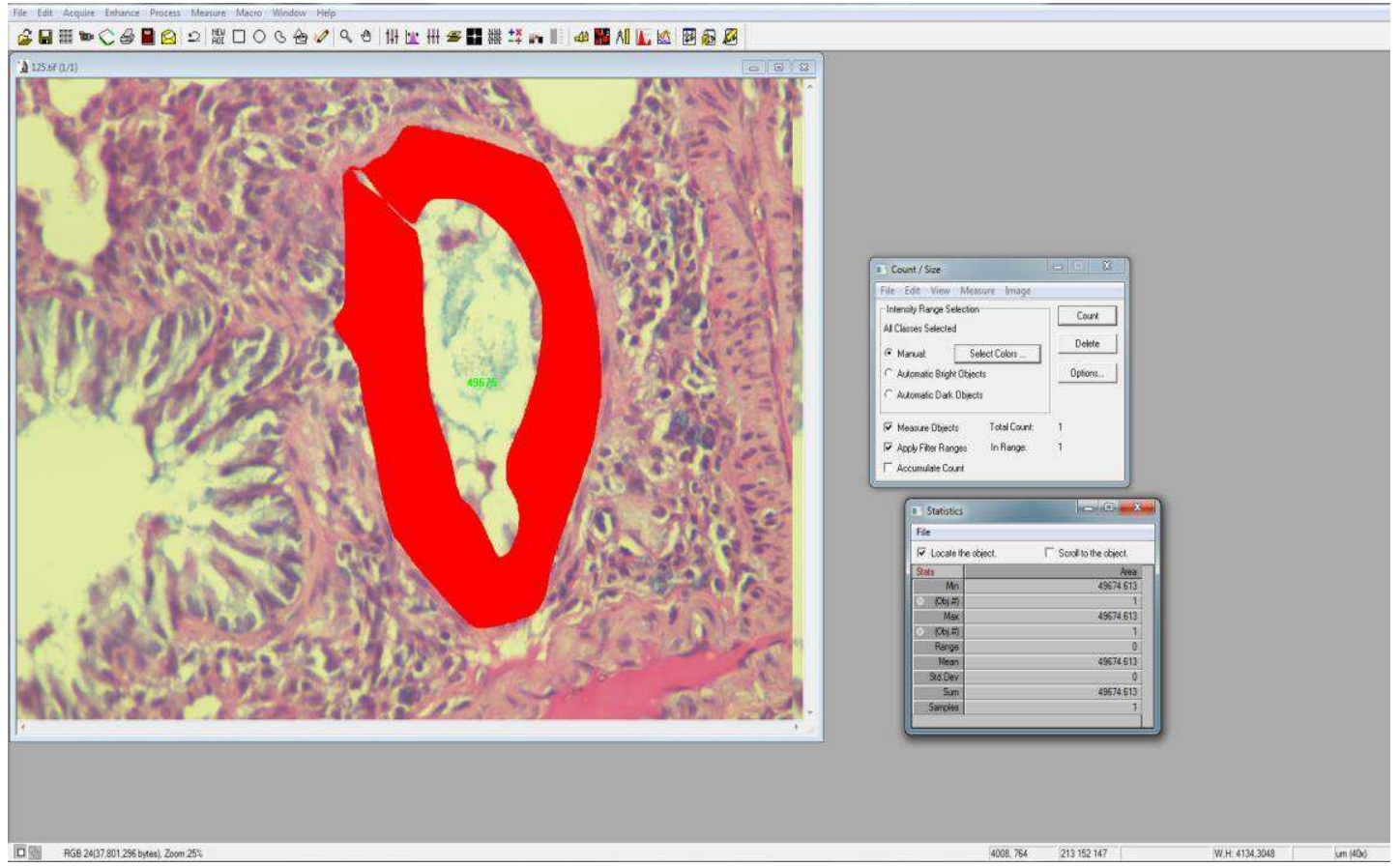

Figura 17 - Delimitação da área do brônquio respiratório pelo pesquisador, com uso do programa de computador, para quantificação do percentual de área corada. 


\subsection{Análise da proliferação de linfócitos e macrófagos}

A análise da proliferação de linfócitos e macrófagos foi avaliada pela expressão do antígeno Ki67 através de reações de imunohistoquímica em cortes histológicos do parênquima pulmonar.

Existem pelo menos quatro fases distintas no ciclo celular: o período antes da síntese de DNA (G1), a fase de síntese de DNA (S), o período após a replicação do DNA (G2) e a fase mitótica (M) que culmina na divisão celular (Levine et al., 1994; Rabenhorst et al., 1994). As células fora do ciclo celular estão na chamada fase $\mathrm{G} 0$ e podem permanecer nesta fase por tempo indeterminado (Hall e Levinson, 1990; Albert et al., 1994; Rabenhorst et al., 1993 e 1994).

O antígeno Ki67 é uma proteína nuclear expressa preferencialmente durante todas as fases do ciclo celular ( $\mathrm{G} 1, \mathrm{~S}, \mathrm{G} 2$ e fase $\mathrm{M})$, mas ausente na interfase (G0) (Scholzen e Gerdes, 2000).

O anticorpo Ki-67 reconhece um antígeno que está associado ao núcleo celular e que, em células continuamente em divisão, é expresso em todas as fases do ciclo celular, exceto em G0 (Gerdes et al., 1984).

\subsection{Análise de apoptose de linfócitos e macrófagos}

O processo de apoptose está intimamente ligado à ação de proteases, denominadas caspases. As caspases (proteases específicas cisteinil-aspartato) constituem uma família importante de moléculas de sinalização com várias tarefas, dependendo do subtipo e do órgão envolvidos. A ativação de caspases 
também é um marcador de danos celulares em doenças como acidente vascular cerebral e infarto do miocárdio (Lavrik et al., 2005).

A caspase-3 tem sido largamente usada como marcador imunohistoquímico por representar a confluência entre os mecanismos intrínsecos e extrínsecos da apoptose (Nakopoulou et al., 2001).

A caspase-3 tem sido implicada como uma caspase efetora associada com a iniciação da cascata de morte celular (Nicholson et al., 1995).

\subsection{Análise estatística}

A análise estatística foi realizada utilizando-se a versão 21 do programa SPSS.

Para verificar se as variáveis estudadas apresentaram distribuição normal e igualdade de variância, foram utilizados os testes de KolmogorovSmirnov e de Levene, respectivamente.

Para as variáveis que apresentaram distribuição normal, foram utilizados os testes de Análise de Variância (ANOVA) de duplo fator e o de Bonferroni para as comparações múltiplas. Para as variáveis sem distribuição normal foram utilizados os testes de Kruskal-Wallis e o de Dunn para as comparações múltiplas.

O nível de significância estabelecido foi de 5\%. Os dados estão apresentados em forma de gráficos e tabelas, e expressos como média+desvio padrão ou mediana e IQ (25\%-75\%). 
5 RESULTADOS 


\section{Resultados}

\subsection{Transportabilidade do muco}

Os valores médios de TM foram maiores no grupo TI em relação ao grupo TII no tempo de 7 dias (Gráfico 1 e Tabela 1). Não houve diferença estatística entre os tempos avaliados para cada grupo (Tabela 2).

Gráfico 1 - Distribuição da Transportabilidade do Muco (média + desvio padrão). Comparação entre os grupos Controle, TI e TII em 7, 15 e 30 dias (ANOVA). TI, terapia I; TII, terapia II.

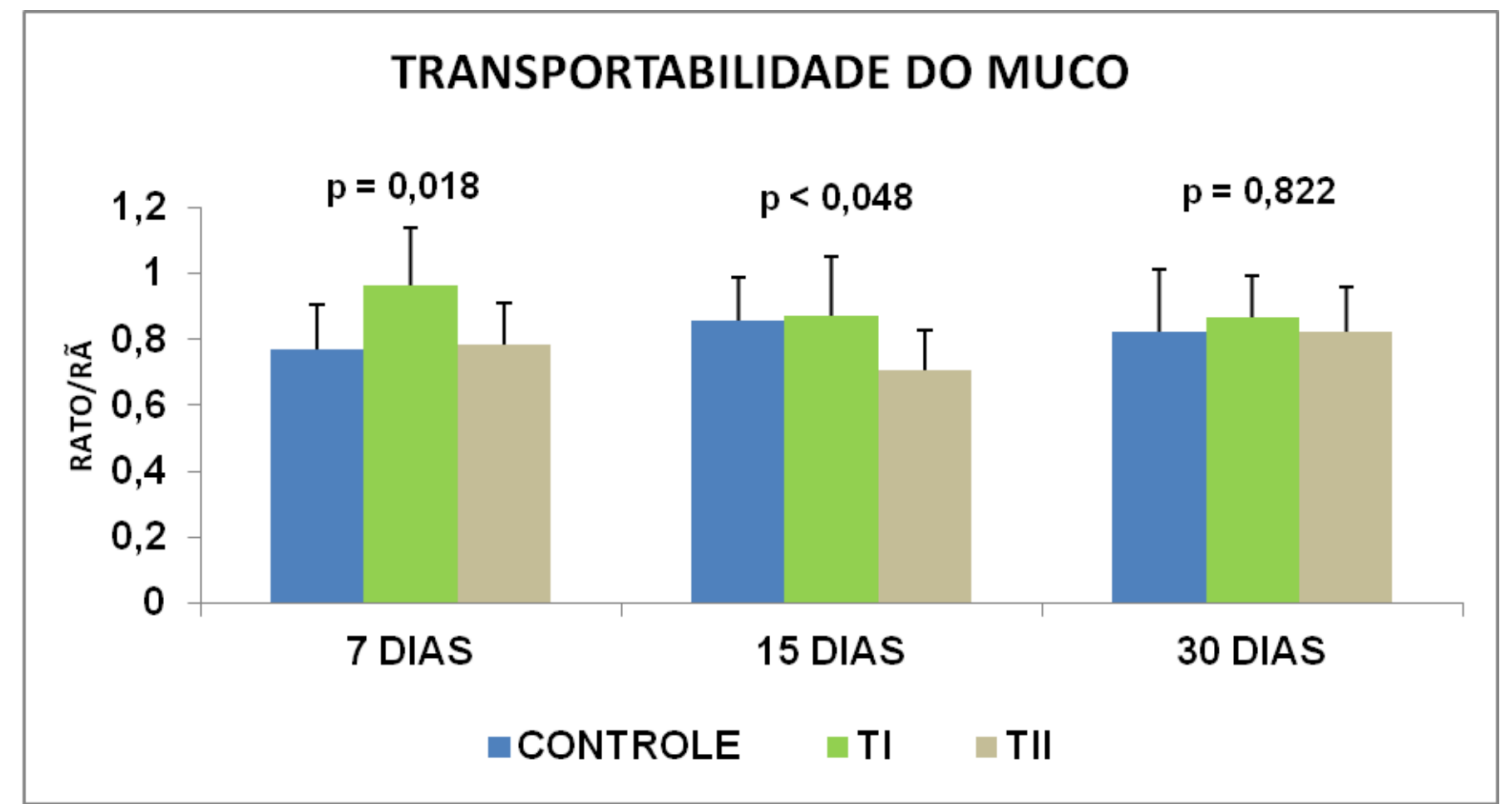

Tabela 1 - Teste de Bonferroni para comparações entre os grupos Controle, TI e TII em 7, 15 e 30 dias em relação aos valores médios de Transportabilidade do Muco.

\begin{tabular}{cccc}
\hline \multicolumn{4}{c}{ TESTE DE BONFERRONI } \\
\hline $\begin{array}{c}\text { Comparações múltiplas } \\
\text { entre grupos }\end{array}$ & 7 DIAS & Valor de $\mathbf{p}$ \\
\hline CONTROLE x TI & 0,050 & $>0,999$ & 30 DIAS \\
CONTROLE x TII & $>0,999$ & 0,101 & $>0,999$ \\
TI x TII & 0,045 & 0,085 & $>0,999$ \\
\hline
\end{tabular}


Tabela 2 - Teste de Bonferroni para comparações entre os tempos 7, 15 e 30 dias para os grupos Controle, TI e TII em relação aos valores médios de Transportabilidade do Muco.

\begin{tabular}{cccc}
\hline \multicolumn{4}{c}{ TESTE DE BONFERRONI } \\
\hline $\begin{array}{c}\text { Comparações múltiplas } \\
\text { entre tempos }\end{array}$ & CONTROLE & Valor de $\mathbf{p}$ & TII \\
\hline $7 \times 15$ & 0,762 & TI & 0,923 \\
$7 \times 30$ & $>0,999$ & 0,645 & $>0,999$ \\
$15 \times 30$ & $>0,999$ & $>0,999$ & 0,338 \\
\hline
\end{tabular}

\subsection{Frequência de batimento ciliar in situ}

A FBC dos grupos TI e TIl foi menor nos tempos de 7 e 15 dias em relação ao grupo C (Gráfico 2). A comparação entre as terapias mostrou que TI foi menor em 7 dias, sendo, porém, maior que TII em 15 dias (Tabela 3). Na avaliação entre tempos, a FBC foi menor no grupo $\mathrm{TI}$ em 7 dias em comparação a 15 dias, e menor no grupo TII em 15 dias quando comparado a 30 dias (Tabela 4).

Gráfico 2 - Distribuição da Frequência de Batimento Ciliar (média + desvio padrão). Comparação entre os grupos Controle, Tl e TIl em 7, 15 e 30 dias (ANOVA). TI, terapia I; TII, terapia II.

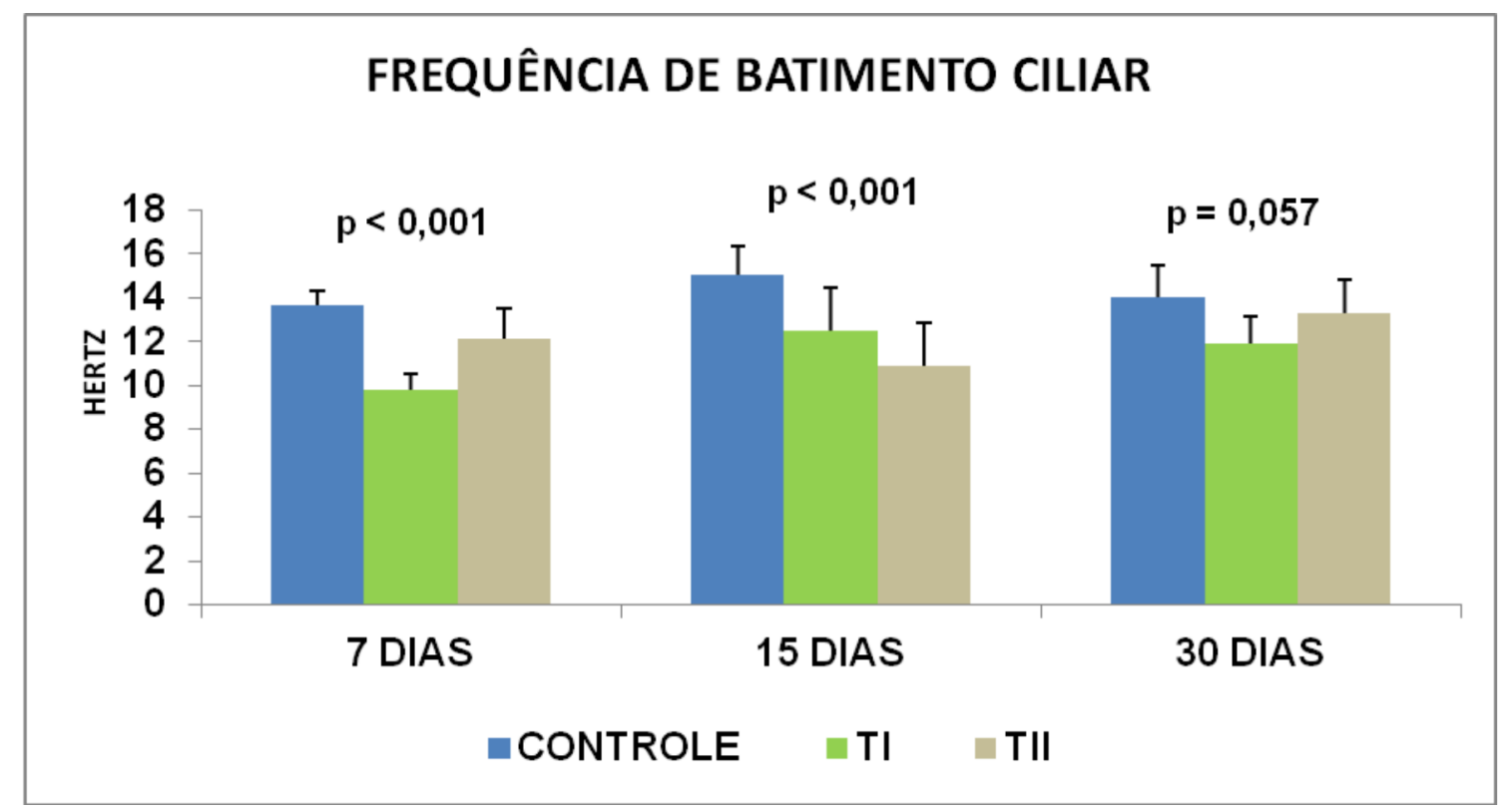


Tabela 3 - Teste de Bonferroni para comparações entre os grupos Controle, TI e TII em 7, 15 e 30 dias em relação aos valores médios de Frequência de Batimento Ciliar.

\begin{tabular}{cccc}
\hline \multicolumn{4}{c}{ TESTE DE BONFERRONI } \\
\hline $\begin{array}{c}\text { Comparações múltiplas } \\
\text { entre grupos }\end{array}$ & 7 DIAS & Valor de $\mathbf{p}$ \\
\hline CONTROLE x TI & $<0,001$ & $<0,001$ & 30 DIAS \\
CONTROLE x TII & 0,043 & $<0,001$ & 0,051 \\
TI x TII & 0,001 & 0,045 & 0,919 \\
\hline
\end{tabular}

Tabela 4 - Teste de Bonferroni para comparações entre os tempos 7, 15 e 30 dias para os grupos Controle, TI e TIl em relação aos valores médios de Frequência de Batimento Ciliar.

\begin{tabular}{cccc}
\hline \multicolumn{4}{c}{ TESTE DE BONFERRONI } \\
\hline $\begin{array}{c}\text { Comparações múltiplas } \\
\text { entre tempos }\end{array}$ & CONTROLE & Valor de $\mathbf{p}$ & TII \\
\hline $7 \times 15$ & 0,104 & TI & 0,177 \\
$7 \times 30$ & $>0,999$ & 0,001 & 0,178 \\
$15 \times 30$ & 0,323 & $>0,999$ & 0,001 \\
\hline
\end{tabular}

\subsection{Velocidade de transporte mucociliar in situ}

Os grupos TI e TIl apresentaram menor VTMC em 7, 15 e 30 dias em relação ao grupo C (Gráfico 3); além disso, observou-se um prejuízo ainda maior da VTMC no grupo TI quando comparado a TII em 7 dias (Tabela 5). Ao longo do tempo, o grupo TII apresentou VTMC menor em 15 dias em comparação com 7 e 30 dias (Tabela 6). 
Gráfico 3 - Distribuição da Velocidade de Transporte Mucociliar (média + desvio padrão). Comparação entre os grupos Controle, TI e TII em 7, 15 e 30 dias (ANOVA). TI, terapia I; TII, terapia II.

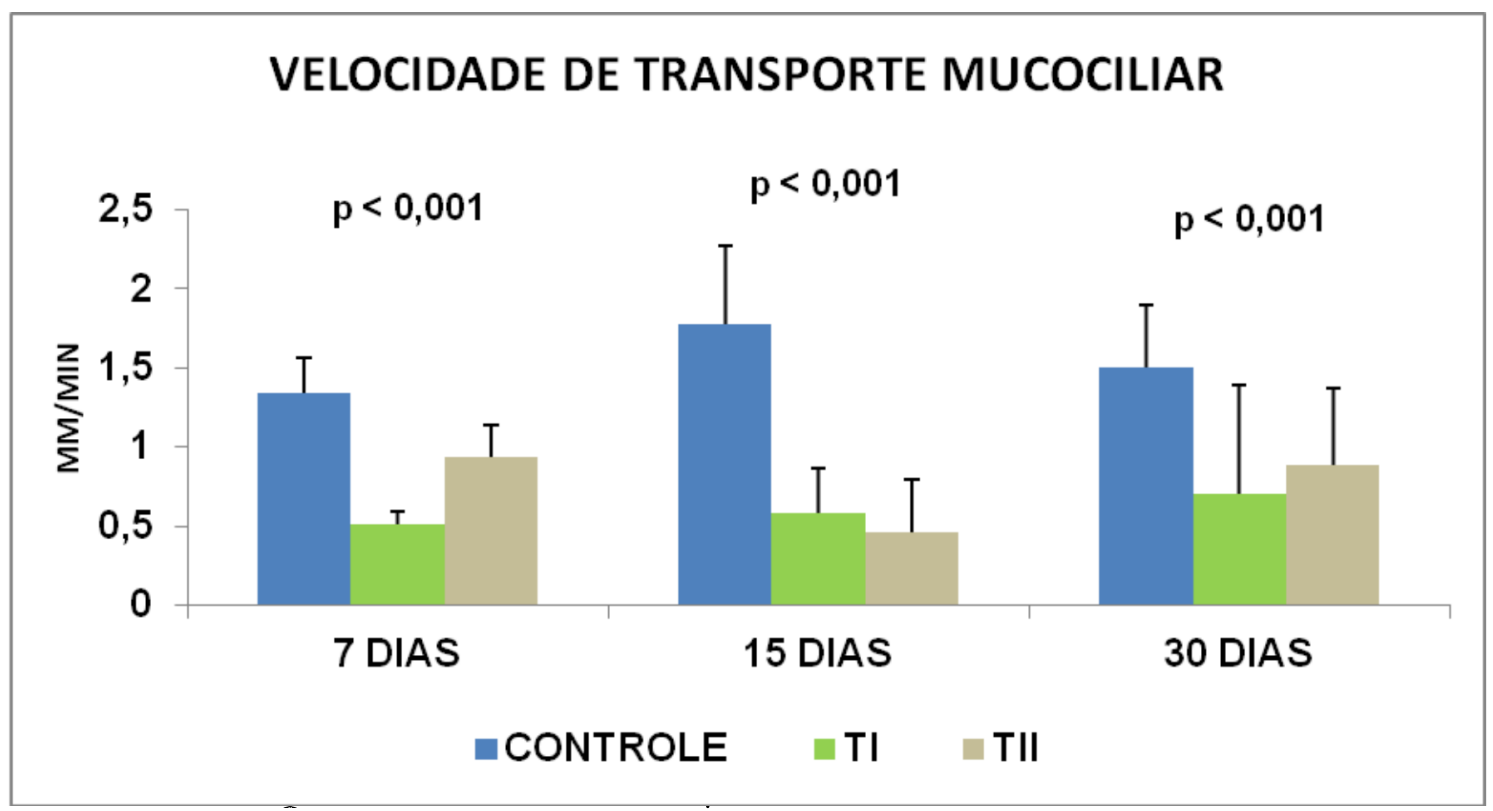

Tabela 5 - Teste de Bonferroni para comparações entre os grupos Controle, $\mathrm{TI}$ e TII em 7, 15 e 30 dias em relação aos valores médios de Velocidade de Transporte Mucociliar.

\section{TESTE DE BONFERRONI}

\begin{tabular}{cccc}
\hline $\begin{array}{c}\text { Comparações múltiplas } \\
\text { entre grupos }\end{array}$ & 7 DIAS & Valor de $\mathbf{p}$ \\
\hline CONTROLE $\times$ TI & $<0,001$ & $<0,001$ & 30 DIAS \\
CONTROLE x TII & 0,033 & $<0,001$ & 0,001 \\
TI x TII & 0,028 & $>0,999$ & 0,001 \\
\hline
\end{tabular}

Tabela 6 - Teste de Bonferroni para comparações entre os tempos 7, 15 e 30 dias para os grupos Controle, TI e TII em relação aos valores médios de Velocidade de Transporte Mucociliar.

\begin{tabular}{cccc}
\hline \multicolumn{4}{c}{ TESTE DE BONFERRONI } \\
\hline $\begin{array}{c}\text { Comparações múltiplas } \\
\text { entre tempos }\end{array}$ & CONTROLE & Valor de p & TI \\
\hline $7 \times 15$ & 0,026 & $>0,999$ & 0,019 \\
$7 \times 30$ & 0,967 & $>0,999$ & $>0,999$ \\
$15 \times 30$ & 0,326 & $>0,999$ & 0,044 \\
\hline
\end{tabular}




\subsection{Produção de muco neutro e ácido}

Em relação ao grupo $\mathrm{C}$, os grupos $\mathrm{Tl}$ e $\mathrm{TIl}$ produziram menos muco neutro em todos os tempos estudados (Gráfico 4 e Tabela 7). Na análise ao longo do tempo, houve diferença apenas no grupo TII, que apresentou maior quantidade de muco neutro em 30 dias quando comparado a 7 dias (Tabela 8).

Gráfico 4 - Distribuição da quantidade de muco neutro (mediana e IQ). Comparação entre os grupos Controle, TI e TII em 7, 15 e 30 dias (KruskalWallis). TI, terapia I; TII, terapia II. Asteriscos e círculos representam outliers.

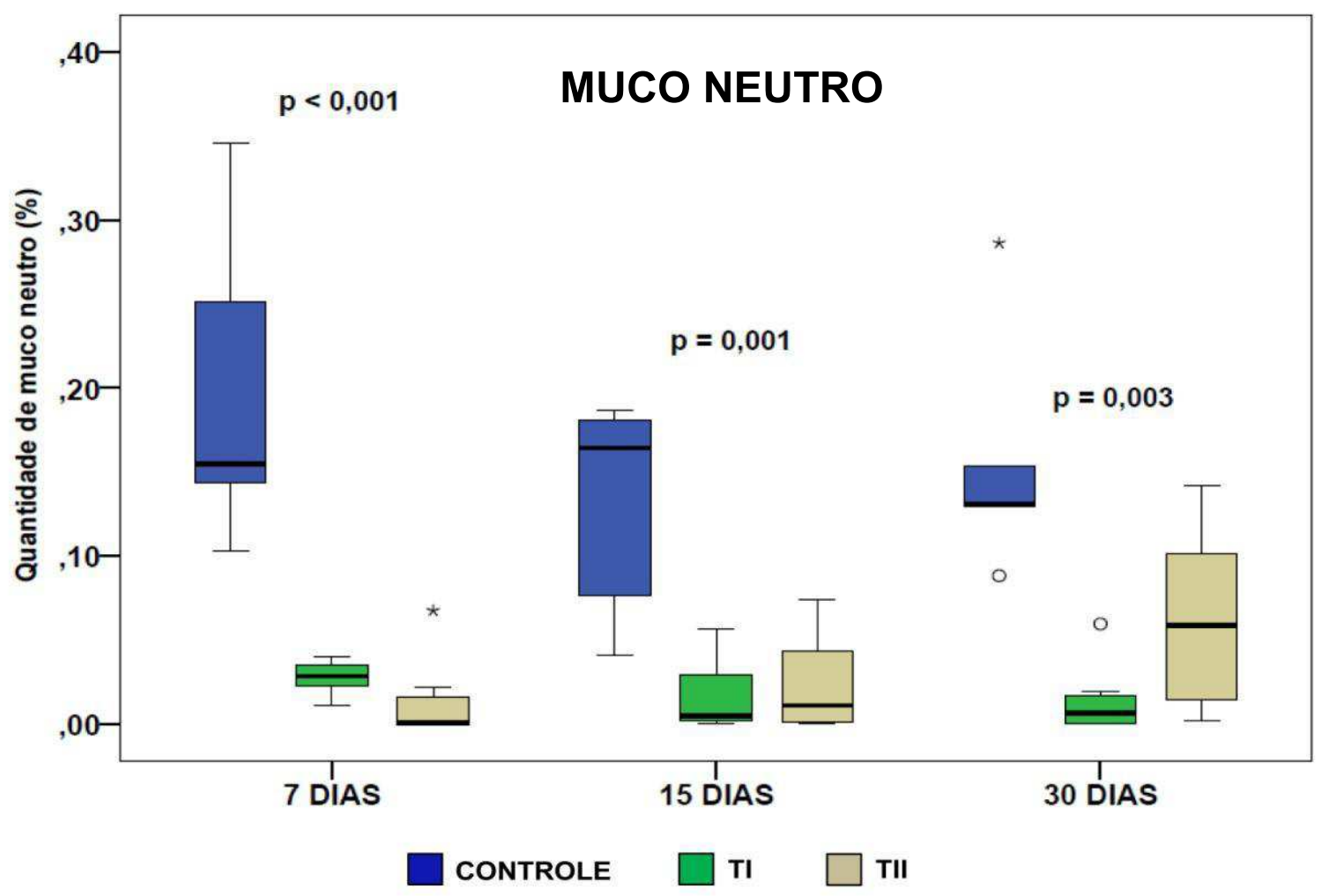


Tabela 7 - Teste de Dunn para comparações entre os grupos Controle, TI e TII em 7, 15 e 30 dias em relação aos valores médios de quantidade de muco neutro.

\begin{tabular}{cccc}
\hline \multicolumn{4}{c}{ TESTE DE DUNN } \\
\hline $\begin{array}{c}\text { Comparações múltiplas } \\
\text { entre grupos }\end{array}$ & 7 DIAS & Valor de $\mathbf{p}$ \\
\hline CONTROLE $\times$ TI & 0,034 & 0,002 & 30 DIAS \\
CONTROLE x TII & $<0,001$ & 0,012 & 0,003 \\
TI $\times$ TII & 0,128 & $>0,999$ & 0,297 \\
\hline
\end{tabular}

Tabela 8 - Teste de Dunn para comparações entre os tempos 7, 15 e 30 dias para os grupos Controle, TI e TII em relação aos valores médios de quantidade de muco neutro.

\begin{tabular}{cccc}
\hline \multicolumn{4}{c}{ TESTE DE DUNN } \\
\hline $\begin{array}{c}\text { Comparações múltiplas } \\
\text { entre tempos }\end{array}$ & CONTROLE & Valor de $\mathbf{p}$ \\
\hline $7 \times 15$ & $>0,05$ & TI & TII \\
$7 \times 30$ & $>0,05$ & 0,158 & 0,507 \\
$15 \times 30$ & $>0,05$ & $>0,999$ & 0,019 \\
\hline
\end{tabular}

A quantidade de muco ácido produzido pelas células caliciformes dos animais dos grupos $\mathrm{TI}$ e TIl foi significativamente maior em relação ao grupo C nos tempos estudados (Gráfico 4 e Tabela 9). Não houve diferença entre os tempos na comparação interna de cada grupo (Tabela 10). 
Gráfico 5 - Distribuição da quantidade de muco ácido (mediana e IQ). Comparação entre os grupos Controle, TI e TII em 7, 15 e 30 dias (KruskalWallis). TI, terapia I; TII, terapia II. Asteriscos e círculos representam outliers.

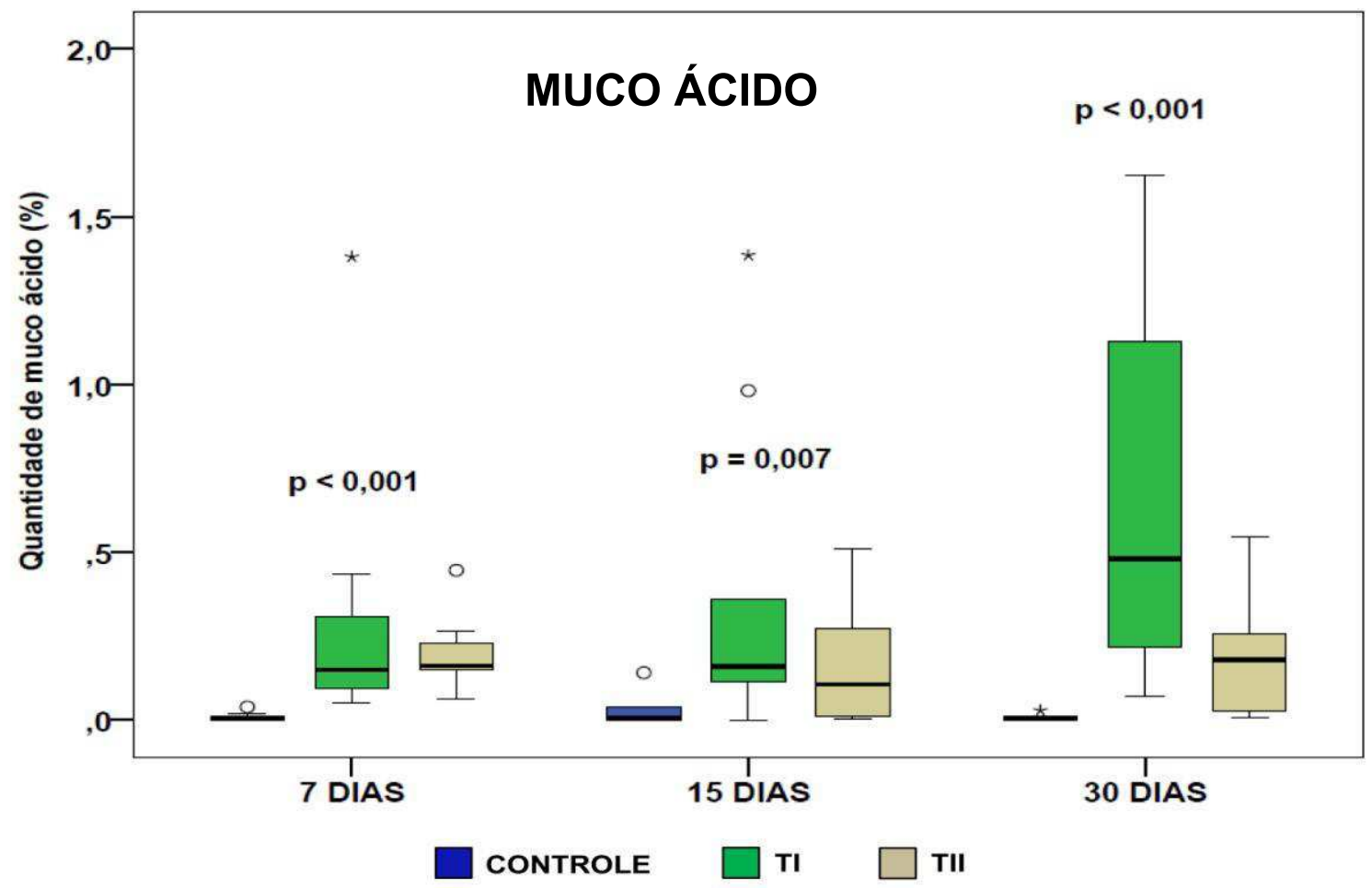

Tabela 9 - Teste de Dunn para comparações entre os grupos Controle, TI e TII em 7, 15 e 30 dias em relação aos valores médios de quantidade de muco ácido.

\begin{tabular}{cccc}
\hline \multicolumn{4}{c}{ TESTE DE DUNN } \\
\hline $\begin{array}{c}\text { Comparações múltiplas } \\
\text { entre grupos }\end{array}$ & 7 DIAS & Valor de $\mathbf{p}$ \\
\hline CONTROLE $x$ TI & 0,001 & 0,008 & 30 DIAS \\
CONTROLE x TII & $<0,001$ & 0,076 & $<0,001$ \\
TI $\times$ TII & $>0,999$ & $>0,999$ & 0,014 \\
\hline
\end{tabular}

Tabela 10 - Teste de Dunn para comparações entre os tempos 7, 15 e 30 dias para os grupos Controle, TI e TII em relação aos valores médios de quantidade de muco ácido.

\section{TESTE DE DUNN}

\begin{tabular}{cccc}
\hline $\begin{array}{c}\text { Comparações múltiplas } \\
\text { entre tempos }\end{array}$ & CONTROLE & TI & TII \\
\hline $7 \times 15$ & $>0,05$ & $>0,05$ & $>0,05$ \\
$7 \times 30$ & $>0,05$ & $>0,05$ & $>0,05$ \\
$15 \times 30$ & $>0,05$ & $>0,05$ & $>0,05$ \\
\hline
\end{tabular}




\subsection{Lavado broncoalveolar (LBA)}

$\mathrm{O}$ número de linfócitos foi maior no grupo $\mathrm{Tl}$ em relação ao grupo $\mathrm{C}$ em 7 dias (Gráfico 6 e Tabela 11). Na comparação entre os tempos, apenas o grupo $C$ apresentou um maior número de linfócitos em 30 dias quando comparado a 7 e 15 dias (Tabela 12).

O número de macrófagos, neutrófilos e células totais foi maior nos animais tratados com a $\mathrm{TI}$ em relação aos demais grupos após 15 dias de tratamento (Gráficos 7 a 9 e Tabelas 13, 15 e 17). Na comparação entre os tempos, o grupo $\mathrm{C}$ apresentou valores maiores de macrófagos e células totais no tempo de 30 dias comparado com 7 e 15 dias (Tabelas 14 e 18). Já o grupo TI apresentou número maior de neutrófilos e células totais em 15 dias em comparação com 7 e 30 dias (Tabelas 16 e 18).

Não houve diferença entre os grupos em relação ao número de eosinófilos, células ciliadas e células caliciformes (dados não apresentados). 
Gráfico 6 - Número de linfócitos no lavado broncoalveolar (média + desvio padrão). Comparação entre os grupos Controle, TI e TIl em 7, 15 e 30 dias (ANOVA). TI, terapia I; TII, terapia II.

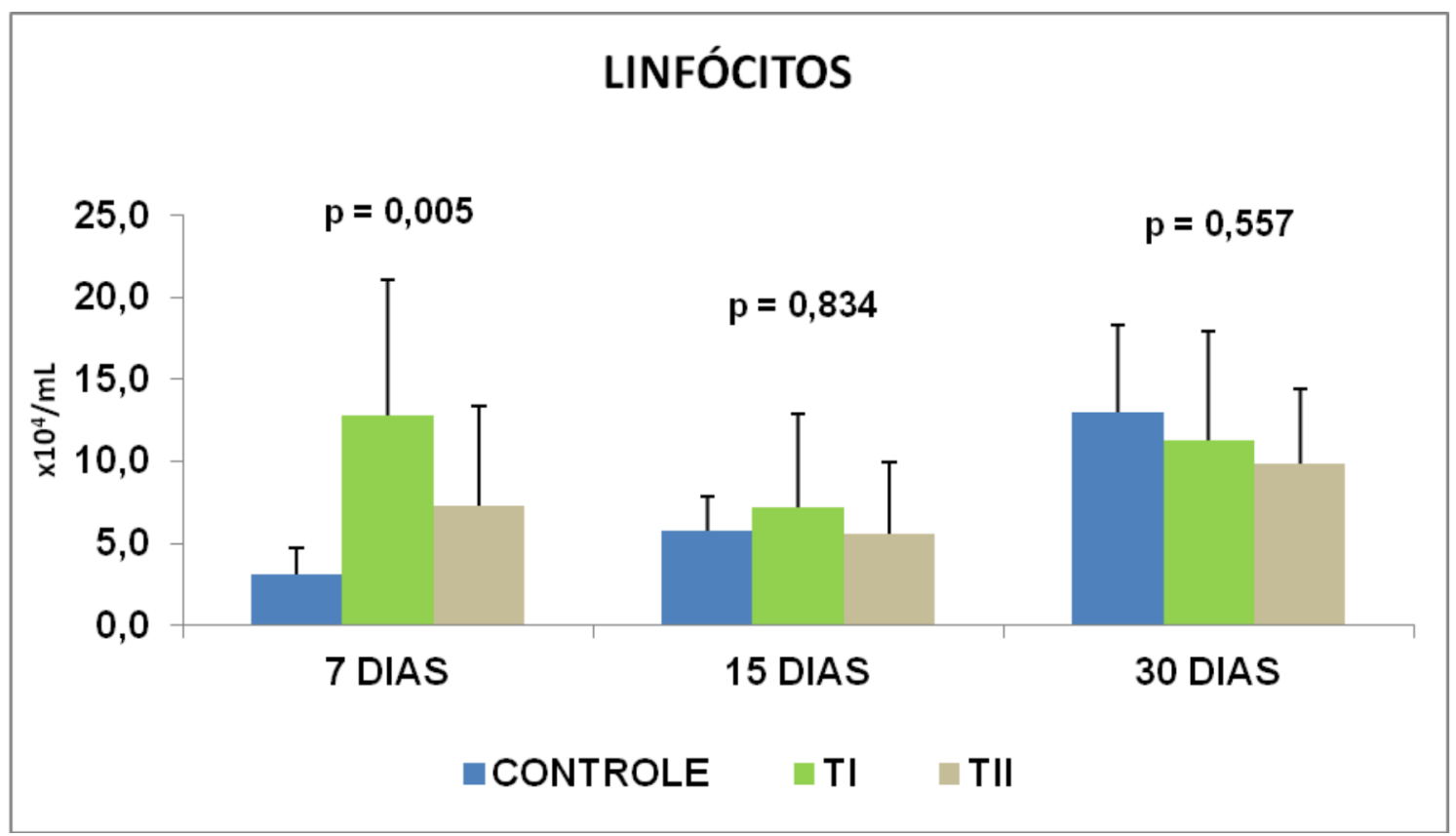

Tabela 11 - Teste de Bonferroni para comparações entre os grupos Controle, TI e TII em 7, 15 e 30 dias em relação aos valores médios de número de linfócitos no lavado broncoalveolar.

\begin{tabular}{cccc}
\hline \multicolumn{4}{c}{ TESTE DE BONFERRONI } \\
\hline $\begin{array}{c}\text { Comparações múltiplas } \\
\text { entre grupos }\end{array}$ & 7 DIAS & Valor de $\mathbf{p}$ \\
\hline CONTROLE x TI & 0,005 & $>0,999$ & 30 DIAS \\
CONTROLE x TII & 0,463 & $>0,999$ & $>0,999$ \\
TI x TII & 0,136 & $>0,999$ & 0,848 \\
\hline
\end{tabular}

Tabela 12 - Teste de Bonferroni para comparações entre os tempos 7, 15 e 30 dias para os grupos Controle, TI e TIl em relação aos valores médios de número de linfócitos no lavado broncoalveolar.

\begin{tabular}{cccc}
\hline \multicolumn{4}{c}{ TESTE DE BONFERRONI } \\
\hline $\begin{array}{c}\text { Comparações múltiplas } \\
\text { entre tempos }\end{array}$ & CONTROLE & Valor de $\mathbf{p}$ & TII \\
\hline $7 \times 15$ & $>0,999$ & TI & $>0,999$ \\
$7 \times 30$ & 0,005 & $>0,999$ & $>0,999$ \\
$15 \times 30$ & 0,037 & 0,534 & 0,393 \\
\hline
\end{tabular}


Gráfico 7 - Número de macrófagos no lavado broncoalveolar (média + desvio padrão). Comparação entre os grupos Controle, TI e TII em 7, 15 e 30 dias (ANOVA). TI, terapia I; TII, terapia II.

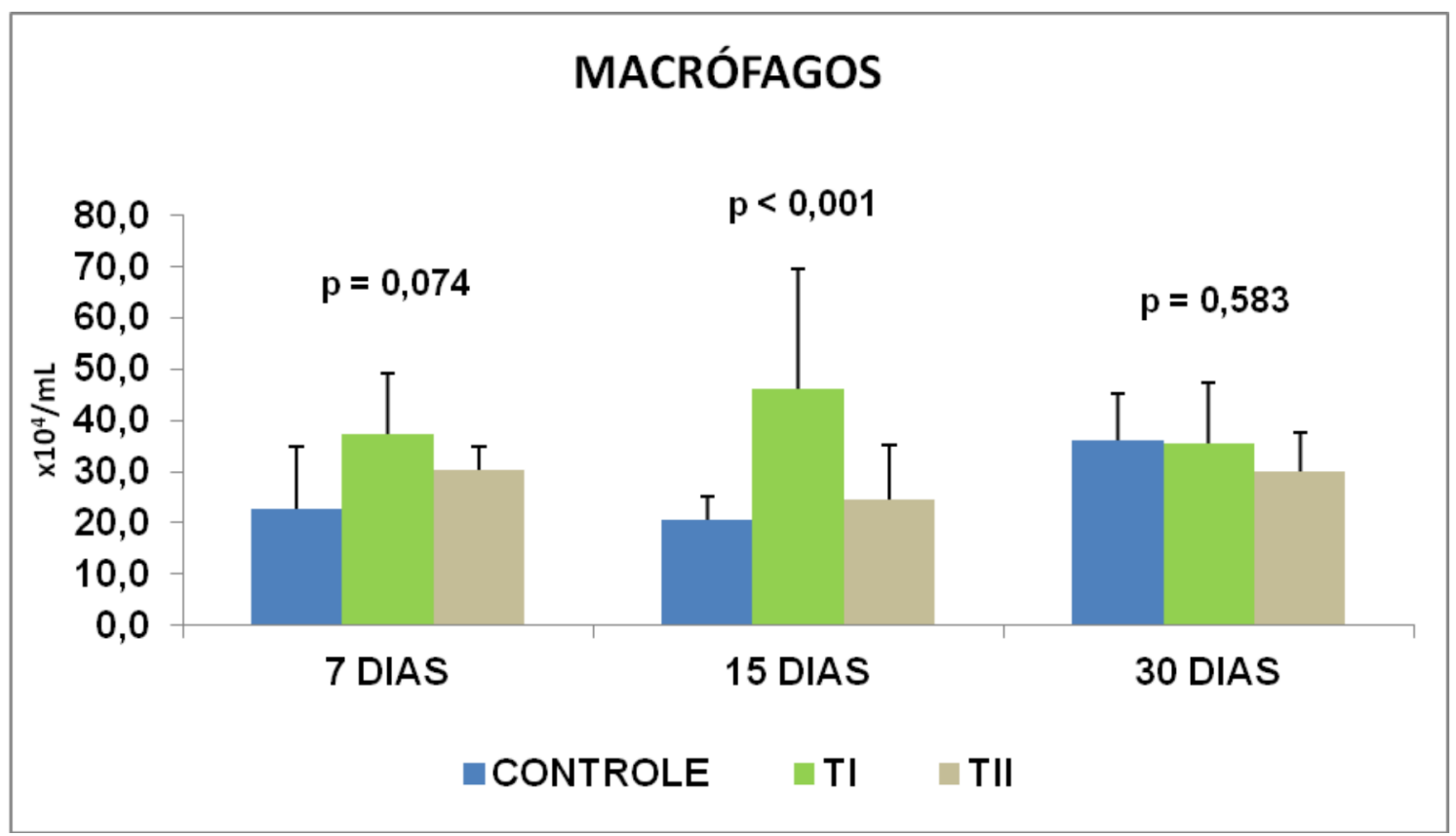

Tabela 13 - Teste de Bonferroni para comparações entre os grupos Controle, TI e Tll em 7, 15 e 30 dias em relação aos valores médios de número de macrófagos no lavado broncoalveolar.

\begin{tabular}{cccc}
\hline \multicolumn{4}{c}{ TESTE DE BONFERRONI } \\
\hline $\begin{array}{c}\text { Comparações múltiplas } \\
\text { entre grupos }\end{array}$ & 7 DIAS & Valor de $\mathbf{p}$ \\
\hline CONTROLE x TI & 0,071 & $<0,001$ & 30 DIAS \\
CONTROLE x TII & 0,731 & $>0,999$ & $>0,999$ \\
TI x TII & 0,661 & 0,002 & $>0,999$ \\
\hline
\end{tabular}

Tabela 14 - Teste de Bonferroni para comparações entre os tempos 7, 15 e 30 dias para os grupos Controle, TI e TII em relação aos valores médios de número de macrófagos no lavado broncoalveolar.

\begin{tabular}{cccc}
\hline \multicolumn{4}{c}{ TESTE DE BONFERRONI } \\
\hline $\begin{array}{c}\text { Comparações múltiplas } \\
\text { entre tempos }\end{array}$ & CONTROLE & Valor de $\mathbf{p}$ \\
\hline $7 \times 15$ & $>0,999$ & TI & TII \\
$7 \times 30$ & 0,121 & 0,463 & $>0,999$ \\
$15 \times 30$ & 0,032 & 0,999 & $>0,999$ \\
& & 0,311 & $>0,999$ \\
\hline
\end{tabular}


Gráfico 8 - Número de neutrófilos no lavado broncoalveolar (média + desvio padrão). Comparação entre os grupos Controle, TI e TII em 7, 15 e 30 dias (ANOVA). TI, terapia I; TII, terapia II.

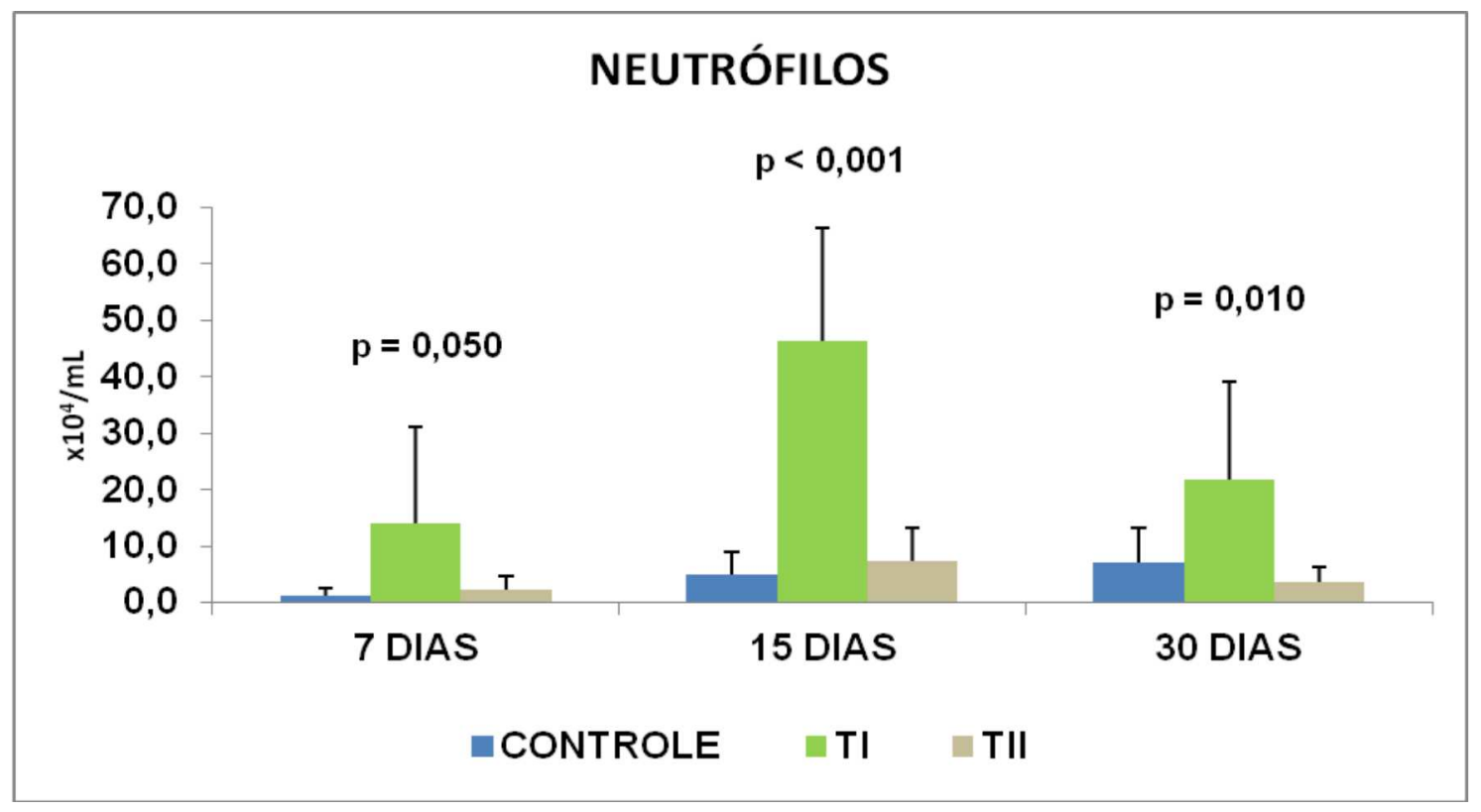

Tabela 15 - Teste de Bonferroni para comparações entre os grupos Controle, TI e TII em 7, 15 e 30 dias em relação aos valores médios de número de neutrófilos no lavado broncoalveolar.

\begin{tabular}{cccc}
\hline \multicolumn{4}{c}{ TESTE DE BONFERRONI } \\
\hline $\begin{array}{c}\text { Comparações múltiplas } \\
\text { entre grupos }\end{array}$ & 7 DIAS & Valor de $\mathbf{p}$ \\
CONTROLE x TI & 0,102 & $<0,001$ & 30 DIAS \\
CONTROLE x TII & $>0,999$ & $>0,999$ & $>0,056$ \\
TI x TII & 0,112 & $<0,001$ & 0,011 \\
\hline
\end{tabular}

Tabela 16 - Teste de Bonferroni para comparações entre os tempos 7, 15 e 30 dias para os grupos Controle, TI e TII em relação aos valores médios de número de neutrófilos no lavado broncoalveolar.

\begin{tabular}{cccc}
\hline \multicolumn{4}{c}{ TESTE DE BONFERRONI } \\
\hline $\begin{array}{c}\text { Comparações múltiplas } \\
\text { entre tempos }\end{array}$ & CONTROLE & Valor de $\mathbf{p}$ \\
\hline $7 \times 15$ & $>0,999$ & TI & TII \\
$7 \times 30$ & 0,979 & $<0,001$ & $>0,999$ \\
$15 \times 30$ & $>0,999$ & 0,552 & $>0,999$ \\
& & $<0,001$ & $>0,999$ \\
\hline
\end{tabular}


Gráfico 9 - Número de células totais no lavado broncoalveolar (média + desvio padrão). Comparação entre os grupos Controle, TI e TII em 7, 15 e 30 dias (ANOVA). TI, terapia I; TII, terapia II.

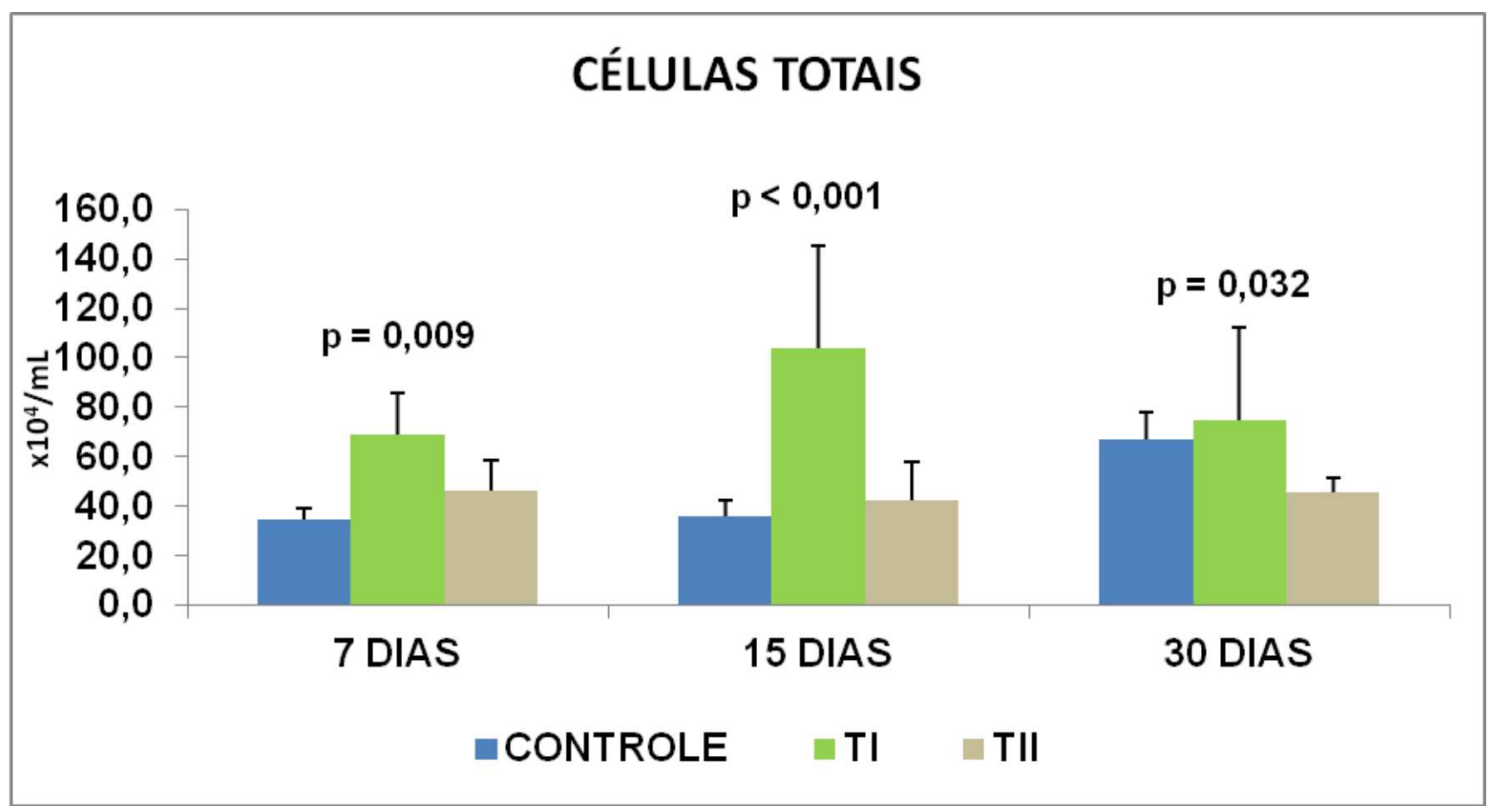

Tabela 17 - Teste de Bonferroni para comparações entre os grupos Controle, TI e TII em 7, 15 e 30 dias em relação aos valores médios de número de células totais no lavado broncoalveolar.

\begin{tabular}{cccc}
\hline \multicolumn{4}{c}{ TESTE DE BONFERRONI } \\
\hline $\begin{array}{c}\text { Comparações múltiplas } \\
\text { entre grupos }\end{array}$ & 7 DIAS & Valor de $\mathbf{p}$ \\
\hline CONTROLE x TI & 0,010 & $<0,001$ & 30 DIAS \\
CONTROLE x TII & 0,935 & $>0,999$ & $>0,999$ \\
TI $\times$ TII & 0,093 & $<0,001$ & 0,172 \\
\hline
\end{tabular}

Tabela 18 - Teste de Bonferroni para comparações entre os tempos 7, 15 e 30 dias para os grupos Controle, TI e TIl em relação aos valores médios de número de células totais no lavado broncoalveolar.

\begin{tabular}{cccc}
\hline \multicolumn{4}{c}{ TESTE DE BONFERRONI } \\
\hline $\begin{array}{c}\text { Comparações múltiplas } \\
\text { entre tempos }\end{array}$ & CONTROLE & Valor de $\mathbf{p}$ \\
\hline $7 \times 15$ & $>0,999$ & TI & TII \\
$7 \times 30$ & 0,021 & 0,005 & $>0,999$ \\
$15 \times 30$ & 0,016 & 0,999 & $>0,999$ \\
& & 0,045 & $>0,999$ \\
\hline
\end{tabular}




\subsection{Histologia}

O número de células mononucleares e polimorfonucleares presentes no parênquima pulmonar foi maior nos animais tratados com ambas as terapias em relação aos do grupo Controle em todos os tempos estudados. Além disso, na comparação entre as terapias, o grupo TI apresentou maior número de células mononucleares em 7 dias e polimorfonucleares nos 3 tempos (Gráficos 10 e 11 e Tabelas 19 e 21). Na comparação entre tempos, o grupo TII apresentou valores maiores de células mononucleares em 15 e 30 dias em relação a 7 dias, e de polimorfonucleares em 30 dias em comparação com 7 dias (Tabelas 20 e 22).

Não houve diferença entre os grupos em relação ao índice de edema (dados não apresentados). 
Gráfico 10 - Número de células mononucleares no parênquima pulmonar (média + desvio padrão). Comparação entre os grupos Controle, TI e TII em 7, 15 e 30 dias (ANOVA). TI, terapia I; TII, terapia II.

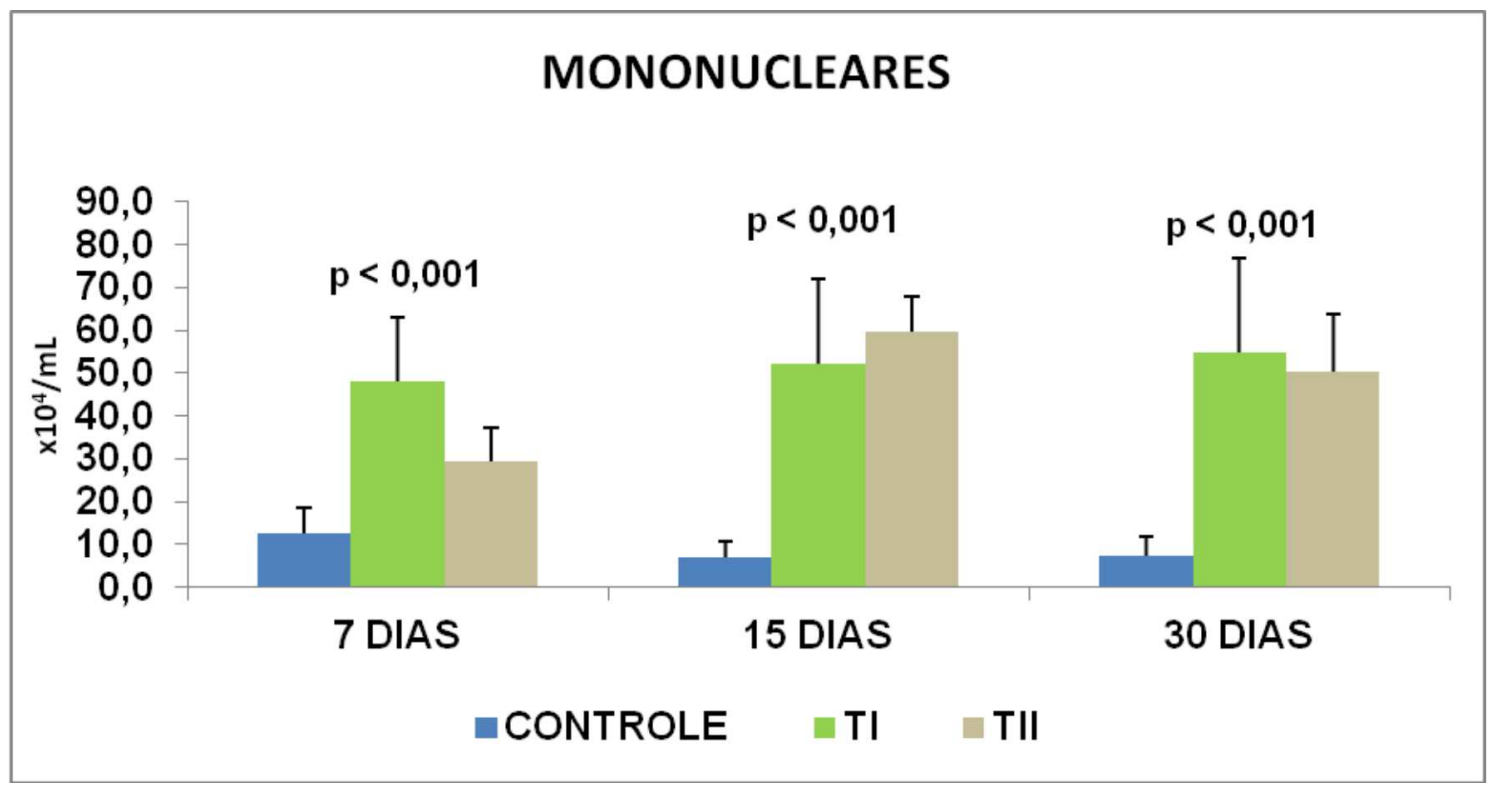

Tabela 19 - Teste de Bonferroni para comparações entre os grupos Controle, TI e TII em 7, 15 e 30 dias em relação aos valores médios de número de células mononucleares no parênquima pulmonar.

\begin{tabular}{cccc}
\hline \multicolumn{4}{c}{ TESTE DE BONFERRONI } \\
\hline $\begin{array}{c}\text { Comparações múltiplas } \\
\text { entre grupos }\end{array}$ & 7 DIAS & Valor de $\mathbf{p}$ \\
\hline CONTROLE x TI & $<0,001$ & $<0,001$ & 30 DIAS \\
CONTROLE x TII & 0,041 & $<0,001$ & $<0,001$ \\
TI x TII & 0,019 & 0,899 & $>0,001$ \\
\hline
\end{tabular}

Tabela 20 - Teste de Bonferroni para comparações entre os tempos 7, 15 e 30 dias para os grupos Controle, TI e TII em relação aos valores médios de número de células mononucleares no parênquima pulmonar.

\begin{tabular}{cccc}
\hline \multicolumn{4}{c}{ TESTE DE BONFERRONI } \\
\hline $\begin{array}{c}\text { Comparações múltiplas } \\
\text { entre tempos }\end{array}$ & CONTROLE & Valor de $\mathbf{p}$ & TII \\
\hline $7 \times 15$ & $>0,999$ & $>0,999$ & $<0,001$ \\
$7 \times 30$ & $>0,999$ & 0,987 & 0,01 \\
$15 \times 30$ & $>0,999$ & $>0,999$ & 0,585 \\
\hline
\end{tabular}


Gráfico 11 - Número de células polimorfonucleares no parênquima pulmonar (média + desvio padrão). Comparação entre os grupos Controle, TI e TII em 7, 15 e 30 dias (ANOVA). TI, terapia I; TII, terapia II.

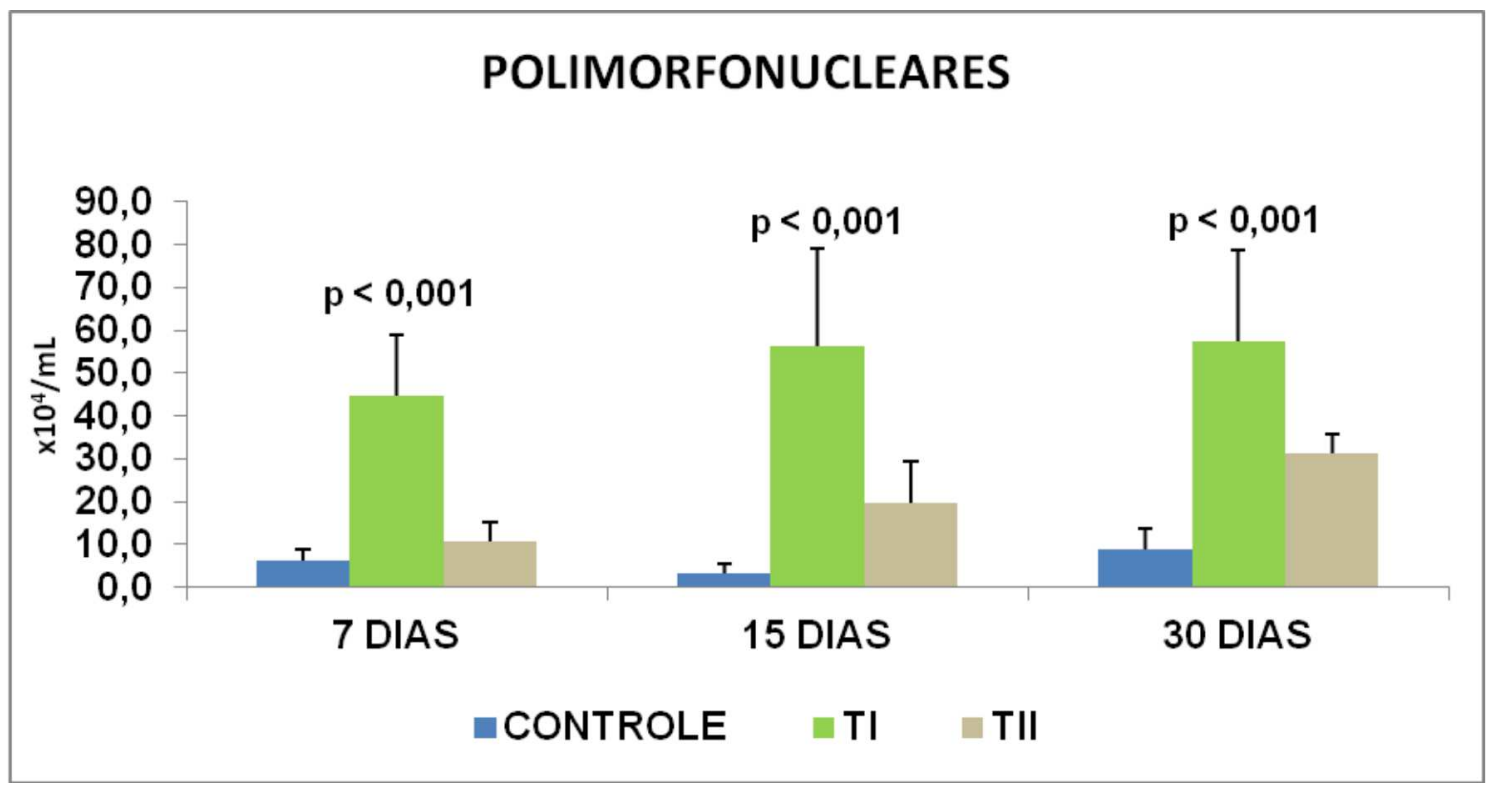

Tabela 21 - Teste de Bonferroni para comparações entre os grupos Controle, TI e TII em 7, 15 e 30 dias em relação aos valores médios de número de células polimorfonucleares no parênquima pulmonar.

\begin{tabular}{cccc}
\hline & TESTE DE BONFERRONI \\
\hline $\begin{array}{c}\text { Comparações múltiplas } \\
\text { entre grupos }\end{array}$ & 7 DIAS & Valor de $\mathbf{p}$ \\
\hline CONTROLE x TI & $<0,001$ & $<0,001$ & 30 DIAS \\
CONTROLE x TII & $>0,999$ & 0,023 & $<0,001$ \\
TI x TII & $<0,001$ & $<0,001$ & 0,002 \\
\hline
\end{tabular}

Tabela 22 - Teste de Bonferroni para comparações entre os tempos 7, 15 e 30 dias para os grupos Controle, TI e TII em relação aos valores médios de número de células polimorfonucleares no parênquima pulmonar.

\begin{tabular}{cccc}
\hline \multicolumn{4}{c}{ TESTE DE BONFERRONI } \\
\hline $\begin{array}{c}\text { Comparações múltiplas } \\
\text { entre tempos }\end{array}$ & CONTROLE & Valor de $\mathbf{p}$ & TII \\
\hline $7 \times 15$ & $>0,999$ & 0,274 & 0,446 \\
$7 \times 30$ & $>0,999$ & 0,185 & 0,005 \\
$15 \times 30$ & $>0,999$ & $>0,999$ & 0,223 \\
\hline
\end{tabular}




\subsection{Proliferação de linfócitos e macrófagos}

O número de linfócitos em proliferação no parênquima pulmonar foi menor nos animais dos grupos $\mathrm{Tl}$ e $\mathrm{TIl}$ em relação ao $\mathrm{C}$ em todos os tempos estudados (Gráfico 12 e Tabela 23). Não houve diferença entre os tempos em cada grupo (Tabela 24).

Já os macrófagos apresentaram maior proliferação no grupo TII em 15 dias em comparação com os demais grupos (Gráfico 13 e Tabela 25). Na comparação entre os tempos, o grupo $\mathrm{C}$ apresentou maior número de macrófagos em proliferação em 30 dias quando comparado a 7 dias, enquanto o grupo TII apresentou mais linfócitos marcados com Ki67 em 15 dias em comparação com 7 dias (Tabela 26). 
Gráfico 12 - Número de linfócitos marcados com Ki67 no parênquima pulmonar (média + desvio padrão). Comparação entre os grupos Controle, TI e TII em 7, 15 e 30 dias (ANOVA). TI, terapia I; TII, terapia II.

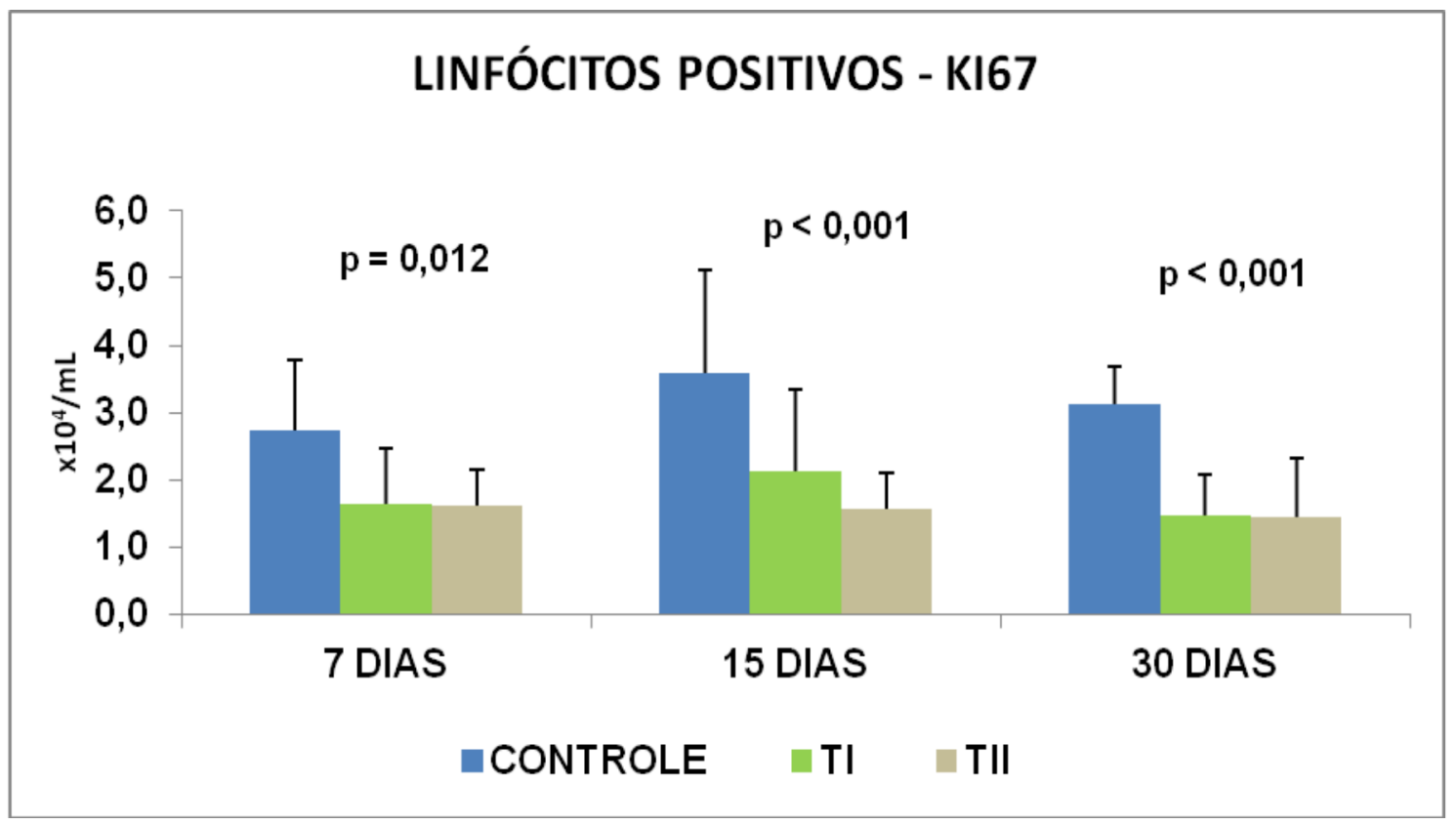

Tabela 23 - Teste de Bonferroni para comparações entre os grupos Controle, TI e TII em 7, 15 e 30 dias em relação aos valores médios de número de linfócitos marcados com Ki67 no parênquima pulmonar.

\begin{tabular}{cccc}
\hline \multicolumn{4}{c}{ TESTE DE BONFERRONI } \\
\hline $\begin{array}{c}\text { Comparações múltiplas } \\
\text { entre grupos }\end{array}$ & 7 DIAS & Valor de $\mathbf{p}$ \\
\hline CONTROLE x TI & 0,030 & 0,003 & 30 DIAS \\
CONTROLE x TII & 0,029 & $<0,001$ & 0,001 \\
TI x TII & $>0,999$ & 0,565 & 0,001 \\
\hline
\end{tabular}

Tabela 24 - Teste de Bonferroni para comparações entre os tempos 7, 15 e 30 dias para os grupos Controle, TI e TII em relação aos valores médios de número de linfócitos marcados com Ki67 no parênquima pulmonar.

\begin{tabular}{cccc}
\hline \multicolumn{4}{c}{ TESTE DE BONFERRONI } \\
\hline $\begin{array}{c}\text { Comparações múltiplas } \\
\text { entre tempos }\end{array}$ & CONTROLE & Valor de $\mathbf{p}$ & TII \\
\hline $7 \times 15$ & 0,132 & TI & $>0,999$ \\
$7 \times 30$ & $>0,999$ & $>0,757$ & $>0,999$ \\
$15 \times 30$ & 0,892 & 0,417 & $>0,999$ \\
\hline
\end{tabular}


Gráfico 13 - Número de macrófagos marcados com Ki67 no parênquima pulmonar (média + desvio padrão). Comparação entre os grupos Controle, TI e TII em 7, 15 e 30 dias (ANOVA). TI, terapia I; TII, terapia II.

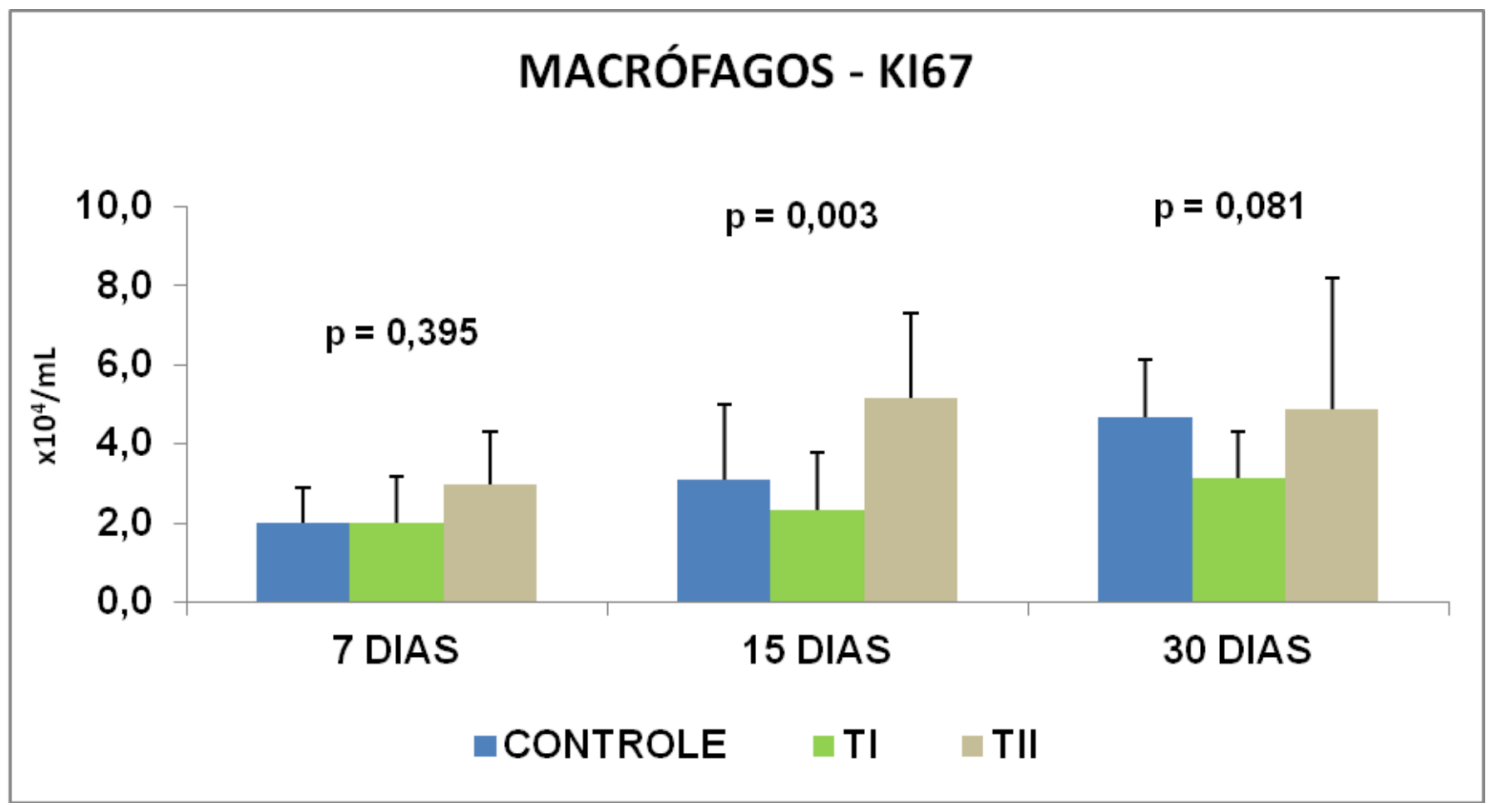

Tabela 25 - Teste de Bonferroni para comparações entre os grupos Controle, TI e TII em 7, 15 e 30 dias em relação aos valores médios de número de macrófagos marcados com Ki67 no parênquima pulmonar.

\begin{tabular}{cccc}
\hline \multicolumn{4}{c}{ TESTE DE BONFERRONI } \\
\hline $\begin{array}{c}\text { Comparações múltiplas } \\
\text { entre grupos }\end{array}$ & 7 DIAS & Valor de $\mathbf{p}$ \\
\hline CONTROLE x TI & $>0,999$ & $>0,999$ & 30 DIAS \\
CONTROLE x TII & 0,732 & 0,038 & 0,236 \\
TI $\times$ TII & 0,702 & 0,003 & 0,999 \\
\hline
\end{tabular}

Tabela 26 - Teste de Bonferroni para comparações entre os tempos 7, 15 e 30 dias para os grupos Controle, TI e TII em relação aos valores médios de número de macrófagos marcados com Ki67 no parênquima pulmonar.

\begin{tabular}{cccc}
\hline \multicolumn{4}{c}{ TESTE DE BONFERRONI } \\
\hline $\begin{array}{c}\text { Comparações múltiplas } \\
\text { entre tempos }\end{array}$ & CONTROLE & Valor de $\mathbf{p}$ & TII \\
\hline $7 \times 15$ & 0,535 & $>0,999$ & 0,023 \\
$7 \times 30$ & 0,008 & 0,537 & 0,061 \\
$15 \times 30$ & 0,211 & $>0,999$ & $>0,999$ \\
\hline
\end{tabular}




\subsection{Apoptose de linfócitos e macrófagos}

O número de linfócitos em apoptose no parênquima pulmonar foi maior nos animais dos grupos $\mathrm{TI}$ e TIl em relação ao $\mathrm{C}$ em todos os tempos estudados. Além disso, o grupo TII apresentou maior número de linfócitos apoptóticos que o grupo TII em 7 dias (Gráfico 14 e Tabela 27).

Na comparação entre tempos, o número de linfócitos marcados no grupo TI foi maior em 15 dias quando comparado ao de 7 dias, enquanto o grupo TII apresentou mais linfócitos marcados em 7 dias em relação a 30 dias (Tabela 28).

O número de macrófagos em apoptose foi menor no grupo TII em relação ao grupo $\mathrm{C}$ em 7 dias. Por outro lado, o grupo $\mathrm{Tl}$ apresentou mais macrófagos apoptóticos em 15 e 30 dias em comparação com o grupo C (Gráfico 15 e Tabela 29).

Na comparação entre os tempos, apenas o grupo $C$ apresentou uma redução do número de macrófagos em apoptose nos tempos 15 e 30 dias em relação a 7 dias (Tabela 30). 
Gráfico 14 - Número de linfócitos marcados com caspase no parênquima pulmonar (média + desvio padrão). Comparação entre os grupos Controle, TI e TII em 7, 15 e 30 dias (ANOVA). TI, terapia I; TII, terapia II.

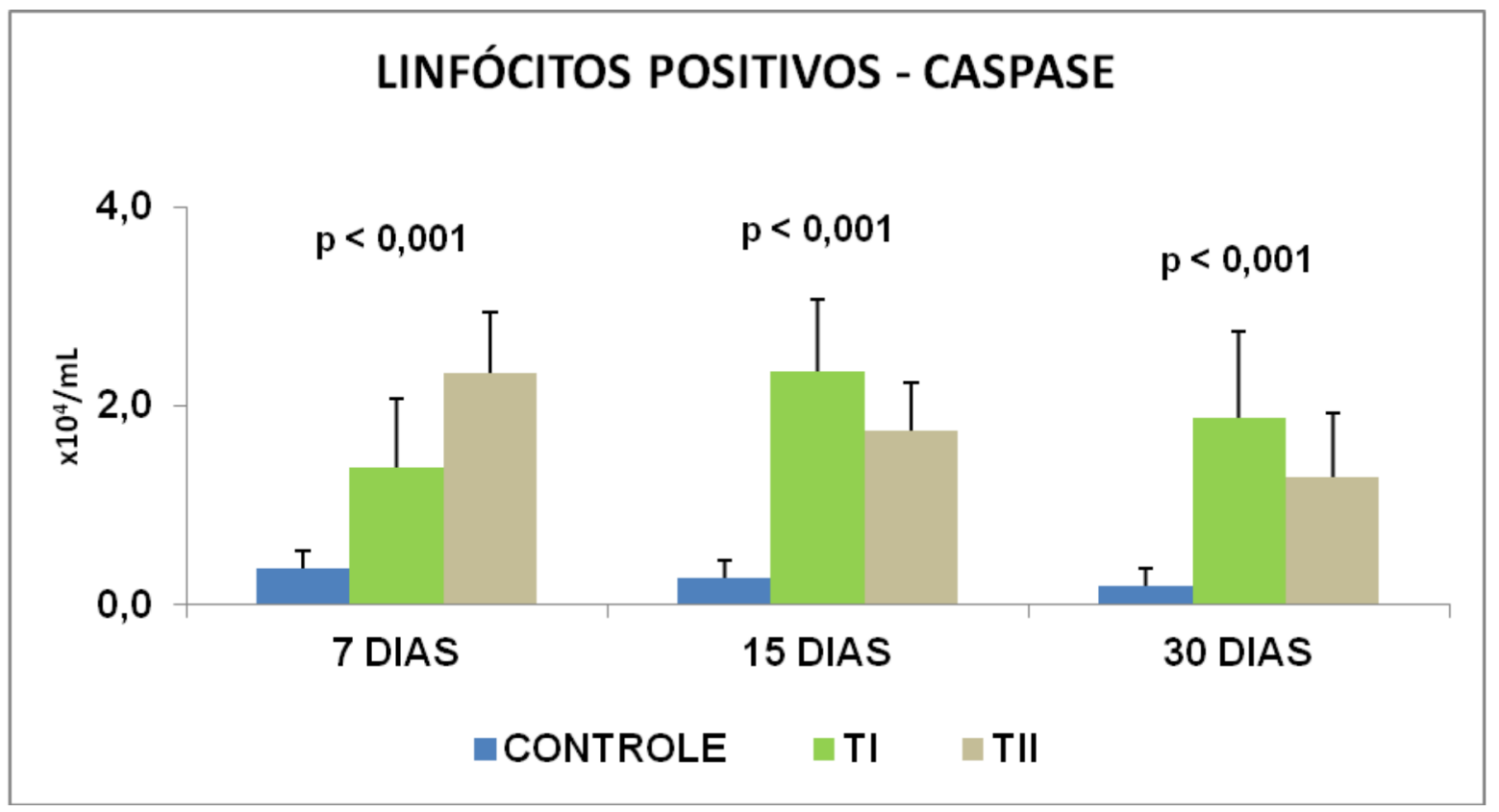

Tabela 27 - Teste de Bonferroni para comparações entre os grupos Controle, TI e TII em 7, 15 e 30 dias em relação aos valores médios de número de linfócitos marcados com caspase no parênquima pulmonar.

\begin{tabular}{cccc}
\hline \multicolumn{4}{c}{ TESTE DE BONFERRONI } \\
\hline $\begin{array}{c}\text { Comparações múltiplas } \\
\text { entre grupos }\end{array}$ & 7 DIAS & Valor de $\mathbf{p}$ \\
\hline CONTROLE x TI & $<0,001$ & $<0,001$ & 30 DIAS \\
CONTROLE x TII & $<0,001$ & $<0,001$ & $<0,001$ \\
TI x TII & 0,001 & 0,075 & 0,001 \\
\end{tabular}

Tabela 28 - Teste de Bonferroni para comparações entre os tempos 7, 15 e 30 dias para os grupos Controle, TI e TII em relação aos valores médios de número de linfócitos marcados com caspase no parênquima pulmonar.

\begin{tabular}{cccc}
\hline \multicolumn{4}{c}{ TESTE DE BONFERRONI } \\
\hline $\begin{array}{c}\text { Comparações múltiplas } \\
\text { entre tempos }\end{array}$ & CONTROLE & Valor de $\mathbf{p}$ & TII \\
\hline $7 \times 15$ & $>0,999$ & 0,001 & 0,078 \\
$7 \times 30$ & $>0,999$ & 0,227 & $<0,001$ \\
$15 \times 30$ & $>0,999$ & 0,314 & 0,232 \\
\hline
\end{tabular}


Gráfico 15 - Número de macrófagos marcados com caspase no parênquima pulmonar (média + desvio padrão). Comparação entre os grupos Controle, TI e TII em 7, 15 e 30 dias (ANOVA). TI, terapia I; TII, terapia II.

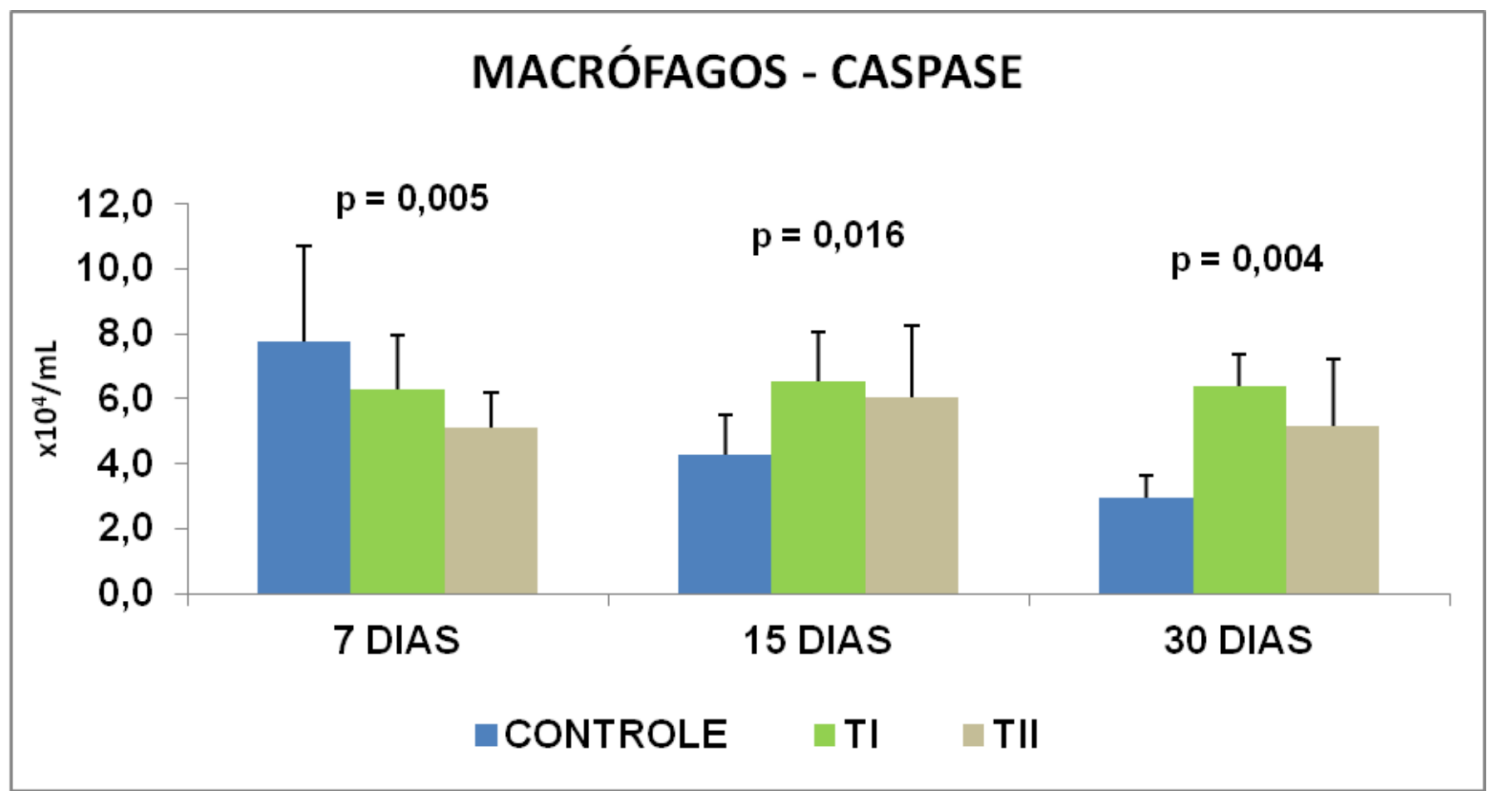

Tabela 29 - Teste de Bonferroni para comparações entre os grupos Controle, TI e TII em 7, 15 e 30 dias em relação aos valores médios de número de macrófagos marcados com caspase no parênquima pulmonar.

\begin{tabular}{cccc}
\hline \multicolumn{4}{c}{ TESTE DE BONFERRONI } \\
\hline $\begin{array}{c}\text { Comparações múltiplas } \\
\text { entre grupos }\end{array}$ & 7 DIAS & Valor de $\mathbf{p}$ \\
\hline CONTROLE x TI & 0,203 & 0,018 & 30 DIAS \\
CONTROLE x TII & 0,004 & 0,101 & 0,003 \\
TI x TII & 0,408 & $>0,999$ & 0,057 \\
\hline
\end{tabular}

Tabela 30 - Teste de Bonferroni para comparações entre os tempos 7, 15 e 30 dias para os grupos Controle, TI e TIl em relação aos valores médios de número de macrófagos marcados com caspase no parênquima pulmonar.

\begin{tabular}{cccc}
\hline \multicolumn{4}{c}{ TESTE DE BONFERRONI } \\
\hline $\begin{array}{c}\text { Comparações múltiplas } \\
\text { entre tempos }\end{array}$ & CONTROLE & Valor de $\mathbf{p}$ \\
\hline $7 \times 15$ & $<0,001$ & TI & TII \\
$7 \times 30$ & $<0,001$ & $>0,999$ & 0,733 \\
$15 \times 30$ & 0,449 & $>0,999$ & $>0,999$ \\
& &
\end{tabular}




\section{Discussão}

As drogas ciclosporina, azatioprina, prednisona, micofenolato e tacrolimus, já testadas isoladamente em nosso laboratório, alteraram de alguma forma o aparelho mucociliar (Pazetti et al., 2008; Pego-Fernandes et al., 2008; Paes e Silva et al., 2011 e Oliveira-Braga et al., 2012). Julgamos oportuno dar continuidade a essa linha de pesquisa, avaliando a ação dessas drogas no esquema da terapia tríplice, que é a forma que os pacientes de transplante pulmonar recebem no seu tratamento pós-operatório.

Existem dois esquemas principais de terapia tríplice: o esquema clássico, com ciclosporina, azatioprina e prednisona, drogas descobertas e usadas há mais tempo (Cooper et al., 1987); e o esquema novo, constituído pelas drogas tacrolimus, micofenolato e prednisona (Knoop et al., 2004; Christie et al., 2010). Neste estudo chamamos o esquema novo de Terapia I e o esquema clássico de Terapia II.

Estudos mostram que os pacientes que utilizam o esquema novo apresentam uma maior sobrevida (Izbicki et al., 2002), menor incidência de rejeição e da síndrome da bronquiolite obliterante (Gerbase et al, 2001; Kobashigawa et al., 2006; Halloran et al., 2011). Porém, os dados referentes aos efeitos colaterais dessas drogas ainda são limitados, e são raros os estudos desses efeitos, especificamente sobre o aparelho mucociliar. Por isso, consideramos importante o estudo e comparação da influência desses dois esquemas de terapia tríplice na depuração mucociliar das vias aéreas. 
O aparelho de depuração mucociliar do sistema respiratório é formado pelos cílios e pelo muco, e funciona basicamente pela interação desses dois componentes. O muco deve possuir propriedades ideais, na sua viscosidade e elasticidade, permitindo uma boa interação com as células ciliadas e com os cílios, proporcionando um movimento que consiga empurrar o muco aderido com agentes nocivos, ao longo da superfície epitelial das vias aéreas em direção à faringe, consequentemente eliminando-as através da deglutição, ou ainda pela tosse e espirro (Macchione et al., 1995).

Havendo alterações na espessura ou na qualidade do muco, nos movimentos ciliares, bem como na inervação e vascularização local, haverá um prejuízo no transporte mucociliar, ocasionando uma estagnação do muco respiratório, podendo levar a infecções pulmonares (Peatfield e Richardson, 1983; Wagener e Headley, 2003; Bush et al., 2006).

Experimentalmente, existem algumas técnicas que podem ser usadas para avaliar as propriedades viscoelásticas do muco respiratório. A avaliação da transportabilidade do muco em palato de rã é uma dessas técnicas e já foi usada diversas vezes em nossa linha de pesquisa (Pazetti et al., 2007, PegoFernandes et al., 2008, Paes e Silva et al., 2011). A qualidade do muco também pode ser avaliada por sua composição química, por meio de corantes específicos que evidenciam seu grau de neutralidade ou de acidez. A mudança na composição do muco pode estar relacionada com agentes poluentes, toxinas e microorganismos (Macchione e Saldiva, 2006; Pires-Neto et al., 2006). 
Neste estudo, observamos que o esquema novo da terapia tríplice (TI) afetou apenas agudamente (7 dias) a TM, não havendo diferença em relação ao grupo controle nos tempos mais tardios (15 e 30 dias). Ademais, ambas as terapias alteraram a produção de muco pelas células caliciformes, seja pelo aumento da produção de muco ácido, seja pela diminuição da produção de muco neutro em todos os tempos estudados. Essas alterações na produção de muco neutro e ácido denotam uma situação de submissão das células caliciformes do epitélio respiratório a agentes tóxicos, como poluentes ou, no caso, drogas imunossupressoras.

Os estudos que investigaram a ação isolada das drogas do esquema clássico mostraram que a ciclosporina (Pazetti et al., 2008), a azatioprina (Pego-Fernandes et al., 2008) e a prednisona (Oliveira-Braga et al., 2012) prejudicaram a qualidade do muco e sua transportabilidade, sendo que a ciclosporina e a prednisona também diminuíram a produção de muco nas vias aéreas. Em corroboração a esses dados, estudos in vitro relataram que os glicocorticoides diminuem a liberação e produção de muco nas vias aéreas (Marom et al., 1984; Roca-Ferrer et al., 2000).

Além disso, estudos mostraram que a prednisona diminuiu a expressão de genes relacionados à produção de mucinas constituintes do muco respiratório (Marom et al., 1984), e que a betametasona suprimiu a produção de muco pelas células caliciformes, além de reduzir os níveis de citocinas próinflamatórias que, por sua vez, estimulam a produção de muco (Kai et al., 1996 e Lu et al., 2005). Podemos inferir que essas alterações na produção de proteínas que formam o muco são capazes de modificar suas características 
viscoelásticas e, em consequência, estar diretamente relacionadas ao prejuízo de sua transportabilidade pelas células ciliadas.

Em relação às drogas que compõem o esquema novo, os estudos são mais escassos e, apesar de um deles ter mostrado que o micofenolato não alterou a qualidade do muco (Paes e Silva et al., 2011), não encontramos na literatura trabalhos que avaliem a ação do tacrolimus na TM. Porém, dados ainda não publicados por nosso grupo sobre a ação do tacrolimus, neste mesmo modelo animal, mostraram que ele não alterou a TM nem a produção de muco neutro, mas causou um aumento significativo da produção de muco ácido. Dessa forma, podemos inferir que o mesmo efeito observado no presente estudo, em relação ao novo esquema tríplice, pode ter sido devido à ação do tacrolimus.

O outro componente do aparelho mucociliar, o cílio, é o responsável direto pela remoção do muco. Algumas alterações da frequência e do padrão do batimento ciliar podem ser causadas por mudanças ultraestruturais dos cílios, como ausência dos braços internos ou externos de dineína, deleção ou transposição de pares de microtúbulos centrais ou periféricos, além de mudanças na composição interna das células ciliadas. Tais alterações podem resultar em estase de secreções e, consequentemente, infecções respiratórias de repetição (Litt, 1970; Chilvers et al., 2003).

Apesar de não termos analisado a ultraestrutura dos cílios, no presente estudo observamos que ambas as terapias prejudicaram a FBC após 7 e 15 dias de tratamento, sendo que o esquema novo diminuiu a FBC mais intensamente em 7 dias. Nos estudos já realizados sobre os efeitos isolados 
das drogas do esquema clássico, tanto a azatioprina (Pego-Fernandes et al., 2008) como a prednisona (Oliveira-Braga et al., 2012) não alteraram a FBC. Por outro lado, Pazetti et al. (2008) observaram que a ciclosporina diminuiu significativamente a frequência dos cílios. Assim, é possível supor que a ciclosporina foi a responsável pela a alteração da FBC nesse esquema clássico no presente estudo.

Paradoxalmente, sabe-se que a ciclosporina influencia a concentração do cálcio citoplasmático (Mihatsh et al., 1998), fazendo com que ocorra uma elevação de cálcio iônico mediado por receptores de ATP, e provocando assim um aumento da FBC (Sanderson e Dirksen, 1989; Hansen et al, 1993). No entanto, parece haver também uma relação direta entre a citotoxicidade induzida pela ciclosporina e mudanças na atividade de enzimas mitocondriais (Sovcicova et al., 2002). Isso pode explicar a influência da ciclosporina sobre a atividade das células do epitélio respiratório, prejudicando o mecanismo de batimento ciliar.

Em relação às drogas que compõem o esquema novo, o micofenolato isoladamente não interferiu nos mecanismos de defesa do aparelho mucociliar; porém, quando associado ao procedimento cirúrgico de secção e anastomose brônquica esquerda, houve uma diminuição da FBC no período de 7 e 30 dias (Paes e Silva et al., 2011). Estudos mostram ainda que o tacrolimus, devido à sua ligação com a imunofilina FKBP12, pode ser responsável também por alterações no cálcio citoplasmático, o qual interfere no batimento ciliar (Bultynck et al., 2000). 
O resultado da interação entre os dois principais componentes do aparelho mucociliar já analisados, cílios e muco, pode ser quantificado pela medida da velocidade de transporte mucociliar in situ, constituindo uma medida direta da capacidade de depuração desse sistema. Dentre as diversas técnicas disponíveis para análise da VTMC, optamos pela observação direta do deslocamento de partículas aderidas ao muco ao longo do epitélio traqueobrônquico por unidade de tempo, devido à disponibilidade de equipamento bem como pela grande experiência do nosso grupo na aplicação da técnica.

Vale ressaltar que a depuração mucociliar, para que seja eficiente, depende de uma série de fatores, como a presença de um epitélio íntegro com funcionamento ciliar coordenado, adequada composição e tamanho da camada periciliar, além de um muco com propriedades viscoelásticas ideais (AlbertiniYagi et al., 2005).

Neste trabalho verificamos que ambos os esquemas, novo e clássico, prejudicaram a VTMC; porém, com o esquema clássico houve um prejuízo maior no período de 15 dias, sendo confirmado com os dados das drogas estudadas isoladamente. Com efeito, a ciclosporina reduziu a VTMC inicialmente, mas permitiu sua recuperação no período de 30 e 90 dias (Pazetti et al., 2007). De maneira semelhante, a azatioprina diminuiu a VTMC no período de 7 dias, mas não teve o mesmo efeito após 15 e 30 dias de tratamento (Pego-Fernandes et al., 2008). Por outro lado, a prednisona não alterou a VTMC em nenhum dos momentos avaliados (Oliveira-Braga et al., 2012). Isso nos sugere que a ciclosporina e a azatioprina juntas causam esse 
prejuízo inicial da VTMC, que se recupera após 30 dias de uso dessas medicações.

Em relação às drogas do esquema novo, um estudo mostrou que o micofenolato não alterou a VTMC quando administrado isoladamente aos animais (Paes e Silva et al., 2011). Entretanto, o tratamento com tacrolimus causou a diminuição da VTMC aos 7, 15 e 30 dias (dados não publicados). Dessa forma, podemos supor que o tacrolimus foi o responsável pela diminuição da VTMC dos animais tratados com o esquema novo de imunossupressão em nosso estudo.

Acreditamos que as alterações dos componentes do aparelho mucociliar, observadas no presente estudo, podem ser decorrentes tanto da ação tóxica direta das drogas imunossupressoras quanto de uma ação indireta, devido ao aumento da susceptibilidade a infecções e agentes tóxicos presentes no ar inalado. De fato, os animais usados no presente estudo são de padrão sanitário convencional, o que significa que não são mantidos em condições totalmente assépticas no ambiente do biotério.

Apesar de haver um sistema de filtração e circulação de ar no interior das salas onde os animais são mantidos, devido à entrada e saída de pesquisadores no ambiente sem medidas de higienização e desinfecção, comuns em biotérios de níveis sanitários mais elevados, o ar que os animais respiram tem a mesma composição que o ar ambiente externo, ou seja, com todos os microorganismos e poluentes próprios da região. Além disso, os animais já possuem uma microbiota própria associada, a qual pode se 
manifestar em situações de baixa imunidade do animal, como é o caso do presente estudo.

A investigação de agentes infecciosos presentes no parênquima pulmonar e nas vias aéreas dos animais não fazia parte dos nossos objetivos iniciais. Porém, amparados pelo parecer de dois patologistas, julgamos que a análise da presença de células inflamatórias ajudaria a identificar situações de infecção e lesão tecidual. Por isso, realizamos a tipagem e quantificação de células inflamatórias no fluido do lavado broncoalveolar e em cortes do tecido pulmonar, obtendo informações importantes para o entendimento dos efeitos adversos dessas drogas imunossupressoras.

De fato, a contagem celular no LBA revelou uma situação bastante alterada nos animais imunossuprimidos, principalmente em relação à terapia nova. O número de linfócitos, ao contrário do que se poderia esperar, foi maior nos animais do grupo TI avaliados em 7 dias, em relação ao grupo controle. Além disso, o número de macrófagos, neutrófilos e células totais também foi maior após o uso da Terapia I em 15 e 30 dias em comparação aos outros dois grupos, não havendo diferença entre estes.

Esses resultados foram coincidentes com os achados no tecido pulmonar, no qual o número de células mono e polimorfonucleares em todos os tempos estudados foi maior nos animais tratados com a Terapia I. Porém, ao contrário do observado no LBA, na maioria dos momentos avaliados, a Terapia Il também causou um aumento de células mono e polimorfonucleares.

Dessa forma, quando analisamos o conjunto desses dados, podemos inferir que o pulmão dos animais imunossuprimidos foi acometido por um maior 
influxo de células inflamatórias ao ponto de serem detectadas inclusive no LBA. Esses achados são corroborados por um estudo que mostrou haver associação entre a toxicidade pulmonar induzida por uma droga imunossupressora e a inflamação linfocítica e granulocítica observadas tanto no LBA quanto nas biópsias de pulmão (Zaas, 2009).

Cabe ressaltar ainda que não houve diferença entre os grupos em relação ao número de células ciliadas e caliciformes presentes no LBA, o que parece indicar a integridade do tecido epitelial traqueobrônquico mesmo com o tratamento com drogas imunossupressoras e na presença de um processo inflamatório.

As análises de proliferação e apoptose de linfócitos e macrófagos no tecido pulmonar também foram bastante elucidativas, mostrando que o número de linfócitos em proliferação foi reduzido em aproximadamente 50\% por ambas as terapias nos 3 tempos avaliados. Já o número de linfócitos apoptóticos aumentou 3 a 4 vezes nos ratos imunossuprimidos em relação aos do grupo controle.

Esses dados indicam que as doses utilizadas de cada droga foram efetivas em cumprir sua função imunossupressora, essencial para o sucesso dos transplantes, ao mesmo tempo inibindo a proliferação e induzindo a morte celular programada de linfócitos (Reichenspurner, 2005).

Por sua vez, o número de macrófagos em proliferação foi maior nos animais tratados por 15 dias com a terapia II em relação aos que foram tratados por apenas 7 dias e em relação aos demais grupos também tratados 
por 15 dias. Além disso, esse número aumentou ao longo do tempo inclusive no grupo controle avaliado aos 30 dias em comparação ao de 7 dias.

Dessa forma, parece haver uma confirmação do que dissemos anteriormente sobre a possibilidade de desenvolvimento de infecções oportunistas nos animais com padrão sanitário convencional, principalmente quando estão imunossuprimidos.

Tais análises não foram realizadas nos estudos anteriores, o que prejudica a comparação com o efeito isolado de cada droga. No entanto, podese supor que a maior presença de células inflamatórias no LBA e no tecido pulmonar desses animais contribuiu significativamente com as alterações observadas dos componentes do epitélio respiratório responsáveis pela depuração mucociliar.

Acreditamos que os resultados obtidos neste estudo são suficientes para mostrar que o comprometimento do sistema mucociliar em decorrência do uso de drogas imunossupressoras é real, mas que novos estudos são necessários para elucidar o mecanismo de ação intracelular de cada uma dessas drogas sobre as células que compõem o epitélio respiratório. Somente com a identificação das rotas bioquímicas será possível estabelecer estratégias de bloqueio da ação indesejável dessas drogas na produção do muco respiratório e na estrutura e no funcionamento dos cílios presentes nesse tecido, a fim de reduzir os índices de morbidade e mortalidade dos pacientes receptores de enxerto pulmonar em decorrência de infecções respiratórias. 
7 CONCLUSÕES 


\section{Conclusões}

Em relação às análises realizadas, podemos concluir que:

$\checkmark$ Ambas as terapias causaram a diminuição da FBC em 7 e 15 dias;

Ambas as terapias causaram a diminuição da VTMC em 7 e 15 dias;

Apenas a TI causou alteração da TM em 7 dias;

$\checkmark$ Ambas as terapias causaram a diminuição da produção de muco neutro e o aumento de muco ácido, sendo a ação da $\mathrm{TI}$ mais pronunciada;

$\checkmark$ Apenas a $\mathrm{TI}$ causou o aumento do número de macrófagos, neutrófilos e células totais no LBA em 7 e 15 dias;

Ambas as terapias causaram um aumento no número de células mononucleares e polimorfonucleares no parênquima pulmonar em todos os tempos estudados. Além disso, na comparação entre as terapias, o grupo $\mathrm{TI}$ apresentou maior número de células mononucleares em 7 dias e polimorfonucleares nos 3 tempos;

$\checkmark$ Ambas as terapias causaram diminuição da proliferação e aumento da apoptose dos linfócitos no parênquima pulmonar em 7, 15 e 30 dias.

$\checkmark$ Apenas a TI causou um aumento do número de macrófagos em apoptose no parênquima pulmonar em 15 e 30 dias. 


\section{REFERÊNCIAS}




\section{Referências}

Aarbakke J. Biology and pharmacology of thiopurines. Pediatr Hematol Oncol 1995; 12(5):511-9.

Aarbakke J, Janka-Schaub G, Elion GB. Thiopurine biology and pharmacology. Meeting report 1997; 18(1):3-7.

Aeba R, Keenan RJ, Hardesty RL, Yousem SA, Hamamoto I, Griffith BP. University of Wisconsin solution for pulmonary preservation in a rat transplant model. Ann Thorac Surg 1992; 53:240-6.

Albert B, Bray D, Lewis J, Raff M, Roberts K, Watson JD. Molecular biology of the cell. 3 ed. New York: Garlani, 1994, 1294p.

Albertini-Yagi CS, Oliveira RC, Vieira JE, Negri EM, de Oliveira LR, Saldiva PH, Lorenzi-Filho G. Sputum induction as a research tool for the study of human respiratory mucus. Respir Physiol Neurobiol 2005;145(1):101-10.

Almeida F.M. Estudo do crescimento pulmonar compensatório após bilobectomia em ratos com enfisema induzido por elastase [dissertação]. São Paulo: Faculdade de Medicina, Universidade de São Paulo; 2012.

Ausiello D, Goldman I. Tratado de Medicina Interna. 24a ed. São Paulo: Elsevier; 2014. v.2.

Bando K, Paradis IL, Komatsu K, Konishi H, Matsushima M, Keena RJ, Hardesty RL, Armitage JM, Griffith BP. Analysis of time-dependent risks for infection, rejection, and death after pulmonary transplantation. Thorac Cardiovasc Surg 1995; 109:49-57.

Bd Biosciences. Caspase-3 Ativaction: An Indicatior of Apoptosis in ImageBased Assay. Application Note. September 2012.

Björkander J, Bake B, Oxelius VA, Hanson LA. Impaired lung function in patients with IgA deficiency and low levels of IgG2 or IgG3. N Engl J Med 1985; 313(12):720-4. 
Bleecker HR. Cholinergic and neurogenic mechanisms in obstructive airways. Am J Med 1986; 81:93-102.

Bove, KE, C Lewis and BK. Debrosse. Proliferation and maturation indices in nephrogenic rests and Wilms tumor: the emergence of heterogeneity from dormant nodular renal blastema. Pediatr Pathol Lab Med 1995; 15:223-44.

Braga KAO, Correia AT, Jatene FB, Pego-Fernandes PM. The effects on mucociliary clearance of prednisone associated with bronchial section. Clinics 2012; 67(6):647-52.

Bullingham RE, Nicholls AJ, Kamn BR. Clinical pharmacokinetics of mycophenolate mofetil. Clin Pharmacokinet 1998; 34(6):429-55.

Bultynck G, De Smet P, Weidema AF, Ver Heyen M, Maes K, Callewaert G, Missiaen L, Parys JB, De Smedt H. Effects of the immunosuppressant FK506 on intracellular $\mathrm{Ca} 2+$ release and $\mathrm{Ca} 2+$ accumulation mechanisms. J Physiol 2000; 525(3):681-93.

Bush A, Payne D, Pike S, Jenkins G, Henke MO, Rubin BK. Mucus properties in children with primary ciliary dyskinesia: comparison with cystic fibrosis. Chest 2006; 129(1):118-23.

Calhoon JH, Nichols L, Davis R. Single lung transplantation: factors in postoperative cytomegalovirus infection. Thorac Cardiovasc Surg 1992; 103:216.

Camargo JJ, Rocha MG, Oliveira ME, Godoy DV. Transplante isolado de pulmão: relato do primeiro caso realizado na América do Sul. J Pneumol 1990;16 (Suppl 1):9.

Castro M. Efeitos Aniinflamatórios e Antiproliferativos dos glicocorticóides: Concordância ou Discordância? Arq Bras Endocrinol Metab 2005; 49(3):334-6.

Chaparro C, Maurer JR, Chamberlain D, De Hoyos A, Winton T, Westney G, Kesten S. Causes of death in lung transplant recipients. J Heart Lung Transplant 1994; 13:758-66. 
Chaparro C, Maurer J, Gutierrez C, Krajden M, Chan C, Winton T, Keshavjee S, Scavuzzo M, Tullis E, Hutcheon M, Kesten S. Infection with Burkholderia cepacia in Cystic Fibrosis: Outcome Following Lung Transplantation. Am J Respir Crit Care Med 2001; 163(1):43-8.

Chen F, Nakamura T, Wada, H. Development of New Organ preservation Solutions in Kyoto University. Transplant Proc 2004; 36(9):2812-5.

Chilvers MA, Rutman A, O' Callaghan. Ciliary beat pattern is associated with specific ultrastructural defects in primary ciliary dyskinesia. J Allergy Clin Immunol 2003; 112 (3):518-24.

Chin D, Boyle GM, Parsons PG, Coman WB. What is transforming growth factor-beta (TGF- $\beta$ )? Br Assoc Plast Surg 2004; 57:215-21.

Christie JD, Edwardas LB, Kucheryavaya AY, Aurora P, Dobbels F, Kirk R, Rahmel AO, Stehlik J, Hertz MI. The Registry of International Society for Heart and Lung Transplantation: Twenty-Seventh Official adult lung and heart-lung transplant report - 2010. J Heart Lung Transplant 2010; 29(10):1104-18.

Clarck AR. Anti-inflamatory functions of glucocorticoid-induced genes. Mol Cell Endocrinol 2007;275(1-2):79-97.

Cooper JD, Pearson FG, Patterson GA, Todd TRJ, Ginsber RJ, Goldberg M, DeMajo WA. Technique of successful lung transplantation in humans. $J$ Thorac Cardiovasc Surg 1987; 93(2):173-81.

Crawford SW. Respiratory infections after organ transplantation. Curr Opin Pulm Med 1995; 1:209-15.

Crystal RG, Randell SH, Engelhardt JF, Voynow J, Sunday ME. Airway Epithelial Cells Current Concepts and Challenges. Proc Am Thorac Soc 2008; 5(7):772-7.

Dong VM, Womer KL, Sayegh MH. Transplantation tolerance: the concept and its applicability. Pediatr Transplant 1999; 3(3):181-92. 
Dummer JS, Montero CG, Griffith BP, Hardesty RL, Paradis IL, Ho M. Infections in heart-lung transplant recipients. Transplantation 1986; 41:725-9.

Duncan MD, Wilkes DS. Transplant-related immunosuppression: a review of immunosuppression and pulmonary infections. Proc Am Thorac Soc 2005; 2(5):449-55.

Durbin C, Guo K, Hoffman W, Eric Schultze A, White S. Estimating leukocyte, platelet, and erythrocyte counts in rats by blood smear examination. Rev Clin Pathol 2009; 38(2)157-62.

Eguchi Y, Ewert D, Tsujimoto, Y. Isolation and characterization of the chicken bcl-2 gene: expression in a variety of tissues including lymphoid and neural organs in adult and embryo. Nucl Acids Res 1992; 20:4187-92.

Ellenhorn JDI, Woodle ES, Ghobreal I, Thistlethwaite JR, Bluestone JA. Activation of human $T$ cells in vivo following treatment of transplant recipients with OKT3. Transplantation 1990; 50(4):608-12.

Fan Y, Xiao YB, Weng YG. Tacrolimus Versus Cyclosporine for Adult Lung Transplant Recipients: A Meta-Analysis. Transplant Proc 2009;41(5):1821-4.

Forte V, Martinez JAB, Succi JE, Perfeito JAJ, Cendon Filha S, Nery LE, Beppu OS. Transplante pulmonar unilateral em paciente com esquistossomose pulmonar forma intersticial: considerações técnicas e evolução. J Pneumol $1991 ; 17(2): 51-8$.

Foster WM. Mucociliary Transport and Cough in Humans. Pulmonary Pharmacology \& Therapeutics 2002; 15: 277-82.

Gerbase MW, Spiliopoulos A, Fathi M, Nicod LP. Low doses of mycophenolate mofetil with low doses of tacrolimus prevent acute rejection and long term function loss after lung transplantation. Transplant Proc 2001; 33(3):2146-7.

Gerdes J, Lemke H, Baisch H, Wacker HH, Schwab U, Stein H. Cell cycle analysis of a cell proliferation associated human nuclear antigen defined by the monoclonal antibody Ki-67. J Immunol 1984; 133(4):1710-5. 
Griffith BP, Bando K, Hardesty RL, Armitage JM, Keenan RJ, Pham SM, Paradis IL, Yousem SA, Komatsu K, Konishi H, Fung JJ, Starzl TE. A prospective randomized trial of FK506 versus ciclosporine after human pulmonary transplantation. Transplantation 1994;57(6):848-51.

Guide for the care and use of laboratory animals. In: Institute of laboaratory animal resources. National Research Council of the National Academy of Sciences. Washington, D.C: National Academy Press; 1996.

Ha EY, Mun KC. Effect of cyclosporine on apoptosis in bronchial epithelial cells. Transplant Proc 2012; 44(4):985-7.

Hall PA, Levinson DA. Review: assessment of cell proliferation in histological material. J Clin Pathol 1990; 43(2):184-92.

Hall PA, Levison DA, Woods AL, Yu CC, Kellock DB, Watkins JA, Barnes DM, Gillett CE, Camplejohn R, Dover R. Proliferating cell nuclear antigen (PCNA) immunolocalization in paraffin sections: an index of cell proliferation with evidence of deregulated expression in some neoplasms. J Pathol 1990; 162(4):285-94.

Halloran P, Ahsan N, Johnson C, Gonwa T, Stegall M, Hardy M, Metzger R, Shield C, Rocher L, Scandling J, Sorenson J, Mulloy L, Light J, Corwing C, Danovicth G, Wachs M, Van Veldhuisen P, Owen K,Salm K, Tolzman D, King S, FfitzsimmonsW. Year follow up of randomized multicenter kidney transplant study comparing tacrolimus (TAC)+azathioprine (AZA) vs cyclosporinemodified (CSA)+mycophenolate mofetil (MMF) vs TAC+MMF. Am J Transplant 2011;1:405.

Hansen M, Boitano S, Dirksen ER, Sanderson MJ. Intercellular calcium signaling induced by extracellular adenosine-5'-triphosphate and mechanical stimulation in airway epithelial cells. J Cell Sci 1993; 106:995-1004.

Hausen B, Morris RE. Review of immunosuppression for lung transplantation. Novel drugs, new uses for conventional immunosuppressants, and alternative strategies. Clin Chest Med 1997;18(2):353-66. 
Hardy JD, Webb WR, Dalton ML, Walker GR. Lung homotransplantation in man; report of initial case. JAMA 1963; 186:1065-74.

Herrera JM, McNeil KD, Higgins RSD, Coulden RA, Flower CD, Nashef SAM, Wallwork J. Airway complications after lung transplantation: Treatment and longterm outcome. Ann Thorac Surg 2001; 71:989-94.

Hertz MI, Aurora P, Christie JD, Dobbels F, Edwards LB, Kirk R, Kucheryavaya AY, Rahmel AO, Rowe AW, Taylor DO. Registry of the International Society for Heart and Lung Transplantation: A Quarter Century of Thoracic Transplantation. J Heart Lung Transplant 2008; 27:937-42.

Herve P, Silbert D, Cerrina J, Simonneau G, Dartevelle P, The Paris-Sud Lung Transplant Group.Impairment of bronchial mucociliary clearance in long-term survivors of heart/lung and double-lung transplantation. Chest 1993; 103:59-63.

Hess $A D$, Esa $A H$, Colombani PM. Mechanisms of action of cyclosporine: effects on cells of the immune system and on subcellular events in $T$ cell activation. Transplant Proc 1988; 2:30-40.

Houtmeyers E, Gosselink R, Gayan-Ramirez G, Decramer M. Regulation of mucociliary clearance in health and disease. Eur Respir J 1999; 13(5):1177-88.

Izbicki G, Shitrit D, Aravot D, Sulkes J, Saute M, Sahar G, Kramer MR. Improved Survival After Lung Transplantation in Patients Treated With Tacrolimus I Mycophenolate Mofetil as Compared With Cyclosporine / Azathioprine. Transplant Proc 2002; 34:3258-9.

Jatene FB, Pego-Fernandes PM, Medeiros IL. Transplante Pulmonar. Rev Med (São Paulo) 2009 jul.-set.;88(3) ed. especial:111-22.

Jatene FB, Pego-Fernandes PM. Desafios do transplante pulmonar. J Bras Pneumol 2008; 34(5):249-50.

Jeffery PK, Gaillard D, Moret S. Human airway secretory cells during development and in mature airway epithelium. Eur Resp J 1992; 5:93-104. 
Junqueira LC, Carneiro J. Aparelho Respiratório. In: Histologia Básica. 11 ed. Rio de Janeiro: Guanabara Koogan, 2008; 1:339-58.

Kai H, Yoshitake K, Hisatsune A, Kido T, Isohama Y, Takahama K, Miyata T. Dexametasone suppresses mucus production and Muc2 and Muc5ac gene expression by NCl-H292 cells. Am J Physiol Lung Cell Mol Physiol 1996; 271 : L484-8.

Kapoor M, Nomiyama T, Bruemmer D, Kojima F, Crofford LJ. Growth factors and cytokines: emphasis on their role in wound healing and atherosclerosis. Curr Anaest Crit Care 2006; 17:13-20.

Knoop C, Haverich A, Fischer S. Immunosuppressive therapy after human lung transplantation. Eur Respir J 2004;23(1):159-71.

Knowles MR, Boucher RC. Mucus clearance as a primary innate defense mechanism for mammalian airways. J Clin Invest 2002; 109 (5):571-17.

Kobashigawa JA, Miller L, Russell SD, Ewald GA, Zucker MJ, Goldberg LR, Eisen HJ, Salm K, Tolzman D, Gao J, Fitzsimmons W, First R. Tacrolimus with mycophenolate mofetil (MMF) or Silorimuus vs. Cyclosporine with MMF in cardiac transplant patients: 1-year report. Am J Transplant 2006; 6(6):1337-86.

Korsmayer S. Bcl-2: an antidote to programmed cell death. Cancer Surv 1992; 15:105-18.

Kurki P, Vanderlaan M, Dolbear F, Gray J, Tam EM. Expression of proliferating cell nuclear (PCNA) cyclin during cell cycle. Exp Cell Res 1986; 166:209-19.

Lavrik IN, Golks A, Krammer PH. Caspases: pharmacological manipulation of cell death. J Clin Invest 2005; 115:2665-72.

Lebrun D, Warnke RA, Cleary ML. Expression of bcl-2 in fetal tissues suggests a role in morphogenesis. Am J Pathol 1993; 142:743-53.

Levine AJ, Perry ME, Chang A, Silver A, Dittmer D, Wu M, Welsh D. The 1993 Walter Hubert Lecture: The role of p53 tumour suppressor gene in 
tumorigenesis. Br J Cancer 1994; 29(3):409-6.

Litt M. Mucus rheology: relevance to mucociliary clearance. Arch Intern Med 1970; 126:417-23.

Lorenzi-Filho G. Efeitos da nebulização de solução salina e n-acetilcisteína sobre o muco respiratório de ratos [tese]. São Paulo: Faculdade de Medicina, Universidade de São Paulo; 1993.

Lu L, Saulis AS, Liu WR, Roy ND, Chao JD, Ledbetter S, Mustoe TA. The temporal effects of anti-TGF- $\beta 1,2$ and 3 monoclonal antibody on wound healing and hypertrophic scar formation. J Am Coll Surg 2005; 201:391-7.

Lucas AM, Douglas LC. Principles underlying ciliary activity in the respiratory tract. Arch Otolaryngol 1934; 20:528-41.

Lund VJ. Nasal physiology: Neurochemical receptors, nasal cycle, and ciliary action. Allergy Asthma Proc 1996; 17(4):179-84.

Macchione M, Guimarães ET, Saldiva PH, Lorenzi Filho G. Methods for studying respiratory mucus and mucus clearance. Braz J Med Biol Res 1995; 28(1112):1137-55.

Macchione M, Lorenzi-Filho G, Guimarães ET, Junqueira VB, Saldiva PHN. The use of the frog palate preparation to assess the effects of oxidants on ciliated epithelium. Free Radic Biol Med 1998; 24:714-21.

Macchione M, Saldiva PHN. Células do Epitélio Respiratório. In: Naomi Kondo Nakagawa; Viviani Barnabé. (Org.). Fisioterapia do sistema respiratório. 1ed.São Paulo: Sarvier, 2006, v. 1, p. 247-56.

Marom Z, Shelhamer J, Alling D, Kaliner M. The effects of corticosteroids on mucous glycoprotein secretion from human airways in vitro. Am Rev Respir Dis 1984; 129(1):62-5.

McAnally KJ, Valentine VG, Laplace SG, McFadden PM, Seoane L, Taylor DE. Effect of Pre-Transplantation Prednisone on Survival After Lung Transplantation. 
J heart Lung Transplant 2006; 25(1):67-74.

McMormick D, Hall PA. The complexities of proliferating cell nuclear antigen. Histopathology 1992; 21(6):591-4.

Mendeloff EM. The history of pediatric heart and lung transplantation. Pediatr Transplant 2002; 6(4):270-9.

Metras $H$. Note préliminaire sur la graffe totale du poumon chez le chien. CRAcadSci 1950; 231:1176-7.

Mihatsh MJ, Kyo M, Morozumi K, Yamaguchi Y, Nickeleit V, Ryffel B. The side effects of ciclosporine-A and tacrolimus. Clin Nephrol 1998; 49(6):356-63.

Miranda A, Zink R, McSweeney M. Anesthesia for lung transplantation. Semin Cardiothorac Vasc Anesth 2005; 9(3):205-12.

Moreira JS, Andrade CF. Mecanismos de defesa do aparelho respiratório. In: Affonso Berardinelli Tarantino. (Org). Doenças Pulmonares. 6 ed. Rio de Janeiro: Guanabara Koogan, 2008;1:131-9.

Mowry RW. Alcian blue techniques for histochemical study of acidic carbohydrates. J Histochem Cytochem 1956; 4: 407. Apud Harkema JR, Plopper CG, Hyde DM, St George JA. Regional differences in quantities of histochemically detectable muco substances in nasal, paranasal and nasopharyngeal epithelium of the bonnet monkey. J Histochem Cytochem 1987; 35:279-86.

Nakagawa NK, Saldiva PHN, Lorenzi-Filho G. Em: Nakagawa NK, Barnabé V. Fisioterapia do Sistema Respiratório. 1 ed. São Paulo: Sarvier; 2006. p.229-46.

Nakopoulou L, Alexandrou P, Stefanaki K, Panayotopoulou E, Lazaris A, Davaris P. Immunohistochemical expression of caspase-3 as na adverse indicator of the clinical outcome in human breast cancer. Pathobiology 2001; 69(5):266-73.

Negri EM, Komatsuzaki M, Sakae RS. Alterações do epitélio respiratório e 
poluição. J Pneumol 1987; 13(3):13-20.

Nelson S, Bagby GJ, Bainton BG, Summer WR. The effects of acute and chronic alcoholism on tumor necrosis factor and the inflammatory response. $J$ Infect Dis 1989; 160:422-9.

Nelson S, Bagby GJ, Bainton BG, Wilson LA, Tompson JJ, Summer WR. Compartmentalization of intra-alveolar and systemic lipopolysaccharide-induced tumor necrosis factor and the pulmonary inflammatory response. $J$ Infect Dis 1989; 159:189-94.

Neptune WB, Weller R, Bailey CP. Experimental lung transplantation. J Thorac Cardiovasc Surg 1953; 26:606-15.

Newhouse MI, Jordana M, Dolovich $M$. Evaluation of lung epithelial permeability. Eur J Nucl Med 1987; 13:S58-62.

Nicholson DW, Ali A, Thornberry NA, Vaillancourt JP, Ding CK, Gallant M, Gareau Y, Griffin PR, Labelle M, Lazebnik YA. Identification and inhibition of the ICE/CED-3 protease necessary for mammalian apoptosis. Nature 1995; 376:3743.

Oliveira-Braga KA, Nepomuceno NA, Correia AT, Jatene FB, Pego-Fernandes PM. Effects of prednisone on mucociliary clearance in a murine model. Transplant Proc 2012; 44:2486-9.

Orens BJ, Estenne M, Arcasoy S, Conte JV, Corris P, Egan JJ, Egan T, Keshavjee S, Knoop C, Kotlof R, Martinez FJ, Nathan S, Palmer S, Patterson A, Singer L, Snell G, Studer S, Vachiery JL, Glanville AR. International Guidelines for the Selection of Lung Transplant Candidates: 2006 Update-A Consensus Report From the Pulmonary Scientific Council of the International Society for Heart and Lung Transplantation. J Heart Lung Transplant 2006; 25:74-55.

Paes e Silva VF, Pazetti R, Soto SF, Siqueira MMQ, Correia AT, Jatene FB, Pego-Fernandes PM. Effects of mycophenolate sodium on mucociliary clearance using a bronchial section and anastomosis rodent model. Clinics 
$2011 ; 66(8): 1451-6$.

Pazetti R, Pego-Fernandes PM, Jatene FB. Adverse effects of immunosuppressant drugs upon airway epithelial cell and mucociliary clearance: implications for lung transplant. Drugs 2013; 73(11):1157-69.

Pazetti R, Pego-Fernandes PM, Lorenzi-Filho G, Saldiva PHN, Moreira LFP, Jatene FB. Effects of cyclosporine $A$ and bronchial transection on mucociliary transport in rats. Ann Thorac Surg 2008; 85(6):1925-9.

Pazetti R, Pego-Fernandes PM, Ranzani OT, Parra ER, Lorenzi-Filho G, Jatene FB. Cyclosporin A reduces airway mucus secretion and mucociliary clearance in rats. Clinics 2007; 62(3):345-52.

Peatfield AC, Richardson PS. Evidence of non-cholinergic non-adrenergic nervous control of mucus secretion into the cat trachea. $J$ Physiol 1983; 342:335-45.

Pego-Fernandes PM, Said MM, Pazetti R, Moreira LFP, Jatene FB. Efeitos da azatioprina sobre a depuração mucociliar após secção e anastomose brônquica em um modelo experimental em ratos. J Bras Pneumol 2008; 34(5):273-9.

Pierson RN. Lung transplantation: current status and challenges. Transplantation 2006;81(12):1609-15.

Pires-Neto RC, Lichtenfels AJ, Soaes SR, Macchione M, Saldiva PH, Dolhnikoff M: Effects of Sao Paulo air pollution on the upper airways of mice. Environl Res 2006;101(3):356-61.

Proctor DF. Nasal mucus transport and our ambient air. Laryngocospe 1983; 93:58-62.

Puchelle E, Tournier JM, Petit A, Zahm JM, Lauque D, Vidailhet M, Sadoul P. The frog for studying mucus transport velocity and mucociliary frequency. Eur $J$ Respir Dis 1983; 128:293-303.

Qu N, de Vos P, Schelfhorst M, de Haan A, Timens W, Prop J. Integrity of 
airway epithelium is essential against obliterative airway disease in transplanted rat tracheas. J Heart Lung Transplant 2005; 24(7):882-90.

Rabenhorst SH, Burrini RC, Schimitt FCL. Marcadores de proliferação cellular. Rev Bras Pathol Clin 1993; 29(1):24-8.

Rabenhorst SH, Burrini RC, Schimitt FCL. Ciclo celular mecanismos reguladores e marcadores bioquimicos. Rev Bras Cancerol 1994; 40(3):141-7.

Randell SH, Boucher RC. University of North Carolina Virtual Lung Group. Effective mucus clearance is essential for respiratory health. Am J Respir Cell Mol Biol 2006; 35(1):20-8.

Registro Brasileiro de Transplantes - Ano XXI, no 1, Jan/mar 2015 [Associação Brasileira de Transplante de Órgãos]. São Paulo, 2015.

Reichenspurner $\mathrm{H}$. Overview of Tacrolimus-based Immunosuppression After Heart or Lung Transplantation. J Heart Lung Transplant 2005;24:119-30.

Reichenspurner H, Kur F, Treede $\mathrm{H}$. Optimization of the immunosuppressive protocol after lung transplantation. Transplantation 1999; 68:67.

Rivero DH, Lorenzi-Filho G, Pazetti R, Jatene FB, Saldiva PH. Effects of bronchial transection and reanastomosis on mucociliary system. Chest 2001;119(5):1510-5.

Roca-Ferrer J, Mullol J, Perez M, Xaubet A, Molins L, de Haro J, Shelhamer J e Picado C. Effects of topical glucocorticoids on in vitro lactoferrin glandular secretion: Comparison between human upper and lower airways. J Allergy Clin Immunol 2000; 106(6):1053-62.

Rogers DF. Physiology of airway mucus secretion and pathophysiology of hypersecretion. Respir Care 2007; 52(9):1134-46.

Rubin BK, Ramirez O, King M. Mucus-depleted frog palate as a model for the study of mucociliary clearance. J Appl Physiol 1990; 69(2):424-9. 
Sackner MA, Yergin BM, Brito M, Januszkiewicz A. The effect of adrenergic agonists on tracheal mucous velocity. Bull Eur Physiopathol Respir 1979; 15:505-11.

Saldiva, PHN. Aparelho mucociliar: Aspectos funcionais e métodos de estudo. $J$ Pneumol 1990; 16:161-70.

Saldiva PHN, Mauad T, Dolhnikoff M, Bernardi FDC, Silva LFF, Cury PM. Pulmão e Pleura. In: Geraldo Brasileiro Filho. (Org.). Bogliolo Patologia. 8 ed. Rio de Janeiro: Guanabara Koogan. 2011; 1:383-441.

Sanderson MJ, Dirksen ER. Mechanosensitive and betaadrenergic control of the ciliary beat frequency of mammalian respiratory tract cells in culture. Am Rev Respir Dis 1989; 139:432-40.

Sanjar S. Measurement and pharmacology of mucociliary clearance. Agents Actions Suppl 1991; 34:457-70.

Satir P, Christensen ST. Overview of structure and function of mammalian cilia. Annu Rev Physiol 2007; 69:377-400.

Satir P, Sleigh MA. The physiology of cilia and mucociliary interactions. Ann Rev Phisiol 1990; 52:137-55.

Scholzen T, Gerdes J. The Ki-67 Protein: From the Known and the Unknown. $J$ Cell Physiol 2000; 182:311-22.

Shankar S, Fulshman L, Read RC, Theodoropoulos S, Cole PJ, Madden B, Yacoub M. Mucociliary function afther lung transplantation. Transplant Proc 1991; 23(1 Pt 2):1222-3.

Shehata M, Bhandari S, Venkat-Raman G, Moore R, D'Souza R, Riad H, Bahran A, Baker R, Needham C, Andrews C. Effect of conversion from mycophenolate sodium on maximum tolerated dose and gastrointestinal symptoms following kidney transplantation. Transplant Int 2009; 22(8):821-30.

Shevach EM. The effects of cyclosporin A on the immune system. Annu Rev 
Immunol 1985; 3:397-423.

Sibille Y, Reynolds HY. Macrophages and polymorphonuclear neutrophils in lung defense and injury. Am Rev Respir Dis 1990; 141(2):471-501.

Sievers TM, Rossi SJ, Ghobrial RM, Arriola E, Nishimura P, Kawano M, Holt CD. Mycophenolate mofetil. Pharmacotherapy 1997; 17(6):1178-97.

Sioni Y, VirkajarviN, Lehto VP, Paakko P. Hepato-cellular carcinomas with a high proliferation index and a low degree of apoptosis and necrosis are associated with a shortened survival. Br J Cancer 1996; 73:1025-30.

Sleigh MA, Blake JR, Liron N. The propusion of mucus by cilia. Am Rev Respir Dis 1988; 137:726-41.

Sollinger HW. Mycophenolates in transplantation. Clin Transplant 2004; 18:48592.

Sovcikova A, Tulinska J, Kulova J, Likova A, Syrova D, Horakova K. Effect of cyclosporin A in Lewis rats in vivo and HeLa cells in vitro. J Appl Toxicol 2002; 22(3):153-60.

Speich R, van der Bij W. Epidemiology and management of infections after lung transplantation. Clin Infect Dis 2001; 33 (Suppl. 1):S58-65.

Studer SM, Levy RD, Mcneil K, Orens JB. Lung Transplantation outcomes: a review of survival, graft function, heath-related quality of life and costeffectiveness. Eur Respir J 2004; 24(4):674-85.

Taylor JL, Palmer SM. Critical care perspective on immunotherapy in lung transplantation. J Intensive Care Med 2006; 21(6):327-44.

Tomkiewicz RP, App EM, Shennib H, Ramirez O, Nguyen D, King M. Airway mucus and epithelial function in a canine model of single lung autotransplantation. Chest 1995; 107:261-5.

Trindade SHK, Mello Lunior JF, Mion OG, Lorenzi-Filho G, Macchione M, Guimarães ET, Saldiva PH. Methods for Studying Mucociliary Transport. Braz J 
Otorhinolaryngol 2007; 73(5):704-12.

Tsuji T, Shrestha P, Yamada K, Takagi H, Shinozaki F, Sasaki K. Proliferating cell nuclear antigen in malignant and pre-malignant lesions of epitelial origin in the oral cavity and the skin: na immunohistochemical study. Virchows Archiv $A$ Pathol Anat 1992; 420:377-83.

Veale D, Glasper PN, Gascoigne A, Dark JH, Gibson GJ, Corris PA. Ciliary beat frequency in transplanted lungs. Thorax 1993; 48:629-31.

Vondracek SF, Hemstreet BA. Is there an optimal corticosteroid regimen for the management of an acute exarcebation of chronic obstructive pulmonary disease? Pharmacotherapy 2006; 26(4):522-32.

Wagener JS, Headley AA. Cystic Fibrosis: Current Trends in Respiratory Care. Respir Care 2003; 48(3):234-45.

Wanner A, Salathé M, O'Riordan, TG. Mucociliary Clearence in the airways. Am J Respir Crit Care Med 1996; 154:1968-72.

Webster AC, Woodroffe RC, Taylor RS, Chapman JR, Craiy JC. Tacrolimus versus ciclosporin as primary immunosuppression for kidney transplant recipients: meta analysis and meta-regression of randomised trial data. BMJ 2005; 331:810-21.

Wilgus TA, Ferreira AM, Oberyszyn TM, Bergdall VK, Dipietro LA. Regulation of scar formation by vascular endothelial growth factor. Lab Invest 2008; 88: 57990.

Woodroffe R, Yao GL, Meads C, Bayless S, Ready A, Raffery J, Taylor RS. Clinical and cost-effectiveness of newer immunosuppressive regimes in renal tranplantation: a systematic review and modelling study. Heath Technol Assess 2005; 9(21):179-95.

Xavier AM, Pego-Fernandes PM, Correia AT, Pazetti R, Monteiro R, Canzian M, Jatene FB. Influence of cyclosporine $A$ on mucociliary system after lung transplantation in rats. Acta Cir Bras 2007; 22(6):465-9. 
Yamauchi A, Oishi R, Kataoka Y. Tacrolimus-induced neurotoxicity and nephrotoxicity is ameliorated by administration in the dark phase in rats. Cell Mol Neurobiol 2004; 24(5):695-704.

Zaas WD. Update on medical complications involving the lungs. Curr Opin Org Transplant 2009; 14:488-93.

Zayas JG, O'Brien DW, Tais S, Ding J, Lim L, King M. Adaptation of an amphibian mucociliary clearance model to evaluate early effects of tobacco smoke exposure. Resp Res 2004; 5:9.

Zhang P, Bagby GJ, Stoltz DA, Spitzer JA, Summer WR, Nelson S. Modulation of the lung host response by granulocyte colony-stimulating factor in rats challenged with intrapulmonary endotoxin. Shock 1997; 7:193-9.

Zhang P, Bagby GJ, Stoltz DA, Summer WR, Nelson S. Granulocyte colonystimulating factor modulates the pulmonary host response to endotoxin in the absence and presence of acute ethanol intoxication. J Infect Dis 1999; 179: 1441-8.

Zhang P, Summer WR, Bagby GJ, Nelson S. Innate immunity and pulmonary host defense. Immunol Rev 2000; 173:39-51.

Zuckermann A, Reichenspurner H, Birsan T, Treede H, Deviatko E, Reichart B, Klepetko W. Cyclosporine A versus tacrolimus in combination with mycophenolate mofetil and steroids as primary immunosuppression after lung transplantation: One-year results of a 2-center prospective randomized trial. $J$ Thorac Cardiovasc Surg 2003;125(4):891-900. 


\section{APÊNDICE}




\title{
Immunosuppression Effects on Airway Mucociliary Clearance: Comparison Between Two Triple Therapies
}

\author{
Maristela Prado e Silva, MSc, Sônia F. Soto, BSc, Francine M. Almeida, MSc, \\ Tatiana T.K. Limonete, BSc, Edwin R.C. Parra, MD, PhD, Fabio B. Jatene, MD, PhD, \\ Paulo M. Pêgo-Fernandes, MD, PhD, and Rogerio Pazetti, PhD
}

Laboratory of Thoracic Surgery Research-LIM61, Department of Cardiopneumology, Heart Institute (InCor), Hospital das Clinicas, and Department of Pathology, Faculdade de Medicina da Universidade de São Paulo, São Paulo, Brazil

\begin{abstract}
Background. Tacrolimus and mycophenolate have now become the most widely used combination for maintenance immunosuppressive regimens after lung transplantation in comparison with cyclosporine and azathioprine. However, limited information is available with respect to their effects on cells, other than those from the immunologic compartment. We hypothesized that different triple therapies could have different effects on airway mucociliary clearance, playing an important role in respiratory infections observed after lung transplantation.

Methods. Ninety rats were assigned to three groups ( $\mathrm{n}=30$ each): control = vehicle, therapy $1=$ tacrolimus + mycophenolate + prednisone, and therapy 2 = cyclosporine + azathioprine + prednisone. After 7 , 15 , or 30 days of treatment by gavage, the animals were killed and the following parameters were studied: mucus transportability, ciliary beating frequency,
\end{abstract}

A ccording to the International Society of Heart and Lung Transplantation Registry, almost all patients undergoing lung transplantation (LTx) receive maintenance triple therapy consisting of a calcineurin inhibitor, an antimetabolite, and a steroid. Nowadays, the combination of tacrolimus (TAC), mycophenolate sodium (MPS), and prednisone is the most widely used internationally [1]. Some studies show the superiority of this regimen over the combination of cyclosporine (CsA) with azathioprine (AZA) combination in preventing acute rejection episodes and in improving pulmonary function; however, no specific survival advantage has thus far been consistently demonstrated [2-6].

Although immunosuppression is crucial to avoid graft rejection, prolonged use of these immunosuppressive

\footnotetext{
Accepted for publication April 16, 2013.

Presented at the Forty-ninth Annual Meeting of The Society of Thoracic Surgeons, Los Angeles, CA, Jan 26-30, 2013.

Address correspondence to Dr Pazetti, Laboratório de Pesquisa em Cirurgia Torácica - LIM61, Departamento de Cardiopneumologia Faculdade de Medicina da Universidade de São Paulo, Avenida Doutor Arnaldo, 455 - $1^{\circ}$ andar, sala 1220 - CEP 01246-903, São Paulo, SP, Brazil; e-mail: rogeriopazetti@yahoo.com.br.
}

mucociliary transport velocity, and neutral and acid mucus production.

Results. There was a significant decrease in ciliary beating frequency, mucociliary transport velocity, and neutral mucus production in all immunosuppressed animals; indeed, both therapies, mainly therapy 1, caused an increase in acid mucus production for as long as 15 days of treatment.

Conclusions. Both triple therapies impaired airway mucociliary clearance of rats, but therapy 1 had a more deleterious effect. These data suggest that these undesirable effects can contribute to the high incidence of respiratory infections observed in patients undergoing lung transplantation.

(Ann Thorac Surg 2013;96:473-7)

(C) 2013 by The Society of Thoracic Surgeons

agents can cause several side effects, such as malignancy, renal failure, neurotoxicity, hepatotoxicity, and infections [7-9]. Infection complications are the major cause of mortality between 31 days and 1 year after LTx [1], and $65 \%$ of these complications are related to the respiratory tract [7].

Mucociliary clearance (MCC) is an essential defense mechanism of the respiratory tract and continuously removes any inhaled particle from the external environment, such as pollutants or pathogenic microorganisms. The mucociliary apparatus is composed of two principal elements, mucus and cilia, which work together to maintain the cleaning of the respiratory tree. Any disruption in this coordinated action can cause stagnation of the mucus, facilitating the proliferation of viruses and bacteria [10].

We have previously tested some of the most widely used immunosuppressant drugs in a simple drug regimen and have shown that they have different deleterious effects on MCC [11-17]. The present study aimed to verify whether these drugs have the same effects when administered in a triple regimen and to compare the effects of the two principal maintenance triple therapies on airway MCC. 


\section{Material and Methods}

\section{Experimental Design}

Ninety male Wistar rats $(300 \mathrm{~g} \pm 25 \mathrm{~g})$ were equally divided in three groups: control $(\mathrm{C})=$ saline solution $0.9 \%$ (Baxter, São Paulo, Brazil); therapy 1 (T1) = TAC $1 \mathrm{mg} / \mathrm{kg}$ (Prograf, Janssen-Cilag, Killorglin, Ireland) + MPS $30 \mathrm{mg} / \mathrm{kg}$ (Myfortic, Novartis, Stein, Switzerland) + prednisone $1.25 \mathrm{mg} / \mathrm{kg}$ (Corticorten, Neoquimica, Anápolis, Brazil); and therapy 2 (T2) = CsA $10 \mathrm{mg} / \mathrm{kg}$ (Sigmasporin Microral, EMS, Hortolândia, Brazil) + AZA $3 \mathrm{mg} / \mathrm{kg}$ (Imuran, Excella GmbH, Nuremberg, Germany) + prednisone $1.25 \mathrm{mg} / \mathrm{kg}$ ). The animals were maintained according to the Guide for the Care and Use of Laboratory Animals [18]. Our institution's ethical committee approved the protocol.

\section{Therapy}

All animals were daily anesthetized with isoflurane $2 \%$ (Isoforine, Cristália, Itapira, Brazil) to facilitate drug administration by gavage during 7,15 , or 30 days.

\section{Euthanasia}

After 7, 15, or 30 days of treatment, 10 animals from each group were anesthetized with intraperitoneal pentobarbital $(50 \mathrm{mg} / \mathrm{kg})$ and euthanized by exsanguination, according to the Report of the American Veterinary Medicine Association Panel on Euthanasia [19].

\section{Data Collection and Analysis}

The lungs were excised from the thoracic cavity, and the following data were collected according to our previous reports [11-17].

1. Mucus transportability (MT): mucus samples were collected from the left and right mainstem bronchi and tested in vitro in a bullfrog palate model.

2. Ciliary beating frequency (CBF): after mucus collection, the ventral wall of the tracheobronchial tree was opened to expose the respiratory epithelium, and CBF was measured by synchronization between a stroboscope (Machine Vision Strobe, Cedarhurst, NY) flashlight and movement of the cilia.

3. Mucociliary transport velocity (MCTV): just after CBF analysis, by use of a light microscope (Olympus, BX50, Tokyo, Japan) fitted with a micrometer scale, MCTV was measured by direct view of particles trapped on the mucus layer moving across airways.

4. Neutral and acid mucus production: serial sections from tracheobronchial tissue were obtained and stained with periodic acid-Schiff and Alcian blue to reveal neutral and acid mucus production by goblet cells. The analysis was performed with Image Pro Plus program [11].

All data were analyzed with the Statistic Package for Social Sciences for Windows (SPSS 13.0 version) program. The Kolmogorov-Smirnov and Levene tests were used to verify the normality and homogeneity of variance, respectively. Two-way analysis of variance was used to verify the interference and interaction of the parametric data, and comparisons among groups were performed with a Bonferroni post-test. Kruskal-Wallis and Mann-Whitney tests with correction of Bonferroni were used to analyze nonparametric data. The results are expressed as mean \pm standard deviation (SD) or median and interquartile range (IQ, $25 \%$ to $75 \%$ ). A $p$ value less than 0.05 was considered significant.

\section{Results}

There was a significant increase in MT after 7 days of treatment with $\mathrm{T} 1$ in comparison with $\mathrm{T} 2(p=0.042)$ and $\mathrm{C}(p=0.047)$ (Fig 1). Both therapies caused a decrease in CBF after 7 days (C vs T1, $p<0.001$; C vs T2, $p=0.043$; T1 vs T2, $p=0.001$ ) and 15 days of treatment (C vs T1 and T2, $p<0.001$; T1 vs T2, $p=0.045$ ) (Fig 2). There was an overproduction of acid mucus in all immunosuppressed animals for as long as 30 days of therapy ( 7 days: $\mathrm{C}$ vs $\mathrm{T} 1$ and $\mathrm{T} 2, p<0.001 ; 15$ days: $\mathrm{C}$ vs $\mathrm{T} 1, p=0.009$; 30 days: $\mathrm{C}$ vs $\mathrm{T} 1$ and $\mathrm{T} 2, p<0.001$ ) (Fig 3 ). By contrast, neutral mucus production was significantly downregulated by $\mathrm{T} 1$ at all studied time points ( 7 days: $\mathrm{C}$ vs $\mathrm{T} 1$ and $\mathrm{T} 2, p<0.001 ; 15$ days: $\mathrm{C}$ vs $\mathrm{T} 1, p=0.036$; 30 days: $C$ vs $\mathrm{T} 1, p=0.027)$. The same occurred in T2-treated animals only after 7 days (Fig 4). The MCTV was slower in $\mathrm{T} 1$ and $\mathrm{T} 2$ groups than in the $\mathrm{C}$ group after 7 days (C vs T1, $p<0.001$; $\mathrm{C}$ vs T2, $p=0.003$; T1 vs $\mathrm{T} 2, p<0.001)$ and 15 days of treatment (C vs T1 and $\mathrm{T} 2, p<0.001$ ) (Fig 5).

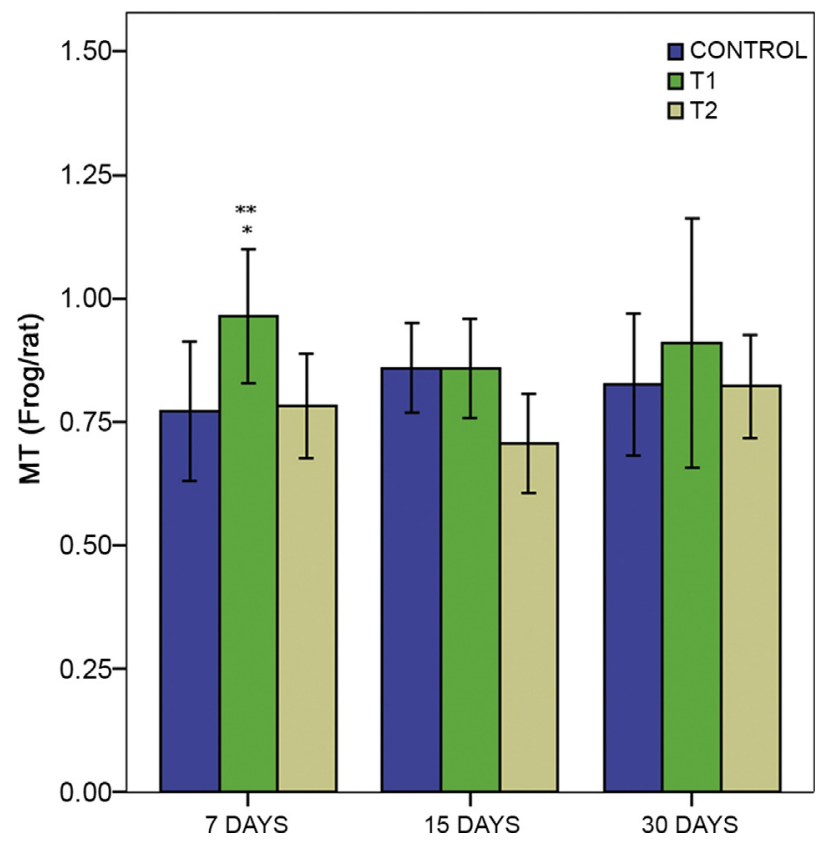

Fig 1. Mucus transportability (mean \pm standard deviation) in rats treated with saline (Control, blue bars), TAC + MPS + prednisone (T1, green bars), or Cs $A+A Z A+$ prednisone (T2, khaki bars) for 7 , 15 or 30 days. There was a significant difference between groups: *vs C, $p=0.047 ;{ }^{* *}$ vs T2, $p=0.042$. (AZA = azathioprine; CsA = cyclosporine; $\mathrm{MPS}=$ mycophenolate sodium; $M T=$ mucus transportability; $T A C=$ tacrolimus; $T 1=$ therapy group $1 ; T 2=$ therapy group 2.) 


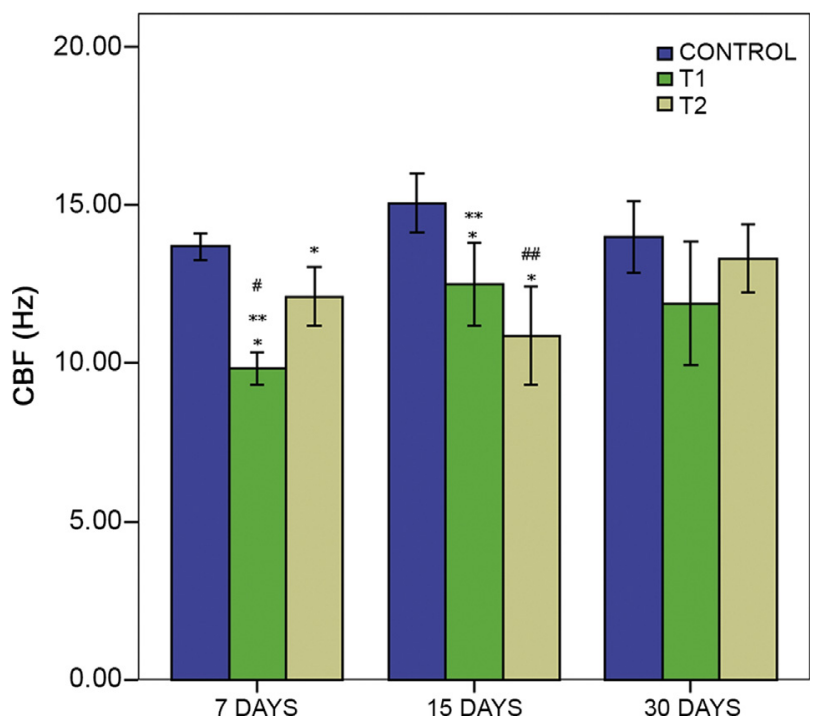

Fig 2. Ciliary beating frequency (mean \pm standard deviation) in rats treated with saline (Control, blue bars), TAC + MPS + prednisone (T1, green bars,) or Cs $A+A Z A+$ prednisone (T2, khaki bars) for 7 , 15, or 30 days. There was a significant difference between groups: *vs C: 7 days: $T 1, p<0.001$, and $T 2, p=0.043 ; 15$ days: $T 1$ and $T 2$ $p<0.001 ;{ }^{* *} v s \mathrm{~T} 2: 7$ days $p<0.001 ; 15$ days $p=0.045$. Comparison over time: \#vs 15 days $p<0.001$; \#\#s 30 days $p=0.001$. (AZA $=$ azathioprine; $C B F=$ ciliary beating frequency; $C S A=$ cyclosporine; MPS = mycophenolate sodium; TAC = tacrolimus; $T 1=$ therapy group 1; T2 = therapy group 2.)

\section{Comment}

Several studies have investigated the effects of immunosuppressant drugs on cells other than those from the immunologic compartment. Actually, airway epithelial cells are of special interest because they are part of the mucociliary system, which is responsible for maintaining the airways free of impurities, and any disturbance in its components may hinder the removal of these impurities and lead to respiratory tract infections [10]. We have previously demonstrated the negative effects of some immunosuppressive drugs on the airway MCC of rats when administered in a single-drug regimen [11-17]. In the present study, we observed the similar effects of two triple regimens, mainly in regard to TAC-based therapy.

Some clinical studies have shown impairment of MCC after LTx [20-22]. However, they did not determine the contribution of each component of the mucociliary system in this dysfunction. In previous experimental studies in rats, we have reported the deleterious effects of two factors involved in LTx: bronchial section and immunosuppression. After bronchial section and reanastomosis, there was a marked decrease of MCC, caused in part by alterations in surface properties of the mucus [23].

With regard to immunosuppression, several agents have been tested in this model, and we observed the characteristic effects of each drug. CsA caused a decrease in CBF, mucus production, and MCTV for as long as 90 days of treatment [11-13]. By contrast, AZA had deleterious effects on MCC only 7 days after bronchial section, but it showed a protective effect of the mucus rheologic properties for as

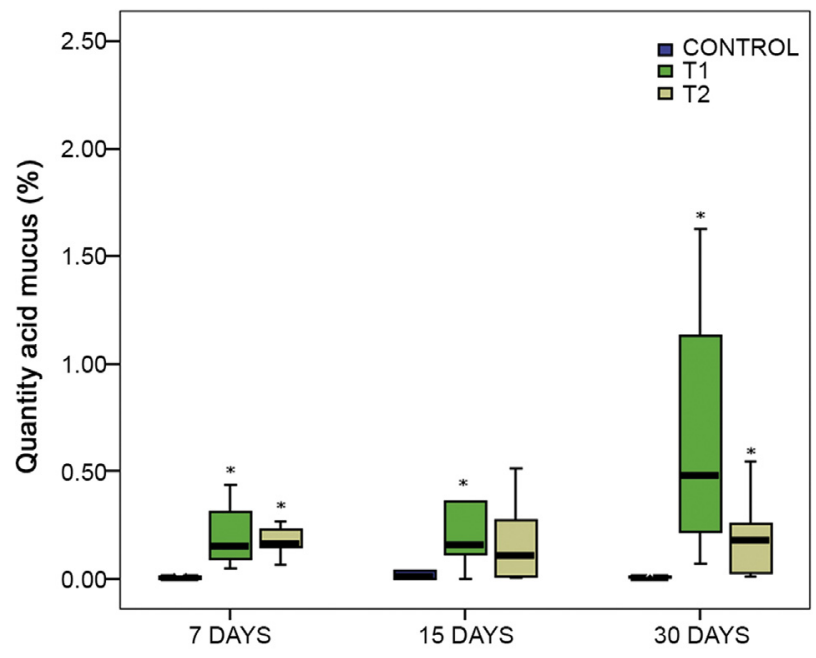

Fig 3. Acid mucus production (median and interquartile range, 25\% to $75 \%)$ in rats treated with saline (Control, blue bars), TAC + MPS + prednisone (T1, green bars), or Cs $A+A Z A+$ prednisone (T2, khaki bars) for 7, 15, or 30 days. There was a significant difference between groups: ${ }^{*}$ vs $C: 7$ days: $T 1$ and T2, $p<0.001 ; 15$ days: $T 1, p=0.009 ; 30$ days: $T 1$ and $T 2, p=0.001$. (AZA = azathioprine; $C_{S} A=$ cyclosporine; MPS = mycophenolate sodium; $T A C=$ tacroimus; $T 1=$ therapy group $1 ; T 2=$ therapy group 2.$)$

long as 30 days of treatment [14]. In turn, MPS did not alter mucus viscoelastic properties, but it caused a significant decrease of both CBF and MCTV for as long as 30 days [15]. The opposite effects were observed in rats treated with prednisone, which means that this corticosteroid changed the mucus properties, causing a decrease in MT but, interestingly, did not affect the CBF and MCTV [17]. Furthermore, we have partial results from the isolated effects of TAC that show a significant impairment of MCC by reducing MT, CBF, MCTV, and neutral mucus production and by overregulating acid mucus production (data not published).

In the present study, it seems that the combination of these drugs resulted in a synergistic effect on MCC impairment. Although both therapies caused slower CBF for as long as 15 days, the decrease in CBF at 7 days was more significant in the animals treated with $\mathrm{T} 1$. We could hypothesize that a decreased CBF would be sufficient to explain MCC impairment after LTx; however, we found conflicting studies either confirming [20-22] or rejecting [24] this hypothesis. It is well known that ciliary activity depends on the oscillation in intracellular calcium concentration $\left(\left[\mathrm{Ca}^{2+}\right]_{\mathrm{i}}\right)[25]$, which is increased by ATP, a purinergic agonist [26]. One study demonstrated that TAC, but not CsA, inhibited ATP-induced $\left[\mathrm{Ca}^{2+}\right]_{\mathrm{i}}$ oscillations in cow tracheal epithelium [27].

Our results also showed that acid mucus was equally overproduced after treatment with both therapies for as long as $\mathbf{3 0}$ days. However, neutral mucus production was downregulated by $\mathrm{T} 1$ in all time points, whereas T2 had this effect only after 7 days of treatment. As a consequence of respiratory diseases, or other factors such as pollutants and drug toxicity, which might harm or 


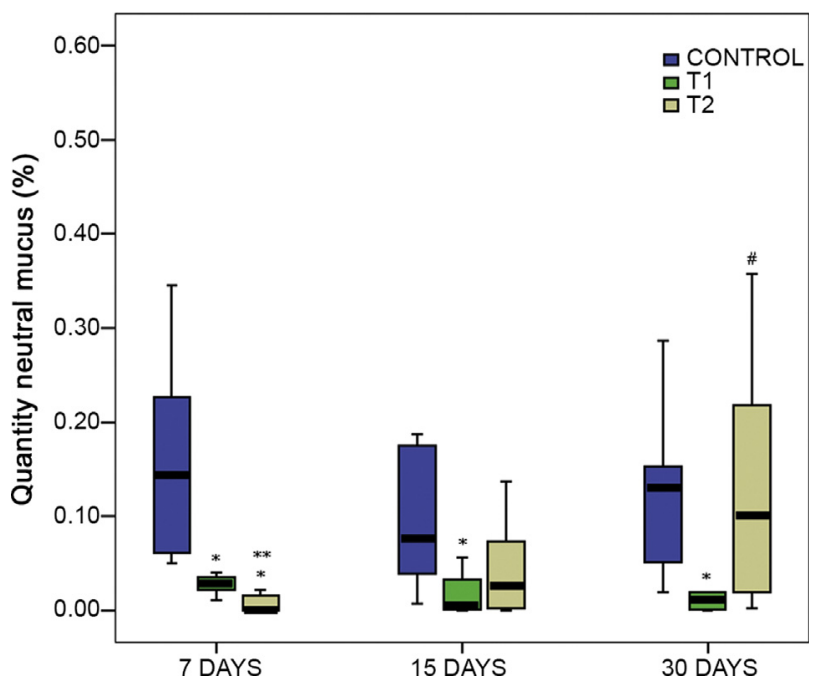

Fig 4. Neutral mucus production (median and interquartile range, $25 \%$ to $75 \%)$ in rats treated with saline (Control, blue bars), TAC + MPS + prednisone (T1, green bars), or Cs $A+A Z A+$ prednisone (T2, khaki bars) for 7,15 , or 30 days. There was a significant difference between groups: ${ }^{*}$ vs $C: 7$ days: $T 1$ and T2, $p<0.001 ; 15$ days: $T 1, p=0.036 ; 30$ days: $T 1, p=0.027 ;{ }^{* *} v s$ T1: 7 days, $p=0.019$. Comparison over time: \#vs 7 days, $p=0.007$. (AZA = azathioprine; Cs $A=$ cyclosporine; MPS = mycophenolate sodium; $T A C=$ tacrolimus; $T 1=$ therapy group $1 ; T 2=$ therapy group 2.)

damage the respiratory epithelium, an increase in the number of cells of mucous secretion and a decrease in the number of ciliated and serous cells can occur. In this situation, acids and sulfated mucopolysaccharides are overproduced, altering the physicochemical characteristics of the mucus, which becomes more acidic. Moreover, the periciliary layer of mucus becomes shorter, and the cilia have difficulty in performing their strokes of propulsion and recovery. Thus, the removal and disposal of microorganisms are reduced, favoring infectious processes [28]. Data from the most recent International Society of Heart and Lung Transplantation Registry showed that noncytomegalovirus infections remain the leading cause of death within 1 to 12 months after LTx [1]. Further, $65 \%$ of these infections involve the respiratory system [7], and bacterial bronchopulmonary infections constitute approximately half of all complications [29].

The extensive use of TAC, MPS, and prednisone as a new scheme in LTx, instead of the conventional scheme composed of CsA, AZA, and prednisone, has occurred in recent years without expressive clinical evidence to substantially support a single agent over another or a combination regimen protocol over another. Few studies have compared these agents concerning both the efficacy in avoiding graft rejection and the presence and intensity of side effects [2-6]. Although the majority of these studies have shown a trend to better results with TAC-based therapy, none of them were able to detect a survival advantage of this regimen over CsA. Curiously, one study showed that TAC was associated with a reduced risk for bronchiolitis obliterans, but the

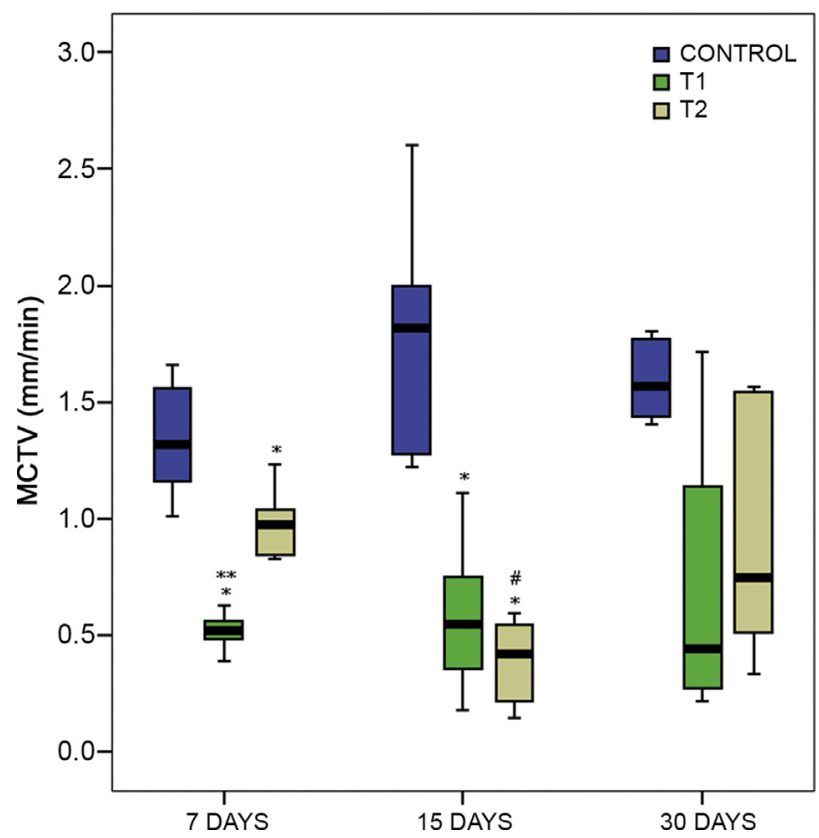

Fig 5. Mucociliary transport velocity (median and interquartile range, $25 \%$ to $75 \%$ ) in rats treated with saline (Control, blue bars), TAC + MPS + prednisone (T1, green bars), or CsA + AZA + prednisone (T2, khaki bars) for 7,15 , or 30 days. There was a significant difference between groups: * ${ }^{*} \mathrm{C}$ : 7 days: T1, $p<0.001$, and $T 2, p=0.003 ; 15$ days: $T 1$ and $T 2, p<0.001$; ${ }^{* *} v s T 2, p<0.001$. Comparison over time: \#vs 7 days, $p=0.007$. (AZA = azathioprine; CsA = cyclosporine; $M C T V=$ mucociliary transport velocity; MPS = mycophenolate sodium; $T A C=$ tacrolimus; $T 1=$ therapy group 1; T2 = therapy group 2.)

survival in the CsA-treated group was marginally greater [6]. Therefore, altogether, it seems that short-term and long-term drug efficacy is not a good endpoint to enable determination of the best immunosuppressive regimen. Instead, the characteristic side effects of each drug could be alternatively considered when the best combination for LTx recipients is being chosen.

We conclude that both triple therapies impaired airway MCC of rats for as long as 15 days either by decreasing CBF, MCTV, and neutral mucus production or by increasing acid mucus production. Actually, the negative side effects from therapy 1 (TAC + MPS) were more pronounced than those from therapy 2 (CsA + AZA). Our results suggest that these immunosuppressive therapies could be related to the high rate of respiratory infections observed after LTx resulting from its side effects on the airway mucociliary system. Of course, the use of immunosuppressive drugs is mandatory to ensure graft and patient survival. However, we believe that special attention must be devoted by clinicians to choose the appropriated regimen for each patient based on the specific side effects of each drug.

This study was performed at the Thoracic and Cardiovascular Surgery Post-Graduation Program of Heart Institute (InCor) of Clinics Hospital of Sao Paulo University Medical School, Sao Paulo, SP, Brazil. It was supported by grants from the State of Sao 
Paulo Foundation (FAPESP), Sao Paulo, SP, Brazil. Francine M. Almeida received research grants from the Scientific Department of Heart Institute (InCor).

\section{References}

1. Christie JD, Edwards LB, Kucheryavaya AY, et al. The Registry of the International Society for Heart and Lung Transplantation: twenty-eighth official adult lung and heartlung transplant report-2011. J Heart Lung Transplant 2011;30: 1104-22.

2. Keenan RJ, Konishi $\mathrm{H}$, Kawai A, et al. Clinical trial of tacrolimus versus cyclosporine in lung transplantation. Ann Thorac Surg 1995;60:580-5.

3. Zuckermann A, Reichenspurner H, Birsan T, et al. Cyclosporine A versus tacrolimus in combination with mycophenolate mofetil and steroids as primary immunosuppression after lung transplantation: one-year results of a 2-center prospective randomized trial. J Thorac Cardiovasc Surg 2003;125:891-900.

4. Reichenspurner H. Overview of tacrolimus-based immunosuppression after heart or lung transplantation. J Heart Lung Transplant 2005;24:119-30.

5. Korom S, Boehler A, Weder W. Immunosuppressive therapy in lung transplantation: state of the art. Eur J Cardiothorac Surg 2009;35:1045-55.

6. Treede H, Glanville AR, Klepetko W, et al. Tacrolimus and cyclosporine have differential effects on the risk of development of bronchiolitis obliterans syndrome: results of a prospective, randomized international trial in lung transplantation. J Heart Lung Transplant 2012;31:797-804.

7. Speich R, van der Bij W. Epidemiology and management of infections after lung transplantation. Clin Infect Dis 2001;33(Suppl1):S58-65.

8. Taylor JL, Palmer SM. Critical care perspective on immunotherapy in lung transplantation. J Intensive Care Med 2006;21:327-44.

9. Aguilar-Guisado M, Givald J, Ussetti P, et al. Pneumonia after lung transplantation in the Resitra cohort: a multicenter prospective study. Am J Transplant 2007;7:1989-96.

10. Randell SH, Boucher RC. Effective mucus clearance is essential for respiratory health. Am J Resp Cell Mol Biol 2006;35:20-8.

11. Pazetti R, Pego-Fernandes PM, Ranzani OT, et al. Cyclosporin A reduces airway mucus secretion and mucociliary clearance in rats. Clinics (São Paulo) 2007;62:345-52.

12. Xavier AM, Pêgo-Fernandes PM, Correia AT, et al. Influence of cyclosporine A on mucociliary system after lung transplantation in rats. Acta Cir Bras 2007;22:465-9.
13. Pazetti R, Pêgo-Fernandes PM, Lorenzi-Filho G, et al. Effects of cyclosporine A and bronchial transection on mucociliary transport in rats. Ann Thorac Surg 2008;85:1925-9.

14. Pego-Fernandes PM, Said MM, Pazetti R, et al. Effects of azathioprine on mucociliary clearance after bronchial section and anastomosis in a rat experimental model. J Bras Pneumol 2008;34:273-9.

15. Silva VFP, Pazetti R, Soto SF, et al. Effects of mycophenolate sodium on mucociliary clearance using a bronchial section and anastomosis rodent model. Clinics 2011;66:1451-5.

16. Braga KA, Nepomuceno NA, Correia AT, Jatene FB, PêgoFernandes PM. The effects on mucociliary clearance of prednisone associated with bronchial section. Clinics 2012;67:647-51.

17. Braga KA, Nepomuceno NA, Correia AT, Jatene FB, Pêgo-Fernandes PM. Effects of prednisone on mucociliary clearance in a murine model. Transplant Proc 2012;44:2486-9.

18. 1996 NRC Guide for the Care and Use of Laboratory Animals. Available at http://www.nap.edu/readingroom/ books/labrats/contents.html. Accessed Jan 22, 2010.

19. Amass KD, Beaver BV, Bennett BT, et al. Report of the AVMA panel on euthanasia. J Am Vet Med Assoc 2001;218:669-96.

20. Read RC, Shankar S, Rutman A, et al. Ciliary beat frequency and structure of recipient and donor epithelia following lung transplantation. Eur Respir J 1991;4:796-801.

21. Veale D, Glasper PN, Gascoigne A, Dark JH, Gibson GJ, Corris PA. Ciliary beat frequency in transplanted lungs. Thorax 1993;48:629-31.

22. Laube BL, Karmazyn YJ, Orens JB, Mogayzel Jr PJ. Albuterol improves impaired mucociliary clearance after lung transplantation. J Heart Lung Transplant 2007;26:138-44.

23. Rivero DH, Lorenzi-Filho G, Pazetti R, Jatene FB, Saldiva PH. Effects of bronchial transection and anastomosis on mucociliary system. Chest 2001;119:1510-5.

24. Dolovich M, Rossman C, Chambers C, Grossman R, Newhouse M, Maurer J. Mucociliary function in patients following single lung or lung/heart transplantation. Am Rev Respir Dis 1987;135(Suppl):A363.

25. Di Benedetto G, Magnus CJ, Gray PT, Mehta A. Calcium regulation of ciliary beat frequency in human respiratory epithelium in vitro. J Physiol 1991;439:103-13.

26. Hayashi T, Kawakami M, Sasaki S, et al. ATP regulation of ciliary beat frequency in rat tracheal and distal airway epithelium. Exp Physiol 2005;90:535-44.

27. Kanoh S, Kondo M, Tamaoki J, et al. Effect of FK506 on ATPinduced intracellular calcium oscillations in cow tracheal epithelium. Am J Physiol Lung Cell Mol Physiol 1999;276:L891-9.

28. Saldiva PH. Aparelho mucociliar: Aspectos funcionais e métodos de estudo. J Pneumol 1990;16:161-70.

29. Nakajima T, Palchevsky V, Perkins DL, Belperio JA, Finn PW. Lung transplantation: infection, inflammation, and the microbiome. Semin Immunopathol 2011;33:135-56.

\section{DISCUSSION}

DR ROBERT D. DAVIS, JR (Durham, NC): Do you have any data regarding the role of the individual agents, ie, if you use just steroids as compared with just mycophenolate or Imuran as compared with the calcineurin inhibitors?

And the second question, did you measure actual drug levels of your dosaging? So after you gave the dose, did you actually measure, for instance, the FK level, cyclosporine level, et cetera?

DR PÊGO-FERNANDES: Thank you for the questions. Yes, we have studied the isolated effects of these drugs, and all data were already published. Actually, one of these studies was presented at the 44th STS and was published in The Annals of Thoracic Surgery.

Now, by suggestion of one of the reviewers of The Annals of Thoracic Surgery, we studied the effects of these drugs in a triple regimen. These results that I showed you are part of our study where we analyzed both triple therapies at 7,15 , and 30 days. And we saw that the negative effects of the therapy with tacrolimus and mycophenolate were worse than those with cyclosporine and azathioprine. We are submitting these data to The Annals of Thoracic Surgery.

DR DAVIS: And the dosage in terms of the actual levels?

DR PÊGO-FERNANDES: Yes, sorry, I forgot your second question. No, we did not perform this dosage. We used the same drug doses from our previous studies and from the literature.

DR DAVIS: Thank you. 